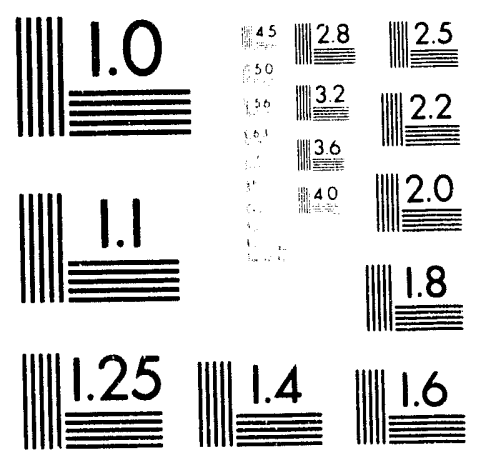



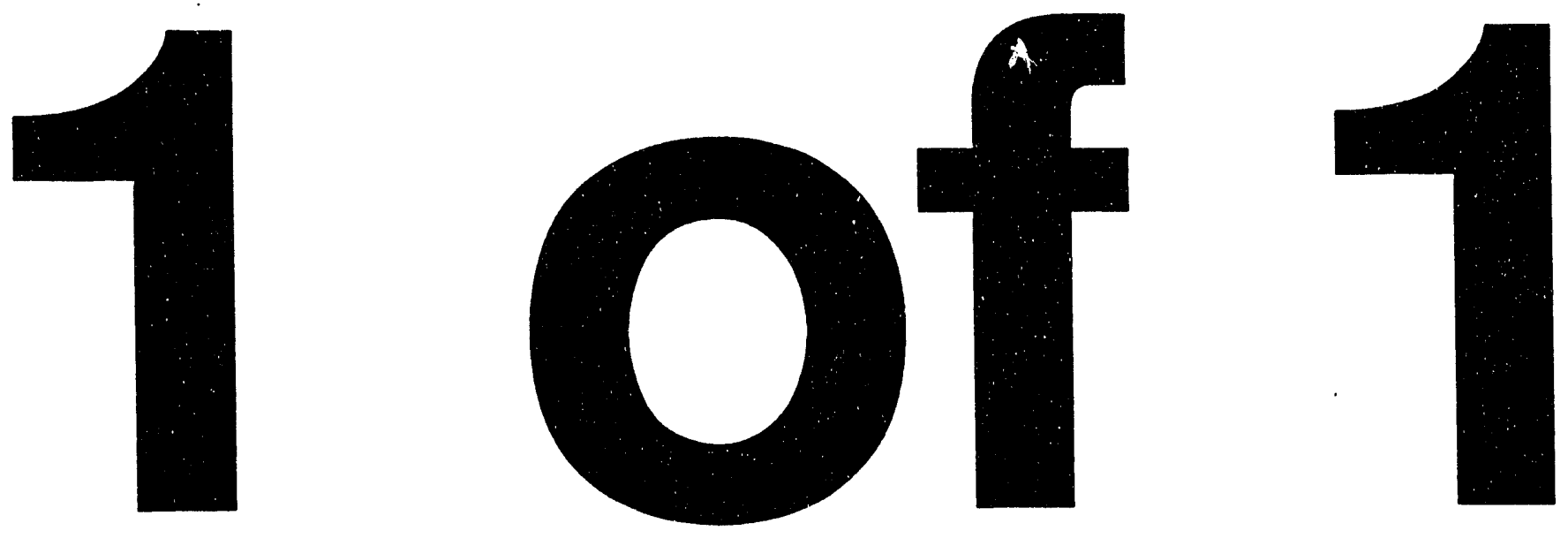
LBL-34410

UC-311

\title{
Water-Enhanced Solvation of Organics
}

\author{
Jane H. Lee \\ (M.S. Thesis) \\ Department of Chemical Engineering \\ University of California \\ and \\ Energy and Environment Division \\ Lawrence Berkeley Laboratory \\ University of California \\ Berkeley, California 94720
}

July 1993

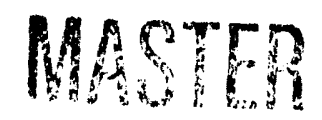

This work was supported by the Assistant Secretary for Conservation and Renewable Energy, Energy Conversion and Utilization Technology (ECUT) Division, of the U.S. Department of Energy under Contract No. DE-AC03-76SF00098. 


\author{
Abstract \\ Water-Enhanced Solvation of Organics \\ Jane H. Lee \\ Master of Science in Chemical Engineering \\ University of California at Berkeley \\ Professor C. Judson King
}

The occurrence of water-enhanced solvation was explored in detail for Lewis acid solutes in Lewis base organic solvents. Water-enhanced solvation can lead to inexpensive extract regeneration processes. The magnitude of water-enhanced solvation for solid solutes was determined by taking the ratio of the solubilities of the solute in the water-saturated solvent and in the low-water content solvent, both were determined by solid-liquid equilibrium measurements. Water-enhanced solvation for volatile solutes was measured by vapor-liquid equilibrium measurements. Vapor-headspace analysis was used to determine the activity coefficients of solutes as a function of organic phase water concentration. The magnitudes of water-enhanced solvation of volatile solutes were normalized and set equal to the slope of the $\log \gamma_{\mathrm{g}}$ vs. $\mathrm{x}_{\mathrm{w}} / \mathrm{x}_{\mathrm{g}}$ curve. From the shape of the graph, the $\Delta\left(\log \gamma_{\mathrm{g}}\right)$ represents the relative change in the activity coefficient of the solute.

The solutes investigated by vapor-headspace analysis were: acetic acid, propionic acid, ethanol, 1,2-propylene glycol and 2,3-butylene glycol. In general, monocarboxylic acids had the largest decrease in activity coefficient with addition of water followed by glycols and alcohols. Propionic acid in cyclohexanone showed the greatest water-enhancement effect, $\Delta\left(\log \gamma_{\text {acid }}\right) / \Delta\left(x_{w} / x_{\text {acid }}\right)=-0.25$. In methylcyclohexanone, the decrease of the activity coefficient of propionic acid was $\Delta\left(\log \gamma_{\text {acid }}\right) / \Delta\left(x_{w} / x_{\text {acid }}\right)=-0.19$. The activity coefficient of propionic acid in methylcyclohexanone stopped decreasing once the water reached a 2:1 
water to acid mole ratio, which implies that a stoichiometric relationship may exist between the water, ketone, and acid.

With the exception of 2,3-butanediol, the activity coefficients of the solutes studied decreased monotonically as the water concentration increased. The activity coefficient curves of ethanol, 1,2-propanediol and 2,3-butanediol did not level of as the water to solute mole ratio became large.

The solutes investigated by solid-liquid equilibrium measurements were: citric acid, gallic acid, phenol, xylenols, and 2-naphthol. The saturation concentration of citric acir in anhydrous butyl acetate increased almost ten fold from $0.0009 \mathrm{~mol} / \mathrm{L}$ to $0.087 \mathrm{~mol} / \mathrm{L}$ after 1.3 $\%(\mathrm{~g} / \mathrm{g})$ water was co-dissolved into the organic phase. In high-water-content methylcyclohexanone, the concentration of citric acid is $1.7 \mathrm{~mol} / \mathrm{L}, 6.9$ times higher than at low-water content. The effect of water-enhanced solvation for citric acid is very large, whereas for phenol and phenol derivatives, the effect of water-enhanced solvation, if it occurs at all, is very small. 


\section{Acknowledgements}

Professor C. Judson King has been a remarkable mentor during my stay here at Berkeley. His wisdom and guidance has helped me with my research and outside interests. I thank Professor John Prausnitz and Professor Ken Raymond for reading this thesis and for their advice. I thank Judie Powers for being the group's cheerleader, organizer, and good friend.

I would like to thank all the members of the King group that I have crossed paths with for their friendship and advice. I have fond memories of all the lab group trips and social gatherings. Special thanks to Scott Moor for his amusing stories and dance lessons, to Jorge Sunkel for coffee breaks and workouts at the gym, to Lisa Tung for everyday gossip and chatter about Bay Area restaurants, to Rob Broekhuis for his "silly" comments and musical entertainment, and to Jack Starr who helped to get me started.

In addition to the King group, I would also like to acknowledge my good friends and classmates, Michael MacDonald, Mike Solomon, Douglas Eames, Karen Koigawachi, and Benjamin Rush for a lot of fond memories. Most importantly, I would like to pay special tribute to my parents, brothers, and relatives for all their support during my stay here at Berkeley. 
Abstract

Acknowledgements

Table of Contents

List of Tables .

List of Figures

Chapter 1 Introduction

1.1 Solutes of Interest

1.2 Scope of Study

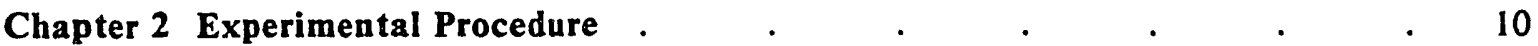

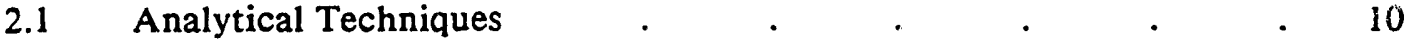

2.1.1 Solid-Liquid Equilibrium $\quad . \quad$. $\quad . \quad$. $\quad . \quad$. 10

2.1.2 Vapor-Liquid Equilibrium $\quad . \quad$. $\quad . \quad$. $\quad$. 11

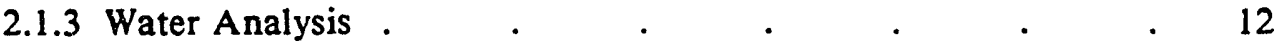

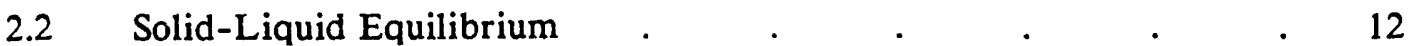

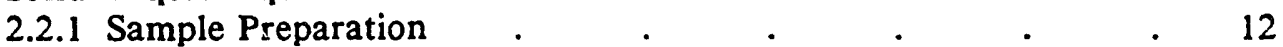

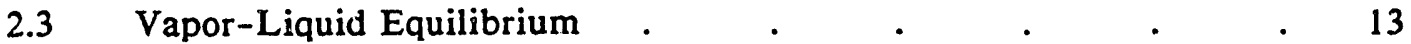

2.3.1 Experirnental Design and Sample Preparation . . . . 13

2.3.2 Vapor Phase Calibration for Liquid Solutes . $\quad$ • $\quad$. 16

2.3.2.a Non-dimerizing Liquid Solutes . . . . 16

2.3.2.b Dimerizing Liquid Solutes . $\quad$. $\quad$. $\quad$. 17

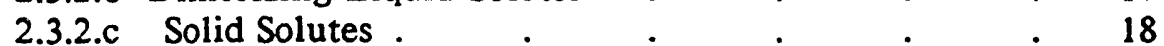

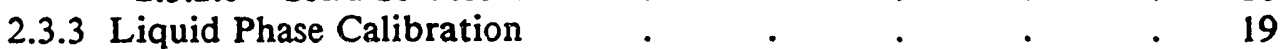

2.3.4 Vapor-Liquid Equilibrium Calculations $\quad . \quad 19$

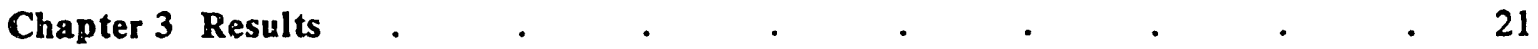

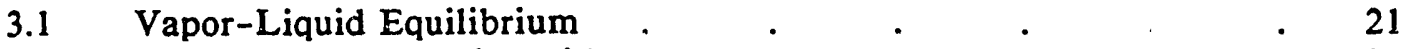

3.1.1 Monocarboxylic Acids . $\quad$. $\quad$. $\quad$. $\quad$. $\quad$. 21

3.1.2 Ethanol . $\quad . \quad$. $\quad . \quad$. $\quad . \quad$. $\quad$. 27

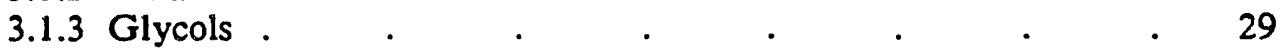

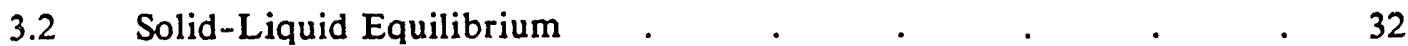

3.2.1 Gallic Acid and Citric Acid . . . . . . 32

3.2.2 Phenol and Phenol Derivatives . . . . . 35 


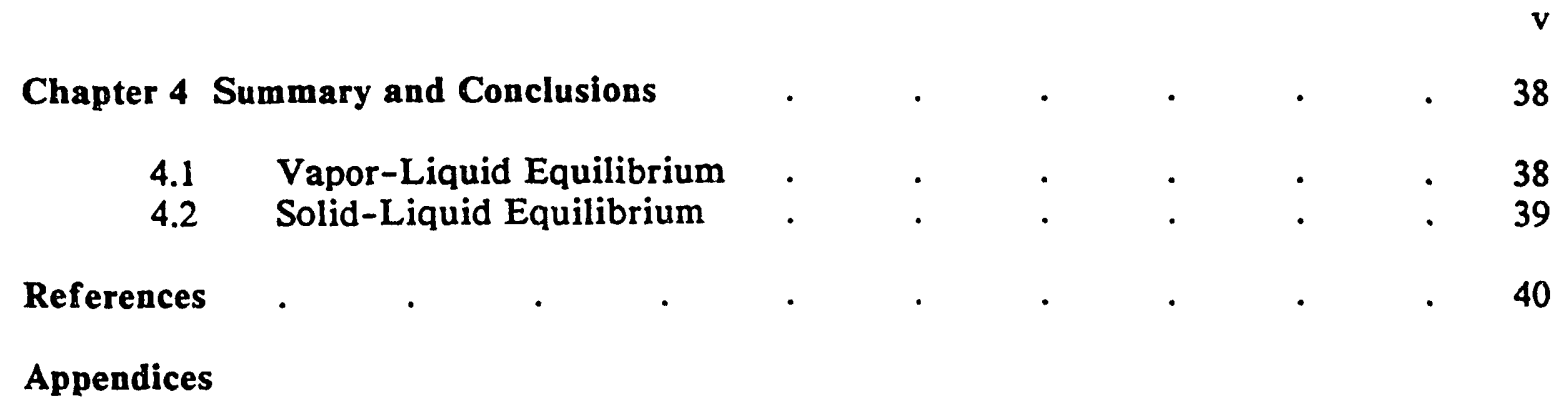

A High Pressure Liquid Chromatography as a Scanning Technique . 42

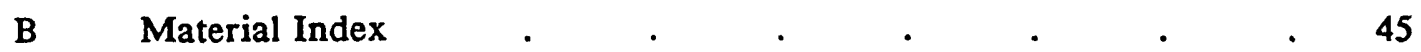

C GC and HPLC Calibration Curves . . . $\quad 47$

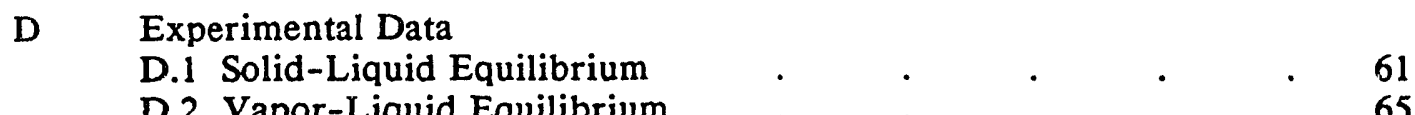

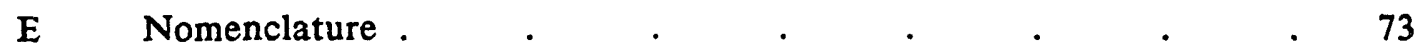


List of Tables

Table

page

1.1 Solubilities of Dicarboxylic Acids in Wet and Dry Solvents at $25^{\circ} \mathrm{C} \quad$ - 2

3.1 Activity Coefficients of Monocarboxylic Acids in Cyclic Ketones at $25^{\circ} \mathrm{C}$. 25

3.2 Activity Coefficients of Ethanol and Glycols in Cyclic Ketones at $25^{\circ} \mathrm{C} \quad$ - 27

3.3 Solubilities of Citric Acid and Gallic Acid in Wet and Dry Solvents at $25^{\circ} \mathrm{C} \quad 33$

3.4 Solubilities of Phenols in Wet and Dry Solvents at $25^{\circ} \mathrm{C} \quad$. $\quad . \quad$. $\quad 35$

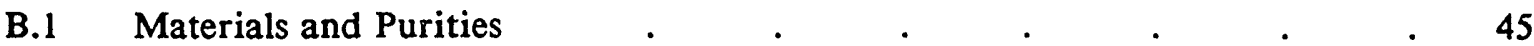

D.1 Solid-Liquid Equilibrium Data at $25^{\circ} \mathrm{C}$, Thermal Conductivity Detector

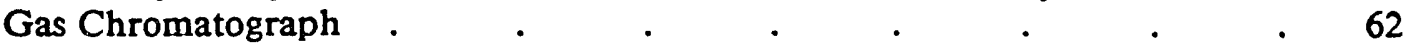

D.2 Solid-Liquid Equilibrium Data at $25^{\circ} \mathrm{C}$, Refractive Index Detector High

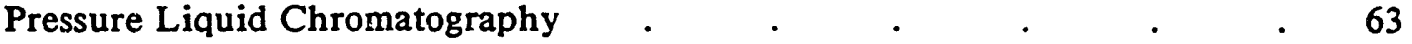

D.3 Solid-Liquid Equilibrium Data at $25^{\circ} \mathrm{C}$, Back Titration with

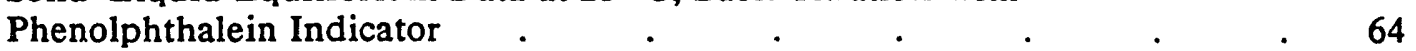

D.4 Acetic Acid Vapor-Liquid Equilibrium Data at $25^{\circ} \mathrm{C}$, Flame Ionization Detector Gas Chromatograph $\quad$. $\quad$. $\quad$. $\quad$ • 65

D.5 Propionic Acid Vapor-Liquid Equilibrium Data at $25^{\circ} \mathrm{C}$, Flame Ionization Detector Gas Chromatograph $\quad$. $\quad . \quad$. $\quad$. 67

D.6 Ethanol Vapor-Liquid Equilibrium Data at $25^{\circ} \mathrm{C}$, Flame Ionization Detector Gas Chromatograph

D.7 1,2-Propylene Glycol Vapor-Liquid Equilibrium Data at $25^{\circ} \mathrm{C}$, Flame Ionization Detector Gas Chromatograph

D.8 2,3-Butylene Glycol Vapor-Liquid Equilibrium Data at $25^{\circ} \mathrm{C}$, Flame Ionization Detector Gas Chromatograph 


\section{List of Figures}

Figure

page

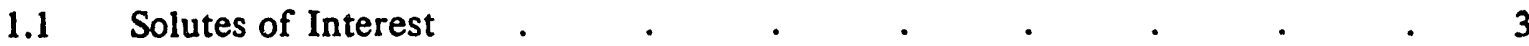

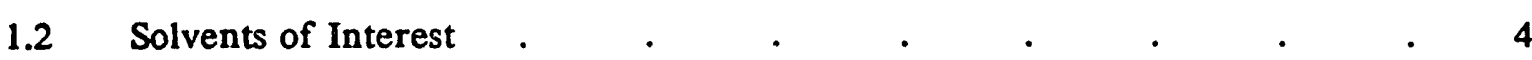

2.1 Water-Jacketed Syringe for Vapor-Headspace Analysis _ . . . 15

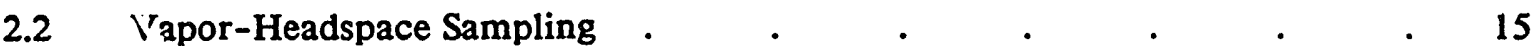

3.1 Vapor-Liquid Equilibrium at $25^{\circ} \mathrm{C}$ for Acetic Acid in Cyclohexanone, with Varying Amounts of Added Water $\quad$ e $\quad$ - $\quad . \quad$. $\quad 22$

3.2 Vapor-Liquid Equilibrium at $25^{\circ} \mathrm{C}$ for a 0.06 Mole Ratio Propionic Acid in Cyclohexanone, with Varying Amounts of Added Water . . . $\quad 23$

3.3 Vapor-Liquid Equilibrium at $25^{\circ} \mathrm{C}$ for a 0.05 Mole Ratio Propionic Acid in Methylcyclohexanone, with Varying Amounts of Added Water . $\quad$. 24

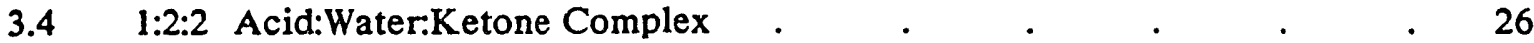

3.5 Vapor-Liquid Equilibrium at $25^{\circ} \mathrm{C}$ for Ethanol in Cyclic Ketones,

3.6 Vapor-Liquid Equilibrium at $25^{\circ} \mathrm{C}$ for a 0.04 Mole Ratio of 1,2-Propanediol in Methylcyclohexanone, with Varying Amounts of Added Water . $\quad 30$

3.7 Vapor-Liquid Equilibrium at $25{ }^{\circ} \mathrm{C}$ for a 0.04 Mole Ratio of 2,3-Butanediol in Methylcyclohexanone, with Varying Amounts of Added Water . . $\quad 31$

3.8 Solid-Liquid Equilibrium at $25^{\circ} \mathrm{C}$ for Citric Acid in Methylcyclohexanone with Varying Amounts of Added Water $\quad . \quad$. $\quad . \quad . \quad$. 34

C.1 2,3-Dimethylphenol GC Calibration in Methylisobutylketone $\quad . \quad$. 47

C.2 2,5-Dimethylphenol GC Calibration in Methylisobutylketone $\quad . \quad$. 47

C.3 2,6-Dimethylphenol GC Calibration in Methylisobutylketone $\quad . \quad$ - 48

$\begin{array}{lllllllll}\text { C.4 Phenol GC Calibration in Methylisobutylketone } & \text { - } & \text {. } & \text {. } & & & 48\end{array}$

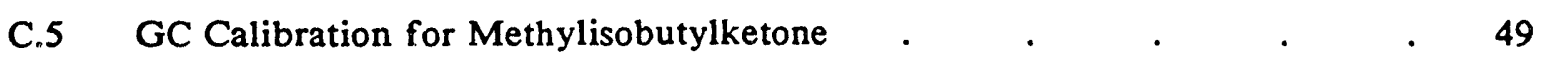

C.6 HPLC Calibration of 2-Naphthol in Cyclohexanone . . . . . 50

C.7 HPLC Calibration of 2-Naphthol in Methylisobutylketone . . . $\quad 51$

C.8 HPLC Calibration of 2-Naphthol in Butyl Acetate $\quad . \quad \ldots \quad$. $\quad . \quad 52$

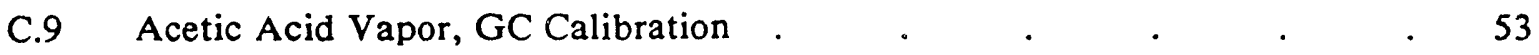


C.10 Propionic Acid Vapor, GC Calibration $\quad$. $\quad$. $\quad$. $\quad$. $\quad$. 53

C.11 Acetic Acid in Cyclohexanone, Liquid GC Calibration $\quad$. $\quad$ • $\quad$. 54

C.12 Propionic Acid in Cyclohexanone, Liquid GC Calibration . . . . $\quad 55$

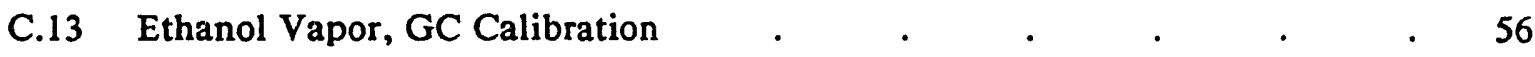

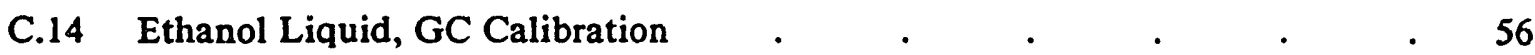

C.15 Ethanol in Methylcyclohexanone, Liquid GC Calibration _ . . $\quad$ - 57

C.16 Ethanol in Cyclohexanone, Liquid GC Calibration _ . . $\quad$. $\quad 57$

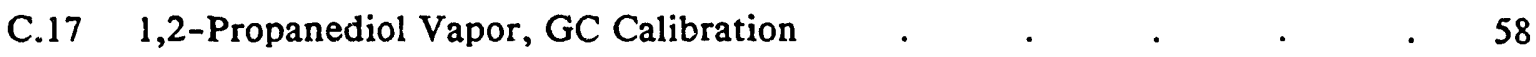

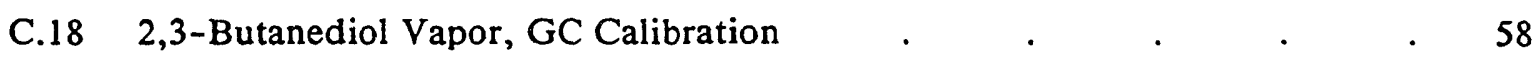

C.19 1,2-Propanediol in Methylcyclohexanone, Liquid GC Calibration . . 59

C.20 2,3-Butanediol in Methylcyclohexanone, Liquid GC Calibration . $\quad$. 60 


\section{Chapter 1. Introduction}

With the uncertainty of petroleum costs and supplies, alternative resources for the production of commodity chemicals are necessary. An abundant alternative to non-renewable fossil fuels is biomass. Fermentation is a high-potential method for producing chemicals from biomass. However, products from fermentation are dilute and are present in complex aqueous fermentation streams. Product concentrations typically range between 40 and $100 \mathrm{~g} / \mathrm{L} .{ }^{1}$ The complexity and concentration of fermentation broths create difficult and challenging separations.

In the conversion of biomass to chemicals, strong efforts are needed to reduce energy costs. In an economic analysis of ethanol production by Daugulis et al. ${ }^{2}$ the most important opportunities for cost savings were found in separation processes, including evaporation and drying.

Distillation, membrane processes, solvent extraction, calcium salt precipitation, electrophoresis, electrodialysis, adsorption, and ion exchange are common techniques for separation and purification. Each of the methods can be energy-intensive, can present toxicity problems to the fermentation process, can have high capital costs, and/or can cause disposal problems.

Starr and $\mathrm{King}^{3}$ conceived a regeneration method for solvent extraction that precipitates the product and can reduce energy consumption. The solubilities of dicarboxylic acids in certain organic solvents increase with increasing water concentration of the organic phase. For adipic, fumaric, and succinic acids in cyclohexanone and methylcyclohexanone, the solubility of the acid increases by a factor of six to eight from the anhydrous state to the water-saturated state (Table 1.1). This phenomenon of water-enhanced solvation can lead to an inexpensive extract regeneration process. Th: 3 process precipitates the acid from solution 
by selectively removing the co-dissolved water from the extract stream by stripping. The removal of a minor component to cause precipitation reduces energy consumption.

Table 1.1 Solubilities of Dicarboxylic Acids in Wet and Dry Solvents at $25^{\circ} \mathrm{C} .^{3}$

\begin{tabular}{|c|c|c|c|}
\hline $\begin{array}{l}\text { Solute } \\
\text { Solvent }\end{array}$ & $\begin{array}{c}\text { Acid } \\
\text { Solubility } \\
\text { [mol/L] }\end{array}$ & $\begin{array}{l}\text { Water } \\
\text { Content } \\
\text { [mol/L] }\end{array}$ & $\begin{array}{l}\text { S(hydrated)/ } \\
\text { S(anhydrous) }\end{array}$ \\
\hline $\begin{array}{l}\text { Fumaric acid } \\
\text { Cyclohexanone }\end{array}$ & $\begin{array}{l}0.053 \\
0.456 \\
\end{array}$ & $\begin{array}{l}0.0 \\
4.75 \\
\end{array}$ & 8.60 \\
\hline $\begin{array}{c}\text { Fumaric acid } \\
\text { Methylcyclohexanone }\end{array}$ & $\begin{array}{l}0.0392 \\
0.295 \\
\end{array}$ & $\begin{array}{l}0.0 \\
2.68 \\
\end{array}$ & 7.53 \\
\hline $\begin{array}{c}\text { Succinic acid } \\
\text { Cyclohexanone }\end{array}$ & $\begin{array}{l}0.136 \\
1.04 \\
\end{array}$ & $\begin{array}{c}0.0 \\
8.32 \\
\end{array}$ & 7.65 \\
\hline $\begin{array}{c}\text { Succinic acid } \\
\text { Methylcyclohexanone } \\
\end{array}$ & $\begin{array}{l}0.083 \\
0.519 \\
\end{array}$ & $\begin{array}{c}0.0 \\
3.44 \\
\end{array}$ & 6.25 \\
\hline $\begin{array}{c}\text { Adipic acid } \\
\text { Cyclohexanone } \\
\end{array}$ & $\begin{array}{c}0.163 \\
1.06 \\
\end{array}$ & $\begin{array}{l}0.0 \\
7.38 \\
\end{array}$ & 6.50 \\
\hline $\begin{array}{c}\text { Adipic acid } \\
\text { Methylcyclohexanone }\end{array}$ & $\begin{array}{l}0.102 \\
0.607 \\
\end{array}$ & $\begin{array}{l}0.0 \\
3.23 \\
\end{array}$ & 5.95 \\
\hline $\begin{array}{l}\text { Succinic acid } \\
\text { 2-Heptanone }\end{array}$ & $\begin{array}{l}0.0231 \\
0.0944 \\
\end{array}$ & $\begin{array}{c}0.0 \\
0.88 \\
\end{array}$ & 4.09 \\
\hline $\begin{array}{c}\text { Adipic acid } \\
\text { Methylisobutylketone }\end{array}$ & $\begin{array}{l}0.0488 \\
0.166 \\
\end{array}$ & $\begin{array}{l}0.18 \\
1.29 \\
\end{array}$ & 3.40 \\
\hline $\begin{array}{c}\text { Fumaric acid } \\
\text { n-Butyl acetate }\end{array}$ & $\begin{array}{l}0.0069 \\
0.0393 \\
\end{array}$ & $\begin{array}{l}0.034 \\
0.700 \\
\end{array}$ & 5.70 \\
\hline $\begin{array}{c}\text { Fumaric acid } \\
\text { Di-n-butyl ether }\end{array}$ & $\begin{array}{l}0.0022 \\
0.0036 \\
\end{array}$ & $\begin{array}{l}0.011 \\
0.083 \\
\end{array}$ & 1.64 \\
\hline $\begin{array}{c}\text { Fumaric acid } \\
\text { Tri- }- \text {-butylphosphate }\end{array}$ & $\begin{array}{l}0.848 \\
0.759 \\
\end{array}$ & $\begin{array}{l}0.156 \\
2.76 \\
\end{array}$ & 0.89 \\
\hline
\end{tabular}

The effect of ter-enhanced solvation is potentially useful for other separations, including processes that involve highly soluble solutes. For example, removal of co-dissolved water could increase driving forces for adsorption, extraction, stripping, and membrane permeation of the solute. The addition of water could also enhance absorption of a solute 
from a gas, leaching of a solute from a solid, or extraction from a non-aqueous immiscible phase.

Some past studies have noted this solvation phenomenon, but there has been ro methodical search to find which classes of solutes and solvents show the largest effects. Van Brunt and King have compiled available information on the effects of hydration on solubility ar 1 solvatinn in organic extraction systems. ${ }^{4}$ Information on ternary interactions is needed. In addition to data on solubilities in water-containing solvents, pertinent data include information on maximum-boiling, ternary azeotropes and cases where liquid-liquid phase envelopes are broad yet shallow.

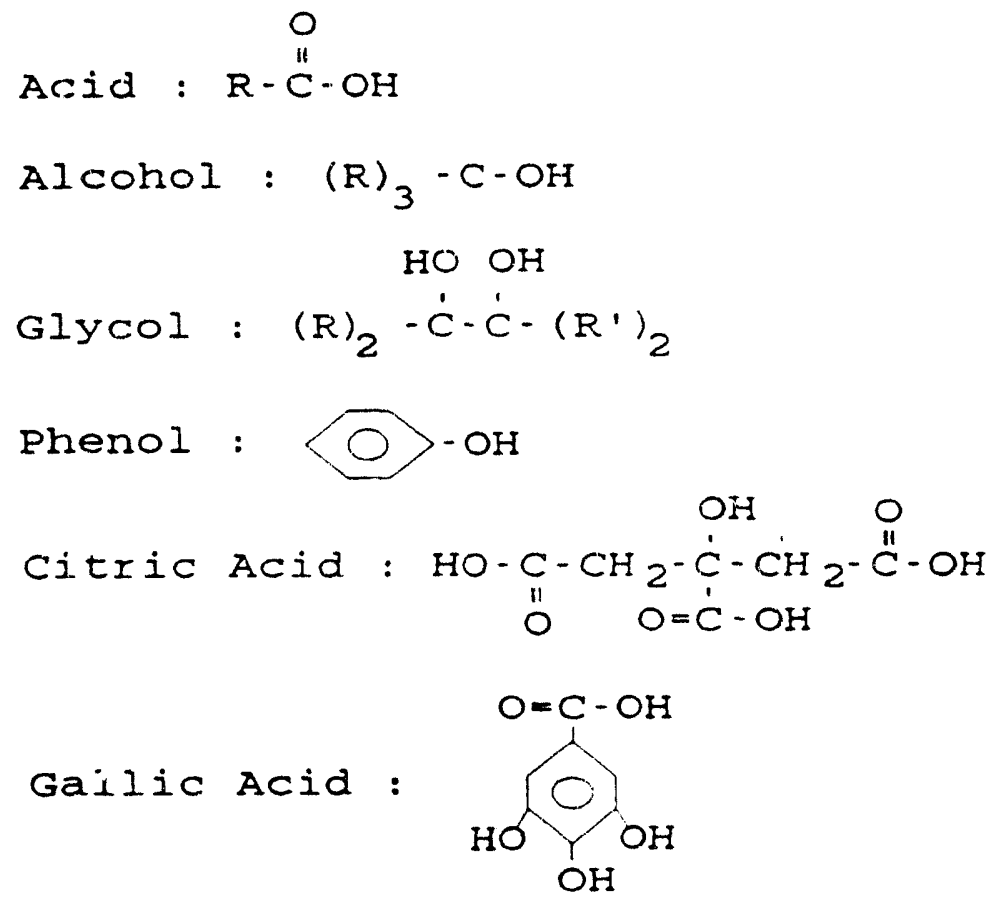

Figure 1.1 Solute Structures

The literature data collected by Van Brunt and King suggest that Lewis acid solutes logeiner with Lewis base organic solvents arc most !:kely to show the water-enhanced 
solvation. The purpose of this research was to explore this effect in detail and to determine the classes of solutes and solvents for which the solubilities of solutes are greatly enhanced. Extending the work of Starr and King on dicarboxylic acids, the solutes of interest are monocarboxylic acids, tricarboxylic acids, alcohols, glycols, and phenols, all of which are solutes identified by Van Brunt and King and are Lewis acids that can be produced from biomass. The chemical structures of the solutes and solvents used in this work are listed in Figures 1.1 and 1.2.

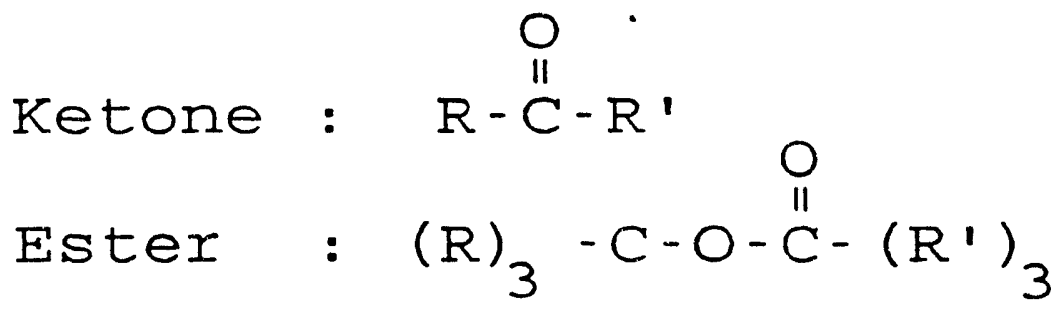

Figure 1.2 Solvent Structures

Organic solvents with an intermediate basicity were chosen for reasons of bond strength. For a ternary complex or solvate to form, water must serve more effectively as a hydrogen acceptor than does the organic solvent. Ketones and esters seem to be the most effective solvents for water-enhanced solvation. Starr and King found that ketones with an available, sterically unhindered electron-donor atom exhibited water-enhanced solvation to the greatest extent. Therefore, cyclohexanone, methylcyclohexanone, 4-methyl-2-pentanone (methylisobutylketone, MIBK), and n-butyl acetate were the solvents used in this study.

Future areas of interest not covered i the scope of this project include the use of other solvents. For example, alcohols, ethers, phosphates, and nitriles are potential solvents for water-enhanced solvation. 


\section{1.i Solutes of Interest}

\section{Acetic Acid}

The commercial methods for manufacturing acetic acid involve oxidation of liquid acetaldehyde, butane or naphtha, or methanol carbonylation. ${ }^{5}$ However, aerobic bacterial oxidation of sugar and starches that come from alcohol, cider, wine, or malt also produce a dilute acetic acid. ${ }^{6}$ The bacterium Acetobacter suboxydans is currently the most efficient species for producing acetic acid, but newer species such as Clostridium thermoaceticum are also being examined as prisible alternatives to synthetic manufacturing. ${ }^{7}$ In a 1991 study, the price of acetic acid by the Acetobacter system was $31 \%$ higher and the Clostridium system was $45 \%$ higher than that by the synthetic route. ${ }^{7}$ The Clostridium process produces the acid at a high rate and yield, but it is difficult to recover the product. By improving the cost of separation, fermentation would be a more competitive alternative to the synthetic route.

Acetic acid is commonly used in the production of vinyl acetate, thermoplastics, and plastic sheeting; as an acidulant and preservative for food products; and in commercial organic syntheses. $^{8}$ The demand for acetic acid in 1991 was 3.61 billion pounds with a predicted three percent annual growth rate. ${ }^{9}$

\section{Propionic Acid}

Propionic acid can also be produced synthetically and by fermentation. The common manufacturing processes are Fischer-Tropsch synthesis from natural gas, ethanol carbonylation, and oxidation of propionaldehyde. Propionic acid can also be obtained by the fermentation of sugars using bacteria of different species of Propionibacterium. ${ }^{8}$ Alternatives to the genus Propionibacterium are Lactobacillus xylosus and Propionibacterium shermanii which convert glucose and xylose to propionic acid through a lactate intermediate. ${ }^{10}$ These 
newer systems of fer higher productivities and improved economics, which give fermentation a better chance in competition with synthetic routes.

In the United States, almost two-thirds of the 220 million pounds per year of propionic acid is used in animal feed, grain preservatives, cellulosic plastics, and herbicides. ${ }^{11}$ Over the last ten years, the demand for propionic acid has increased by over four percent per year, and the increase is expected to continue.

\section{Ethanol}

In $1991,85 \%$ of the ethanol produced in the United States was made via the fermentation of sugars, starch or cellulose. ${ }^{12}$ The yeasts used in the fermentation are strains of Saccharomyces cerevisiae or less commonly Saccharomyces uvarum, Saccharomyces carlsbergensis or Candida brassicae. ${ }^{13}$ The fermentation typically continves until the ethanol reaches a ten percent concentration and the product begins to inhibit the activity of the yeast.

A variety of process improvements have been made to conventional ethanol fermentation. These improvements have involved modifications to the type of feedstock and preparation, fermentation, product recovery, and by-product and waste processing. Among all the modifications, the most significant cost savings are realized in the area of separations. ${ }^{2}$

Ethanol is unique in that it is used in a variety of ways. It is used as a solvent, germicide, beverage, fuel, antifreeze, depressant, and chemical intermediate. ${ }^{5}$ In 1990,1445 million gallons of ethanol were produced, and the fuel and beverage industries consumed $67 \%$ of the ethanol produced by fermentation. ${ }^{12}$ The demand for ethanol by the fuel industry is expected to increase between 5 and $10 \%$ per year for the next 2 years. ${ }^{12}$ With high demands, new and innovative techniques are needed to reduce the cost of ethanol production even further. 


\section{Propylene Glycol}

Propylene glycol (1,2 propanediol) is commonly produced from petrochemical resources by the hydration of propylene oxide. Over 900 million pounds of propylene glycol were manufactured in 1992, and the annual growth rate over the last ten years was five percent per year. ${ }^{14}$ It is primarily used in unsaturated polyester resins for fiberglassreinforced products, in liquid laundry detergents, and in pharmaceutical and food applications.

Both enantiomers of propylene glycol can be produced by fermentation. S(+)-1,2propylene glycol can be produced by the metabolism of L-fucose and L-lactate sugars in the bacterium Escherichia coli. ${ }^{15}$ Cameron and Cooney discovered that the anaerobic thermophilic bacterium, Clostridium thermosaccharolyticum is capable of producing $R(-)-1,2-$ propanediol from a variety of common sugars and corn derivatives. ${ }^{16}$ The product concentration is one percent in the aqueous stream, which also contains the by-products ethanol, lactate, acetate, and acetol. This fermentation process could be a promising route to produce these products from readily available substrates, if the product concentration were higher.

\section{Phenol}

There are numerous ways to produce phenol from petrochemicals; the most important are the sulfonation of benzene, the liquid phase chlorobenzene process, the catalytic vapor phase Raschig process, the cumene hydroperoxide process, and toluene oxidation. ${ }^{6}$ An alternative route for producing phenol and a variety of other chemicals such as hydroquinones and cyclopentanones is the direct thermal liquefaction of cellulosic biomass. Nelson et al. ${ }^{17}$ found that the liquefaction product oil yield from the conversion of cellulose and biomass feedstocks was typically between 20 and $50 \%$. 
One application for the biomass-derived oil is as an adhesive intermediate. Due to the phenol and furan content in the oil, cross-linking with formaldehyde is possible, thereby making an adhesive which is similar to the commercially used phenol-formaldehyde resins.

About 35\% of the phenol manufactured is used as a phenolic resin for the production of epoxy and polycarbonate resins. ${ }^{18}$ Other uses for phenol are in the production of bisphenol A and caprolactam. In 1990, 3950 million pounds were produced. There has been a constant growth rate of three percent a year for the last ten years.

\section{Citric Acid}

Citric acid and citrates are widely used in pharmaceuticals and cosmetics. Citric acid is used as antioxidant in medicines to improve the flavor and mairitain stability of the active ingredient. It can also be used as an anticoagulant for the transportation and storage of blood plasma. Other applications of citric acid are as a component in detergents, as an acidulant in carbonated beverages and food products, and as an iron-sequestering agent. ${ }^{6}$

Citric acid is almost exclusively produced by fermentation using fungus Aspergillus niger using crude raw materials, such as molasses. ${ }^{6}$ The conventional process for separating the acid from the broth is calcium salt precipitation. Lime water is added to the fermentation broth, precipitating calcium citrate. Citric acid is obtained using sulfuric acid through a hydrolyzation of the calcium salt followed by a number of final purification steps. The amount of waste produced by this method is about 2.5 tons per ton of produced citric acid. ${ }^{19}$ The disposal of the calcium sulfate is a major drawback to this process, and alternative separation techniques are needed.

More recently, solvent extraction with high-molecular weight amines in waterimmiscible organic solvents has been used to extract dilute citric acid from aqueous systems. A temperature-swing stripping-operation is used to back-extract the acid from the organic phase into an aqueous liquid leaving all the amine in the organic phase. ${ }^{20,21}$ 


\subsection{Scope of Study}

The overall goal of this project was to explore the occurrence of water-enhanced solvation in more detail for the Lewis acid solutes and Lewis base organic solvents listed above. The systems of most importance are those in which the solubility or volatility of the solute is drastically changed due to the addition of small amounts of co-dissolved water. Starr and $\mathrm{King}^{3}$ did a complete analysis of three dicarboxylic acids and various solvents, and this study extends the search to other classes of solutes. The effect of water-enhanced solvation was measured as a function of water concentration using techniques described in the experimental section. The use of High Pressure Liquid Chromatography as a method for screening organic solutions for water-enhanced solvation was investigated, and the results are described in Appendix A. 
Chapter 2. Experimental Procedure

\subsection{Analytical Techniques}

\subsubsection{Solid - Liquid Equilibrium}

Three different analytical methods -- GC, HPLC and back-titration -- were utilized to quantify the amount of solute dissolved in a sulvent.

\section{Gas Chromatography}

For the phenols with lower boiling points, phenol and xylenols, a Varian 3700 gas chromatograph (GC) with a thermal conductivity detector was used. Helium was the carrier gas, and the column was $1.52 \mathrm{~m} \times 3.18 \mathrm{~mm}$ stainless steel, packed with Porapak Q (Waters Associates) and held at $225^{\circ} \mathrm{C}$. The peak areas were recorded with a Hewlett-Packard 3390A integrator. Day-to-day calibrations were performed using a standard solution.

\section{High Pressure Liquid Chromatography}

For higher boiling phenol derivatives, high pressure liquid chromatography (HPLC) with a Waters differential refractometer R40I (RI) detector was used for the analysis. A Waters $8 \mathrm{~mm}$ by $100 \mathrm{~mm} \mathrm{C}_{18}$ Resolve ${ }^{\mathrm{m}}$ Radial-Pak column was used in a radial compression module with an eluent consisting of a $1: 1(\mathrm{v} / \mathrm{v})$ acetonitrile $: 2 \%(\mathrm{~g} / \mathrm{g})$ acetic acid solution and $0.05 \mathrm{M}$ Waters low UV Pic A reagent. A constant mobile phase flow rate of $1.0 \mathrm{~mL} / \mathrm{min}$ was delivered by a Perkin Elmer Series 10 pump, and the data were recorded with a Waters 746 data module.

HPLC was also used to quantify the amount of citric acid dissolved in butyl acetate. The HPLC equipment and column mentioned previously remained unchanged, but the eluent 
was a $65: 35(\mathrm{v} / \mathrm{v})$ methanol : water solution. In addition, the mobile-phase flow rate was increased to $1.5 \mathrm{~mL} / \mathrm{min}$.

For both GC and HPLC analysis, calibration curves relating peak area to number of moles were generated by analyzing samples of known solute and solvent concentrations (Appendix C).

\section{Back-Titration}

The third analytical technique for solid-liquid equilibrium, acid-base back-titration, was used to measure acid concentrations in organic solutions. A measured volume of $0.1052 \mathrm{M}$ $\mathrm{NaOH}$ solution was well mixed with a known amount of organic phase in a $25 \mathrm{~mL}$ erlenmeyer flask, causing a back extraction of the acid into the aqueous phase. The resulting basic solution was back titrated using a phenolphthalein indicator and a $0.1008 \mathrm{M} \mathrm{HCl}$ solution. The acid concentration in the organic phase was determined by difference. For citric acid in butyl acetate, HPLC was used as the analytical technique instead of back-titration because esters hydrolyze in highly basic solutions.

\subsubsection{Vapor - Liquid Equilibrium}

A Varian 3700 gas chromatograph (GC) with a flame ionization detector (FID) was used to quantify the amount of solute and solvent in the liquid and vapor phases. The organic compounds were separated along a $3.18 \mathrm{~mm}$ by $0.46 \mathrm{~m}$ stainless steel column packed with Porapak PS (Waters Associates). Helium was used as the carrier gas, while hydrogen and air were used to support the flame of the FID. Various column temperature programs were used to aid in the separation. Day-to-day calibrations were performed using a standard solution.

For determination of the liquid phase concentration, the sensitivity of the GC detector was set to $10^{-10} \mathrm{amps} / \mathrm{mV}$. There were lower concentrations in the vapor phase, and therefore 
the sensitivity was increased to either $10^{-11}$ or $10^{-12} \mathrm{amps} / \mathrm{mV}$, depending on the vapor pressure of the solute.

Additional noise was generated by increasing the sensitivity of the GC. The effects of the noise were minimized by adjusting various parameters on the Waters 746 data module. The peak width, peak threshold, and minimum area parameters were adjusted to give reproducible peak areas.

\subsubsection{Water Analysis}

For each of the solid-liquid equilibrium and vapor liquid equilibrium techniques described, the amount of water present in the liquid organic phase was determined by Karl Fischer titration with a Quintel Model MS-1. A modified GFS Chemicals Karl Fischer reagent containing 2-methoxyethanol was used instead of the standard methanol solvent because it prevents formation of acetals and ketals which interfere with the titration. Esters and active carbonyl groups in the presence of methanol form water, which offsets the titration.

\subsection{Solid - Liquid Equilibrium}

\subsubsection{Sample Preparation}

The hydrated samples analyzed for water-enhanced solvation were prepared by adding measured volumes of water and solvent to a $20 \mathrm{~mL}$ scintillation vial. In order to produce

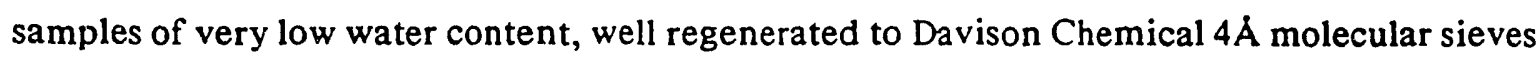
were added to the solvent to remove any water present. The dust particles from the molecular sieves were filtered from the dried solvent using Millipore Millex-ST $0.5 \mu \mathrm{m}$ filters. The 
purities of the chemicals used for both the solid-liquid equilibrium and vapor-liquid equilibrium studies are listed in Appendix B. The water used in the hydrated samples was distilled and deionized to $18 \mathrm{M} \Omega-\mathrm{cm}$ using a Milli-Q water purifier (Millipore Corporation).

The solute of interest was added to the containers in excess and then placed in a New Brunswick Scientific Gyrotory water bath shaker at an elevated temperature for at least 12 hours. Immediately afterwards, the sample was placed in a Fisher Scientific Versa-Bath $\mathrm{S}$ at $25^{\circ} \mathrm{C}$ for a minimum of 24 hours to reach equilibrium. Initially placing the solutions in an elevated temperature bath increased the rate of dissolution. If all the solute dissolved, additional solute was added, and the equilibration process was repeated.

Once the equilibrium solution had been prepared, the solubility was determined by analyzing the liquid phase by one of the three analytical methods previously mentioned.

\subsection{Vapor - Liquid Equilibrium}

\subsubsection{Experimental Design and Sample Preparation}

Both the solutes and solvents of interest were dried using regenerated Davison Chemical $4 \AA$ molecular sieves. Measured amounts of very low water content solute and solvent and water were added to $50 \mathrm{~mL}$ crimp-top vials. Approximately $20 \mathrm{~mL}$ of liquid was added to a vial, leaving about $30 \mathrm{~mL}$ of vapor space. A Teflon-lined silicone septum was applied to the vial by pressure from a crimper, which created a tight seal appropriate for headspace analysis. The Teflon coating minimized any effects of dissolution and diffusion of the organic vapor onto the septum.

The vials were placed in a Labline Orbit water bath shaker held at a constant temperature of $25^{\circ} \mathrm{C}$. The water level of the shaker bath was high enough to cover both the 
liquid and vapor portions of the sample completely. The viais remained in the shaker bath for at least 24 hours before measurements were made.

A clear plexiglas water-jacketed syringe case was constructed to surround the entire body of a one milliliter Hamilton 1001 gas-tight syringe. The design of the case left the syringe needle uncovered and sustained free movement of the plunger. Water flowed through the jacket at a temperature set $3{ }^{\circ} \mathrm{C}$ higher than the sample temperature by means of a constant temperature bath with a Versa Therm proportional electronic temperature controller and a heating blade. A Flowtec model F-360 impeller pump circulated the heated water around the syringe.

Special care was taken when sampling the vapor phase from the vial. The waterjacketed syringe was used to prevent condensation when vapo: samples were taken. ${ }^{1}$ A conical-point, side-port hole needle was connected to the gas-tight syringe via a Teflon luer lock. Side port needles minimize septum coring and give better reproducibility than $22^{\circ}$ bevel and the $90^{\circ}$ cut needles. ${ }^{22}$ To improve the frecision of headspace analysis, the syringe was periodically cleaned with de-ionized water and nitrogen. In addition, the Teflon tip of the plunger was frequently replaced in order to maintain a gas tight seal.

Immediately before the vapor phase was sampled, the agitation mechanism on the shaker bath that held the samples was turned off and then was re-started after the sample was taken. During the actual sampling procedure, the syringe needle was passed through the septum, and the tip was placed a few millimeters away from the liquid surface (Figures 2.1 \& 2.2). The vapor was manually circulated in and out of the syringe ten times before the final volume of vapcr was sampled and analyzed in the GC with a flame ionization detector (FID). The vapor sampling and injection were continuously repeated until the $95 \%$ confidence interval was less than three percent of the average peak area.

Through the repeated vapor injections, there was no apparent decrease in the organic vapor phase concentrations. In addition, the maximum percent depletion of ethanol, the most 
Versatherm Proportional

Electronic Temperature

Controller

Flowtec

Water Jacketed Syringe

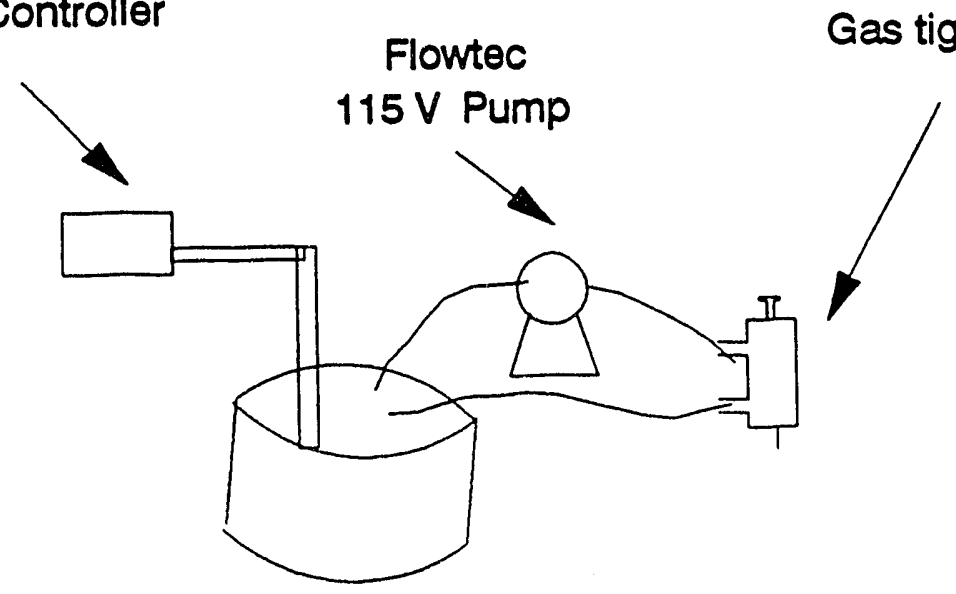

Syringe Water Bath

Figure 2.1 Water Jacketed Syringe for Vapor Headspace Anaylsis

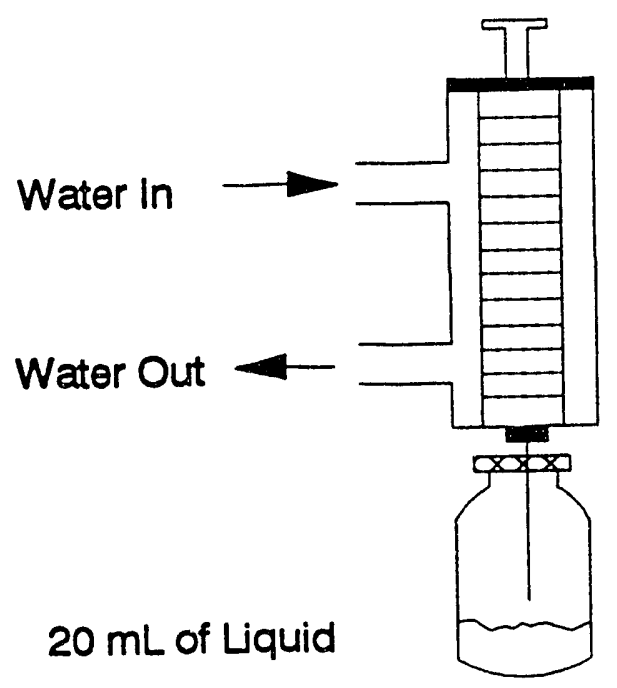

$1 \mathrm{~mL}$ Gas Tight \#1001 Syringe Side Port Needle

Crimp Top $50 \mathrm{~mL}$ Vial $0.05 \mathrm{~mm}$ Teflon Coating

on Silicone Septum (20 mm * $3 \mathrm{~mm})$

Figure 2.2 Vapor Headspace Sampling 
volatile solute examined, within the liquid after the repeated vapor sampling was calculated to be roughly $1.5 * 10^{-4} \%$. This percentage was calculated for an anhydrous 0.02 mole fraction solution of ethanol in cyclohexanone. The other solutes had a much lower percent depletion with the order of magnitude ranging from $10^{-4}$ to $10^{-6} \%$. The percentage loss of the liquid solute in the vapor samples depends on the volatility and activity coefficient of the solute.

The liquid-phase portion of the sample was also analyzed using the FID GC to determine the organic solute and solvent concentrations. A one-microliter Hamilton 7001 syringe with a Chaney adapter and $90^{\circ}$ point needle was used to sample the liquid phase. The extra precautions that were taken when sampling the vapor phase were not necessary for the liquid phase.

\subsubsection{Vapor Phase Calibration for Liquid Solutes}

In vapor headspace calibrations, $20 \mathrm{~mL}$ of pure anhydrous liquid was added to a crimp top vial. Various volumes of sample were injected into the GC, and the peak areas were related to the number of moles in the vapor. To calculate the number of moles of solute in the vapor, the following parameters were needed: sample temperature, injection volume, room pressure, vapor pressure data, and a dimerization constant (if necessary). Other than for the carboxylic acids, the solutes were assumed to not dimerize in the vapor phase.

\subsection{2.a Non-dimerizing Liquid Solutes}

The number of moles in the vapor phase was determined by assuming the ideal gas law.

$$
n_{i}=\frac{P_{i} V}{R T}
$$


$P_{i}$ is the vapor pressure and $r_{i}$ is the number of moles of solute $i$. Pure component vapor pressure data were taken from either Stull or the Chemistry Data Series. ${ }^{23,24}$ By the assumption of an ideal gas, the vapor mole fraction was simply the ratio of solute vapor pressure to total pressure. Because the septum of the vial was pierced during vapor sampling, the total pressure was assumed to be equal to ambient pressure, which was measured daily with a mercury barometer.

\subsection{2.b Dimerizing Liquid Solutes}

Determining the number of moles in the vapor phase for monocarboxylic acids was more complex. Additional information and assumptions were needed to calculate the number of moles in the vapor phase. Dimerization, which is dependent upon temperature, has been fully characterized for both acetic and propionic acids by Prausnitz et al. ${ }^{2 j}$ For both acids, the formation of trimers and higher order oligomers was assumed to be negligible.

The dimerization constant is the equilibrium ratio of the $p_{a_{1}}$ tial pressure $\left(P_{2}\right)$ of the Jimer to the square of the partial pressure $\left(P_{1}\right)$ of the monomer. For the pure acid, the sum of the partial pressures is equivalent to the vapor pressure of the acid. ${ }^{25,26}$

$$
\begin{gathered}
P_{2}^{3}(T)=P_{1}+P_{2} \text { (pure) } \\
P_{2}=K_{2} P_{1}^{2} \\
P_{\text {tot }}=P_{1}+P_{2}+P_{\text {inert }}
\end{gathered}
$$

The rumber of moles of acid (as monomer) in the vapor is given by Equation 2.5a.

$$
n_{a}=\frac{\left(P_{1}+2 P_{2}\right)}{P_{\text {tot }}+P_{2}} \cdot \frac{P_{\text {cot }} V}{R T} * \frac{\left(P_{\text {tod }}+P_{2}\right)}{P_{\text {cot }}}
$$


The number of moles, $\mathrm{n}_{\mathbf{a}}$, can also be calculated from the ideal gas law, taking

$$
y_{a}=\frac{P_{1}+2 P_{2}}{P_{\text {rot }}}
$$

The use of the ideal gas law here offsets the use of $P_{\text {tot }}$ rather than $P_{t}+P_{2}$ in the denominator of Equation 2.5b.

A linear calibration curve was generated by relating the number of vapor acid moles to peak arca (Appendix C). There was only one vapor peak for the acid because the monomer and dimer continually equilibrate during passage through the GC column.

\subsection{2.c Solid Solutes}

Phenol was analyzed for water-enhanced solvation through vapor headspace analysis, as well as the solid-liquid equilibrium measurements described above. The procedure used to prepare and analyze solid solute solutions was identical to that used for liquid solutes except for the type of column used. The organic compounds were separated along a $3.18 \mathrm{~mm}$ by $1.83 \mathrm{~m}$ stainless steel column filled with Porapak Q (Waters Associates) packing.

For calculating the number of moles present in the vapor phase for liquid solutes, vapor pressure data are needed. For solid-vapor equilibria, the number of moles present in the vapor phase is determined by substituting the vapor pressure in Equation 2.1 by the sublimation pressure of the pure solid. For phenol, sublimation pressure data were taken from the CRC Handbook of Chemistry of Physics. ${ }^{27}$ The vapor calibration of solid solutes followed the same methodology as the liquid solutes except for the substitution of sublimation pressure for vapor pressure. 


\subsubsection{Liquid Phase Calibration}

Liquid phase calibrations with the GC were relatively straightforward. Measured amounts of anhydrous solute and solvent were placed in vials, and samples were injected into the GC. The average peak areas were related to the number of moles per unit volume present in the liquid by a linear regression (Appendix C). The amount of water present in the liquid mixture was determined by Karl Fischer titration. Linear regressions between peak area and number of moles gave $\mathrm{R}^{2}$ values of 0.96 or higher.

\subsubsection{Vapor - Liquid Equilibrium Calculations}

In the experiment using vapor headspace analysis, the activity coefficient of the solute in the liquid phase was used as the measure of comparison for water-enhanced solvation. In essence, the activity coefficient data provided information on the degree of accommodation of the solute in the liquid phase.

Beginning with basic thermodynamic equations, the determination of activity coefficients for solutions of solutes other than carboxylic acids reduces to the ratio of pressures and mole fractions. Many assumptions were made in order to reduce the equations.

The proportionality constant for the liquid phase is equivalent to the liquid fugacity of the pure component multiplied by its activity coefficient, $\gamma$. The Lewis fugacity rule was used to relate the fugacity of a component, $f_{i}$, in the vapor phase to the vapor mole fraction times the pure component fugacity. ${ }^{28}$

$$
\begin{gathered}
\mu_{\mathrm{i}}^{\mathrm{V}}=\mu_{\mathrm{i}}^{\mathrm{L}} \\
f_{\mathrm{i}}^{\mathrm{V}}=f_{\mathrm{i}}^{\mathrm{L}} \\
\mathrm{y}_{\mathrm{i}} f_{\mathrm{i}, \text { pure }}=\mathrm{x}_{\mathrm{i}} \gamma_{\mathrm{i}} f^{\mathrm{L}}{ }_{\mathrm{i}, \text { pure }}
\end{gathered}
$$


In equation 2.8 , the equilibrium relationship of chemical potential of component $i, \mu_{i}$, between the vapor and liquid phases is defined. The phase equilibrium (Equation 2.9) was derived by substituting the definition of fugacity into Equation 2.8. Fugacities cannot be measured; therefore further assumptions and substitutions were made. The pure liquid fugacity is equivalent to the saturated equilibrium partial pressure times the saturated fugacity coefficient and the Poynting correction. ${ }^{28}$ The fugacity coefficient corrects for deviations from ideal gas behavior, and the Poynting factor corrects for the compressibility of the liquid. By definition, the fugacity coefficient was substituted into the left hand side of equation 2.10.

$$
\left.\mathrm{y}_{\mathrm{i}} \Phi_{\mathrm{i}} \mathrm{P}=\mathrm{x}_{\mathrm{i}} \gamma_{\mathrm{i}} \mathrm{P}_{\mathrm{i}}{ }^{8} \Phi_{\mathrm{i}}{ }^{8} \text { (P.C. }\right)
$$

The Poynting correction factor (P.C.) was negligible because all the systems were analyzed at room pressure. For the non-carboxylic acid solutions, both fugacity coefficients were assumed to be one, which reduced the equation even further. ${ }^{28}$

$$
y_{i} P=x_{i} \gamma_{i} P_{i}{ }^{8}
$$

For the monocarboxylic acids, the fugacity coefficients cannot be assumed to be one, and therefore the following assumptions were made to correct for dimerization. ${ }^{25,26}$

$$
\begin{gathered}
\phi_{a}^{s}=\frac{P_{1}(x=1)}{P_{a}^{s}} \\
\phi_{a}=\frac{P_{1}}{y_{a} P}
\end{gathered}
$$

Both the vapor and liquid mole fractions were determined using the pure component calibration curves. For each of the samples analyzed, the activity coefficient was calculated as a function of increasing water concentration. 


\section{Chapter 3. Results}

\subsection{Vapor-Liquid Equiíibrium}

Activity coefficient data for volatile Lewis acid solutes were determined by vaporheadspace experiments. The techniques used to measure vapor-liquid equilibrium are described in the experimental section and the experimental data are recorded in Appendix $D$.

\subsubsection{Monocarboxylic Acids}

Liquid activity coefficients were determined by vapor-headspace analysis for monocarboxylic acids in cyclic ketones. For acetic acid in cyclohexanone and for propionic acid in both cyclohexanone and methylcyclohexanone, the liquid activity coefficients of the acids decreased as the water concentration of the organic solvent increased (Figures 3.1a to 3.3a). $\Delta\left(\log \gamma_{8}\right)$ represents the relative change in the activity coefficient of the solute. To allow for the differences in mole fractions and infinitely dilute liquid activity coefficients of the solute in the different cases, plots of $\log \gamma_{8}$ vs. $x_{w} / x_{8}$ were also generated, Figures $3.1 \mathrm{~b}$ to 3.3b.

Table 3.1 compares the ratio of the activity coefficient in the organic solvents of highest and lowest water contents for both acids in the cyclic ketones. In addition, the slope of the $\log \gamma_{\mathrm{s}}$ vs. $\mathrm{x}_{\mathrm{w}} / \mathrm{x}_{\mathrm{a}}$ curve is also reported in Table 3.1 and it is equal to the enhancement factor, "E". The slope and it's standard error were determined by a linear least square fit. This slope is an approximation of the magnitude of the water-enhanced solvation effect, on a normalized basis. A more accurate method of measuring the size of water-enhanced solvation is to take the limit of $\log \left(\gamma_{s}\right) / x_{w} / x_{s}$ as $x_{w}$ approaches zero, however there is not enough experimental data to calculate the limit as $x_{w}$ approaches zero. 

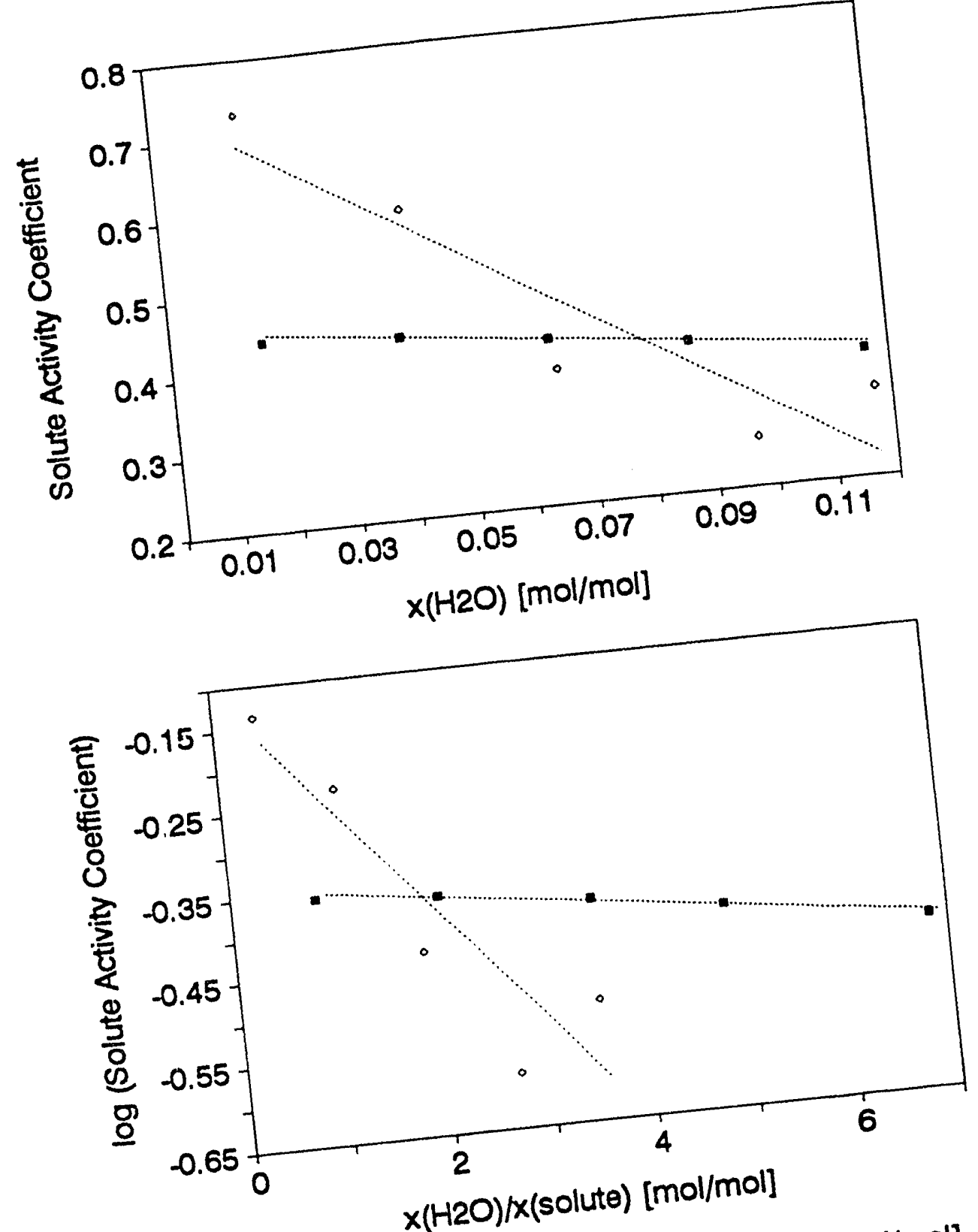

- Acetic Acid/Cyclohexanone $=0.02[\mathrm{~mol} / \mathrm{mol}]$
- Acetic Acid/Cyclohexanone $=0.04[\mathrm{~mol} / \mathrm{mol}]$

- Acetic Acid/Cyclohexanono 25 C for Acetic Acid Figure 3.1 Vapor-Liquid Equilibrium at 25 of

(a) Liquid Activity Coefficient of Acetic Acid as a Function of Organic Phase Water Concentration. (b) Log Activity Coefficient of Acetic Acid astio. 

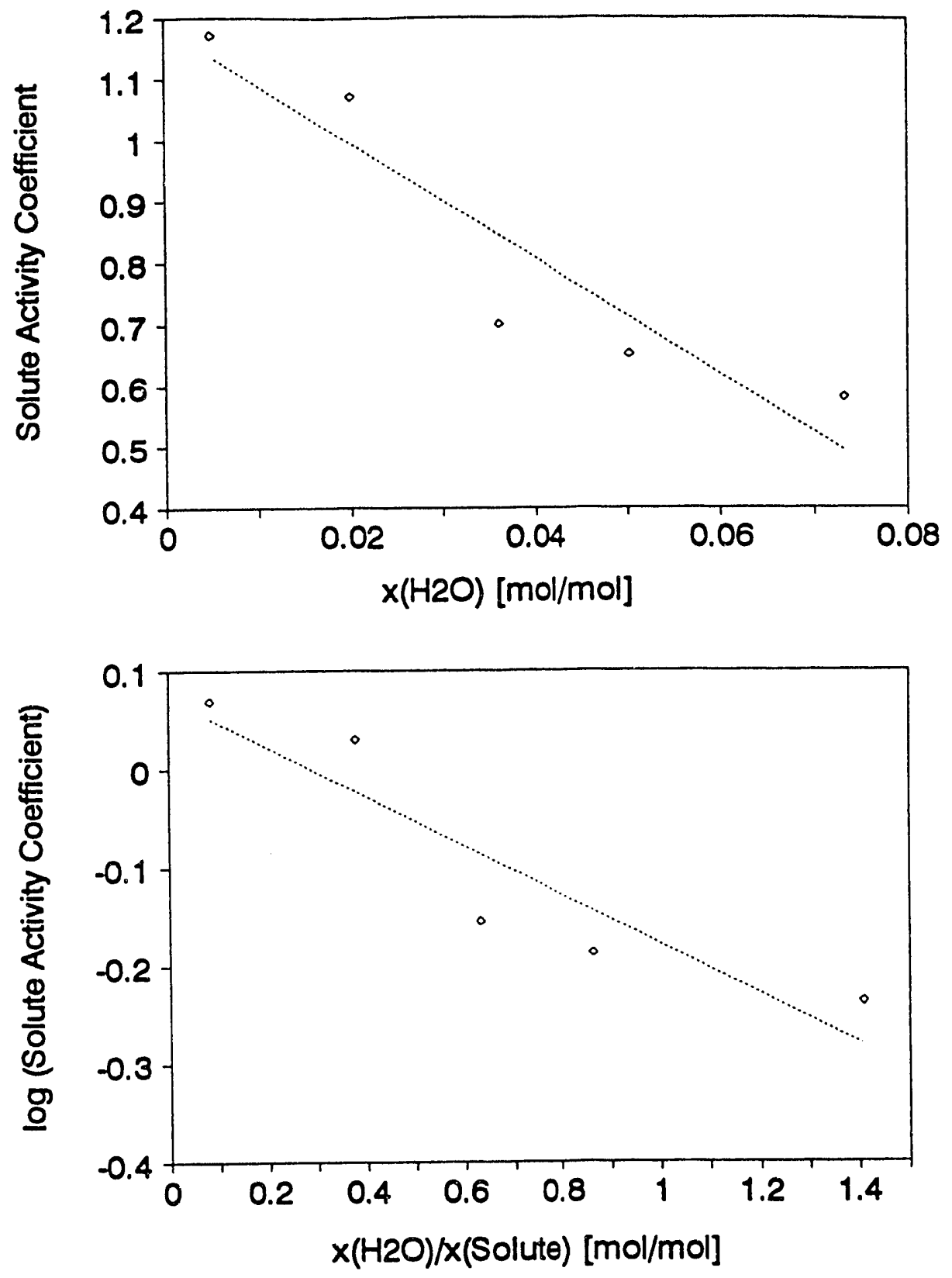

Figure 3.2 Vapor-Liquid Equilibrium at $25 \mathrm{C}$ for a $0.06 \mathrm{Mole}$ Ratio of Propionic Acid in Cyclohexanone, with Varying Amounts of Added Water.

(a) Liquid Activity Coefficient of Propionic Acid as a Function of Organic Phase Water Concentration.

(b) Log Activity Coefficient of Propionic Acid as a Function of Water to Acid Mole Ratio. 

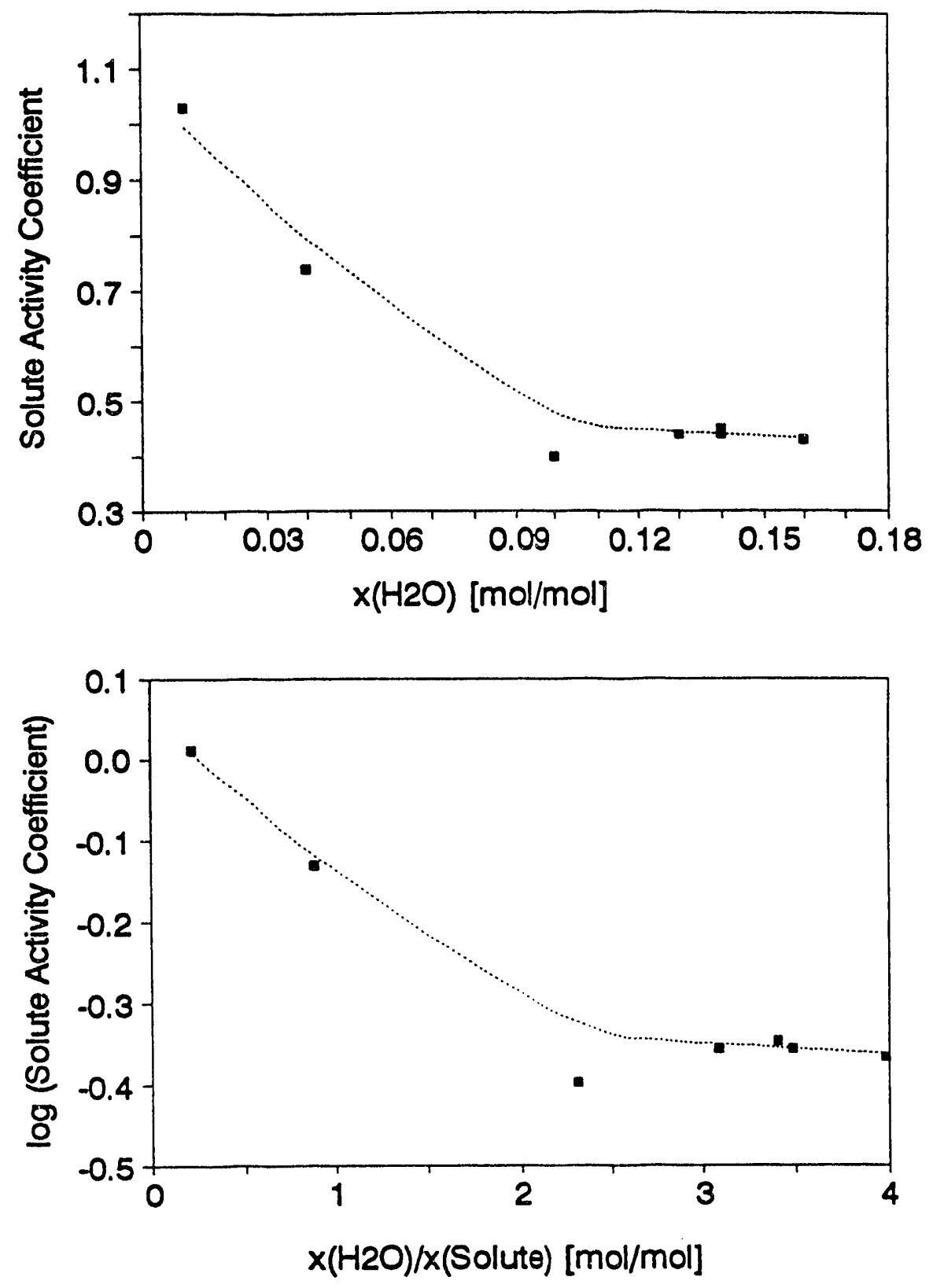

Figure 3.3 Vapor-Liquid Equilibrium at $25 \mathrm{C}$ for a 0.05 Mole Ratio of Propionic Acid in Methylcyclohexanone, with Varying Amounts of Added Water.

(a) Liquid Acitivity Coefficient of Propionic Acid as a Function of Organic Phase Water Concentration.

(b) Log Activity Coefficient of Propionic Acid as a Function of Water to Acid Mole Ratio. 
Propionic acid in cyclohexanone showed the greatest water-enhancement effect, $E=-0.25$. Water in cyclohexanone had a larger effect on the activity coefficient of the acid than did water in methylcyclohexanone. Starr and King found that ketones with more available carbonyl groups increase the solubility factor of certain dicarboxylic acids with increasing water content. ${ }^{3}$ Although water enhances solubilities more in cyclohexanone, cyclohexanone also dissolves more water than methylcyclohexanone.

Table 3.1 Activity Coefficient of Monocarboxylic Acids in Cyclic Ketones at $25^{\circ} \mathrm{C}$

$\begin{array}{lccc}\begin{array}{c}\text { Solute to Solvent } \\ \text { Mole Ratio } \\ \text { Solvent }\end{array} & \begin{array}{c}\gamma \text { Ratio } \\ \text { Low Water: }\end{array} & E=\frac{\Delta(\log \gamma)}{\left(\Delta x_{w} / x_{8}\right)} \\ & \text { High Water } & \pm \text { Standard Error }\end{array}$

\begin{tabular}{|c|c|c|c|}
\hline $\begin{array}{c}\text { Acetic Acid } \\
\text { Cyclohexanone }\end{array}$ & 0.02 & 1.2 & $\begin{array}{r}-0.015 \\
\pm 0.001\end{array}$ \\
\hline $\begin{array}{c}\text { Acetic Acid } \\
\text { Cyclohexanone }\end{array}$ & 0.04 & 2.8 & $\begin{array}{r}-0.14 \\
\pm 0.037\end{array}$ \\
\hline $\begin{array}{c}\text { Propionic Acid } \\
\text { Cyclohexanone }\end{array}$ & 0.06 & 2.0 & $\begin{array}{r}-0.25 \\
\pm 0.062\end{array}$ \\
\hline $\begin{array}{c}\text { Propionic Acid } \\
\text { Methylcyclohexanone }\end{array}$ & 0.05 & 2.6 & $\begin{array}{c}-0.19 \\
\pm 0.0064\end{array}$ \\
\hline
\end{tabular}

The enhancement factor of propionic acid in methylcyclohexanone was calculated using the first three points in Figure 3.3b. The last four points on the curve were not used to calculate the slope $\mathrm{E}$ because the curve leveled out after the water to acid ratio was greater than $2\left(x_{w}=0.1(\mathrm{~mol} / \mathrm{mol})\right)$. The activity coefficient stopped decreasing at high water concentrations, which implies that a stoichiometric relationship may exist between the water, ketone and acid.

A possible explanation for the apparent stoichiometric relationship and the decrease in activity coefficient is hydrogen bonding. A ternary complex may be formed with the 
ketone as a hydrogen acceptor, water, and the acid as a hydrogen donor. Figure 3.4 shows a possible hydrogen bonding complex between the acid, water and ketone.

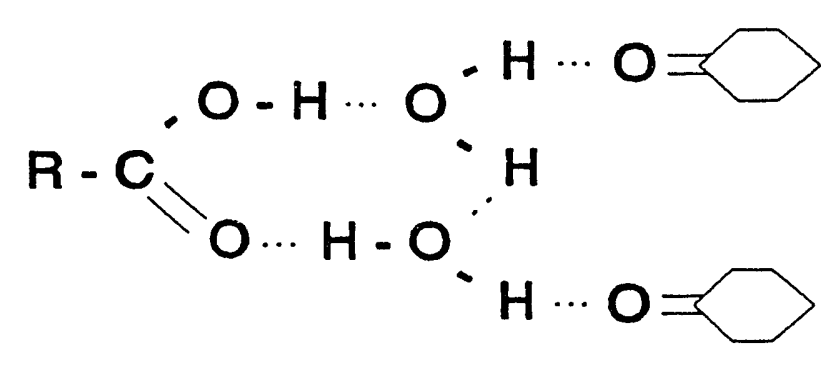

Figure 3.4 1:2:2 Acid:Water:Ketone Complex

Figure 3.4 is an extension of the 1:2 acid:water complex that Christian et al. ${ }^{29}$ proposed through interpretation of vapor pressure data for the trifluoroacetic acid-water system. Starr and $\mathrm{King}^{3}$ proposed that carbonyl groups of ketone molecules would hydrogen bond with the available protons on the water molecule of the complex proposed by Christian et al. Because Starr and King worked with dicarboxylic acids, they hypothesized that a 1:4 dicarboxylic acid:water complex could exist, associated with the same number of ketone molecules. If a stoichiometric complex does not exist between the ketone and water, the water molecules in Figure 3.4 could be surrounded by a group of ketone molecules, giving general solvation.

Acetic acid also exhibited a decrease in volatility, i.e. activity coefficient, when additional amounts of co-dissolved water were added to the cyclohexanone solvent. Figure 3.1b shows the decrease in $\gamma_{s}$ for two different mole ratios of acetic acid in cyclohexanone. The point at the highest water content in Figure 3.1 for 0.04 moles of acetic acid per mole cyclohexanone suggests that the curve may tend to flatten out above $x_{w} / x_{\text {acid }}=2$. The 0.02 $\mathrm{mol} / \mathrm{mol}$ ratio curve is relatively flat over the entire water concentration range of $x_{w}=0.02$ to $0.12(\mathrm{~mol} / \mathrm{mol})$. A possible explanation for the small rate of change, $E=-0.015$, may be the relatively high initial water to acid ratio. Most of the points lie above $x_{w} / x_{\text {acid }}=2$. As rationalized by the postulated complex, once the water to acid ratio becomes 
greater than $2\left(x_{w}=0.04\right)$, additional amounts of co-dissolved water would not cause more complexes to form.

\subsubsection{Ethanol}

Liquid activity coefficients were also determined by vapor-headspace analysis for ethanol in cyclic ketone solvents. The activity coefficient of ethanol decreased as the concentration of water in the organic phase increased (Figures $3.5 \mathrm{a} \& 3.5 \mathrm{~b}$ ). Table 3.2 compares the ratio of the activity coefficients the organic solvent at the highest and lowest water contents and gives the slope of the $\log \gamma_{\mathrm{et}}$ curve for ethanol in cyclic ketones.

Table 3.2 Activity Coefficient for Ethanol and Glycols in Cyclic Ketones at $25^{\circ} \mathrm{C}$

\begin{tabular}{|c|c|c|c|}
\hline $\begin{array}{l}\text { Solute } \\
\text { Solvent }\end{array}$ & $\begin{array}{l}\text { Solute to Solvent } \\
\text { Mole Ratio } \\
\text { [mol/mol] }\end{array}$ & $\begin{array}{c}\gamma \text { Ratio } \\
\text { Low Water: } \\
\text { High Water }\end{array}$ & $\begin{aligned} & E=\frac{\Delta(\log \gamma)}{\left(\Delta x_{w} / x_{s}\right)} \\
\pm & \text { Standard Error }\end{aligned}$ \\
\hline
\end{tabular}

\begin{tabular}{|c|c|c|c|}
\hline $\begin{array}{c}\text { Ethanol } \\
\text { Methylcyclohexanone }\end{array}$ & 0.02 & 1.4 & $\begin{array}{c}-0.025 \\
\pm 0.0026\end{array}$ \\
\hline $\begin{array}{c}\text { Ethanol } \\
\text { Cyclohexanone }\end{array}$ & 0.02 & 1.5 & $\begin{array}{r}-0.024 \\
\pm 0.0095\end{array}$ \\
\hline $\begin{array}{c}\text { Ethanol } \\
\text { Cyclohexanone }\end{array}$ & 0.05 & 1.5 & $\begin{array}{c}-0.093 \\
\pm 0.014\end{array}$ \\
\hline $\begin{array}{c}\text { Propylene Glycol } \\
\text { Methylcyclohexanone }\end{array}$ & 0.04 & 1.6 & $\begin{array}{c}-0.055 \\
\pm 0.0055\end{array}$ \\
\hline $\begin{array}{c}\text { 2,3-Butanediol } \\
\text { Methylcyclohexanone }\end{array}$ & 0.04 & 1.4 & $\begin{array}{c}-0.13 \\
\pm 0.013\end{array}$ \\
\hline
\end{tabular}

There is, in general less water enhancement of solvation for ethanol than for acetic and propionic acids. Also the curves do not flatten as the water to alcohol ratio becomes large. The activity coefficient of ethanol continued to decrease monotonically past a 6:1 water.ethanol molar ratio for both $0.02 \mathrm{~mol} / \mathrm{mol}$ ratio curves. The slopes of $\log \gamma_{\text {et }}$ per $x_{w} / x_{e t}$ 

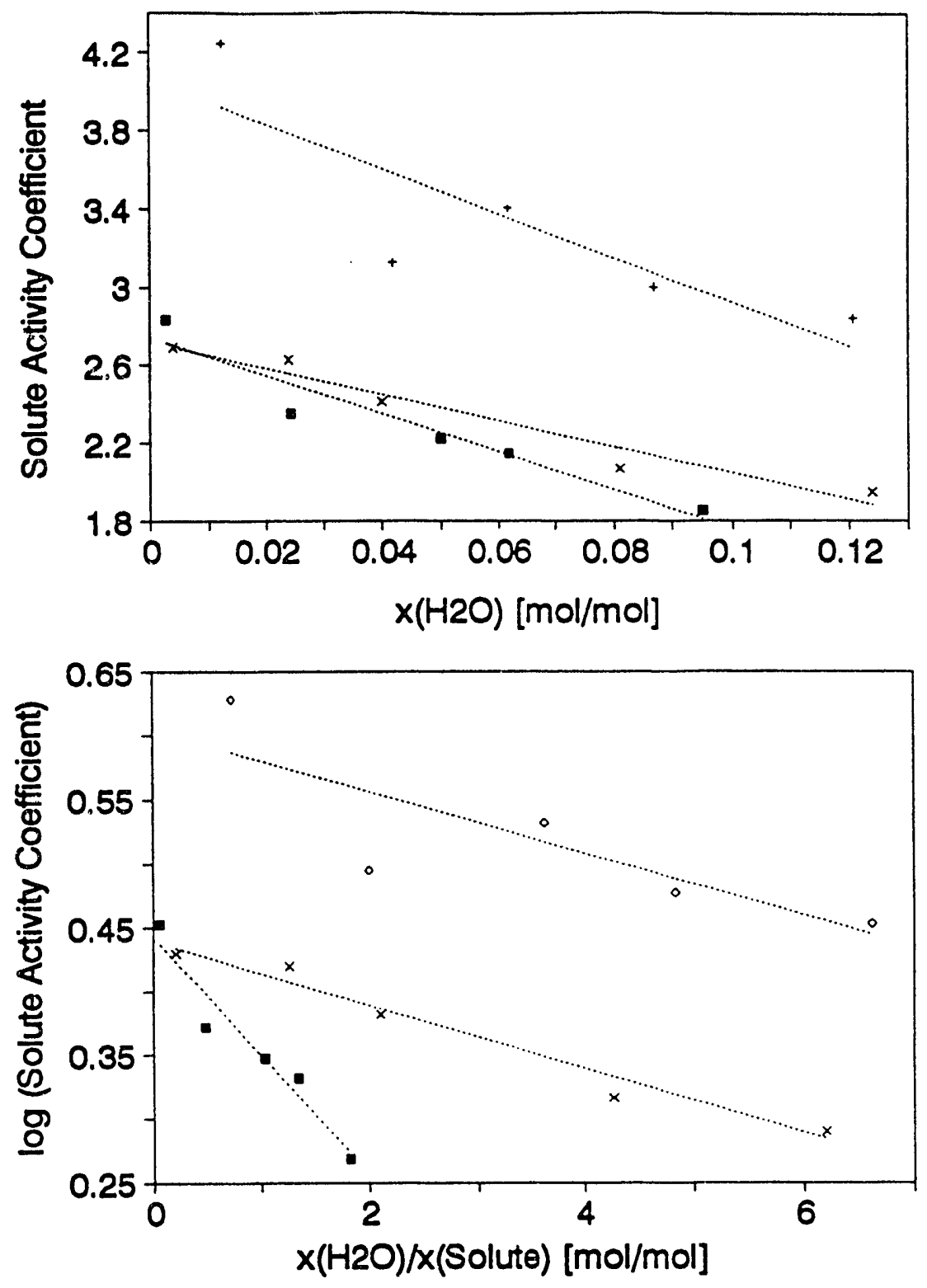

- Ethanol/Cyclohexanone $=0.05[\mathrm{~mol} / \mathrm{mol}]$

- Ethanol/Cyclohexanone $=0.02[\mathrm{~mol} / \mathrm{mol}]$

$\times$ Ethanol/Methylcyclohexanone $=0.02[\mathrm{~mol} / \mathrm{mol}]$

Figure 3.5 Vapor-Liquid Equilibrium at $25 \mathrm{C}$ for Ethanol in Cyclic Ketones, with Varying Amounts of Added Water.

(a) Liquid Activity Coefficient of Ethanol as a Function of Organic Phase Water Concentrations.

(b) Log Activity Coefficient of Ethanol as a Function of Water to Ethanol Mole Ratio. 
for a $0.02 \mathrm{~mol} / \mathrm{mol}$ ratio of ethanol in cyclohexanone and for a $0.02 \mathrm{~mol} / \mathrm{mol}$ ratio of ethanol in methylcyclohexanone were virtually identical. The curve for $0.05 \mathrm{~mol} / \mathrm{mol} \mathrm{ratio}$ ethanol in cyclohexanone has a slope 3.7 times greater than both $0.02 \mathrm{~mol} / \mathrm{mol}$ ratio curves. The effect of water seems to be related more to $x_{w}$ than to $x_{w} / x_{8}$.

\subsubsection{Glycols}

Both propylene glycol (1,2-propanediol) and 2,3-butylene glycol (2,3-butanediol) were analyzed for water-enhanced solvation by vapor-headspace analysis. Table 3.2 compares the percent changes in activity coefficients of alcohols and glycols. The ratios of dry solvent activity coefficient to wet solvent activity coefficient were roughly the same for ethanol and both glycols. The activity coefficient of propylene glycol in methylcyclohexanone may be leveling off above $x_{w} / x_{p g}=2.5$ (Figure 3.6a \& 3.6b).

The enhancement factor of the activity coefficient of propylene glycol was greater than that for the two cases of $0.02 \mathrm{~mol} / \mathrm{mol}$ ratio of ethanol in cyclic ketones but smaller than for the $0.05 \mathrm{~mol} / \mathrm{mol}$ ratio of ethanol in methylcyclohexanone.

The $\log \gamma_{\mathrm{bg}}$ per $\mathrm{x}_{\mathrm{w}} / \mathrm{x}_{\mathrm{bg}}$ slope was roughly calculated using the last four points on the curve because there was a large amount of scatter in the data and the activity coefficient of 2,3-butylene glycol may go through a maximum as the water concentration increased (Figure 3.7a \& 3.7b). A possible explanation for the apparent peak may be the use of 2,3 -butylene glycol as a mixture of DL and meso isomers. The percent composition of 2,3-butylene glycol isomers in the material used is unknown, and further studies using single isomers of 2,3butylene glycol could be revealing. 

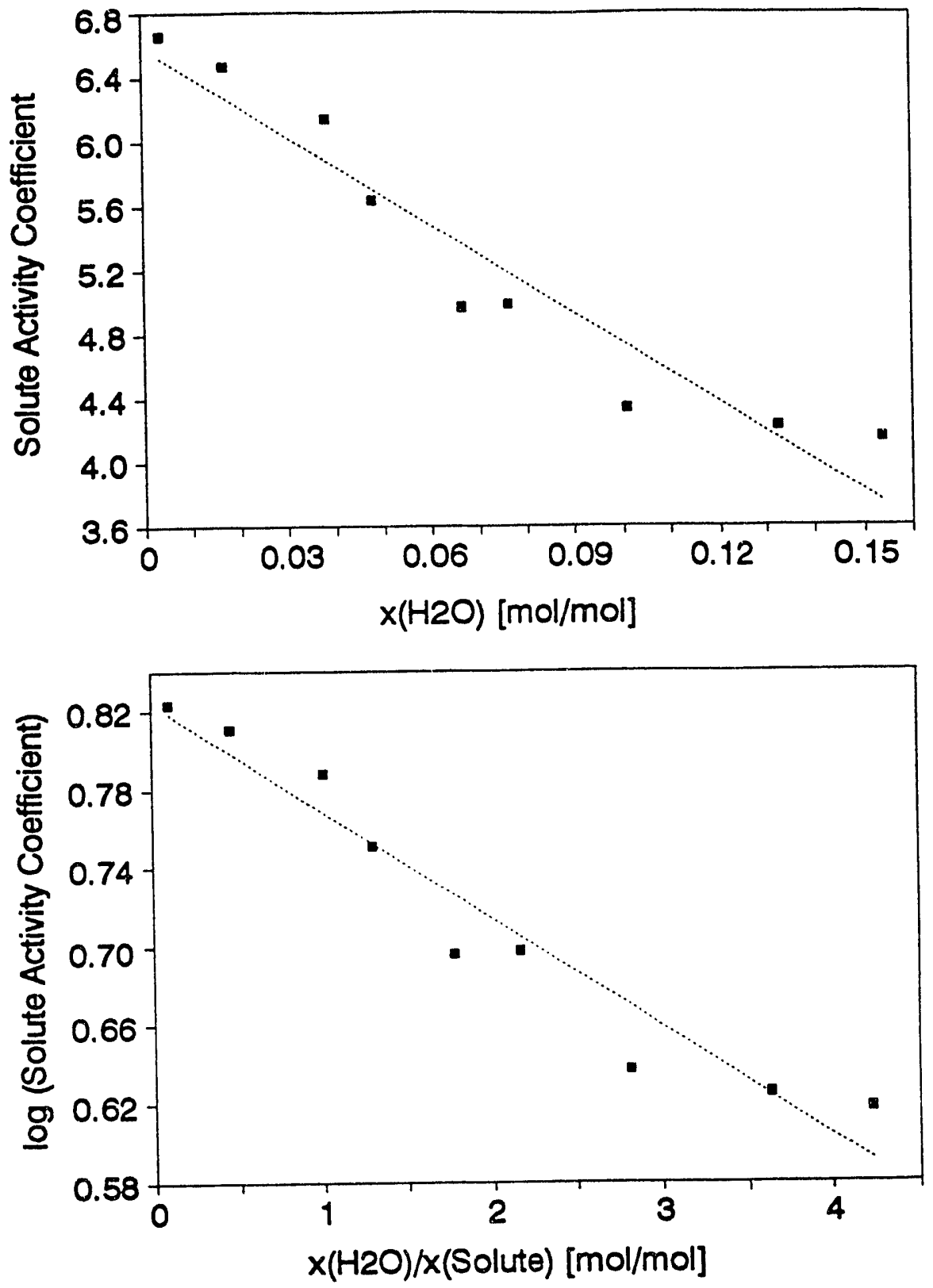

Figure 3.6 Vapor-Liquid Equilbrium at $25 \mathrm{C}$ for a 0.04 Mole Ratio of 1,2-Propanediol in Methylcyclohexanone, with Varying Amounts of Added Water.

(a) Liquid Activity Coefficient of 1,2-Propanediol as a Function of Organic Phase Water Concentration.

(b) Log Activity Coefficient of 1,2-Propanediol as a Function of Water to Diol Mole Ratio. 

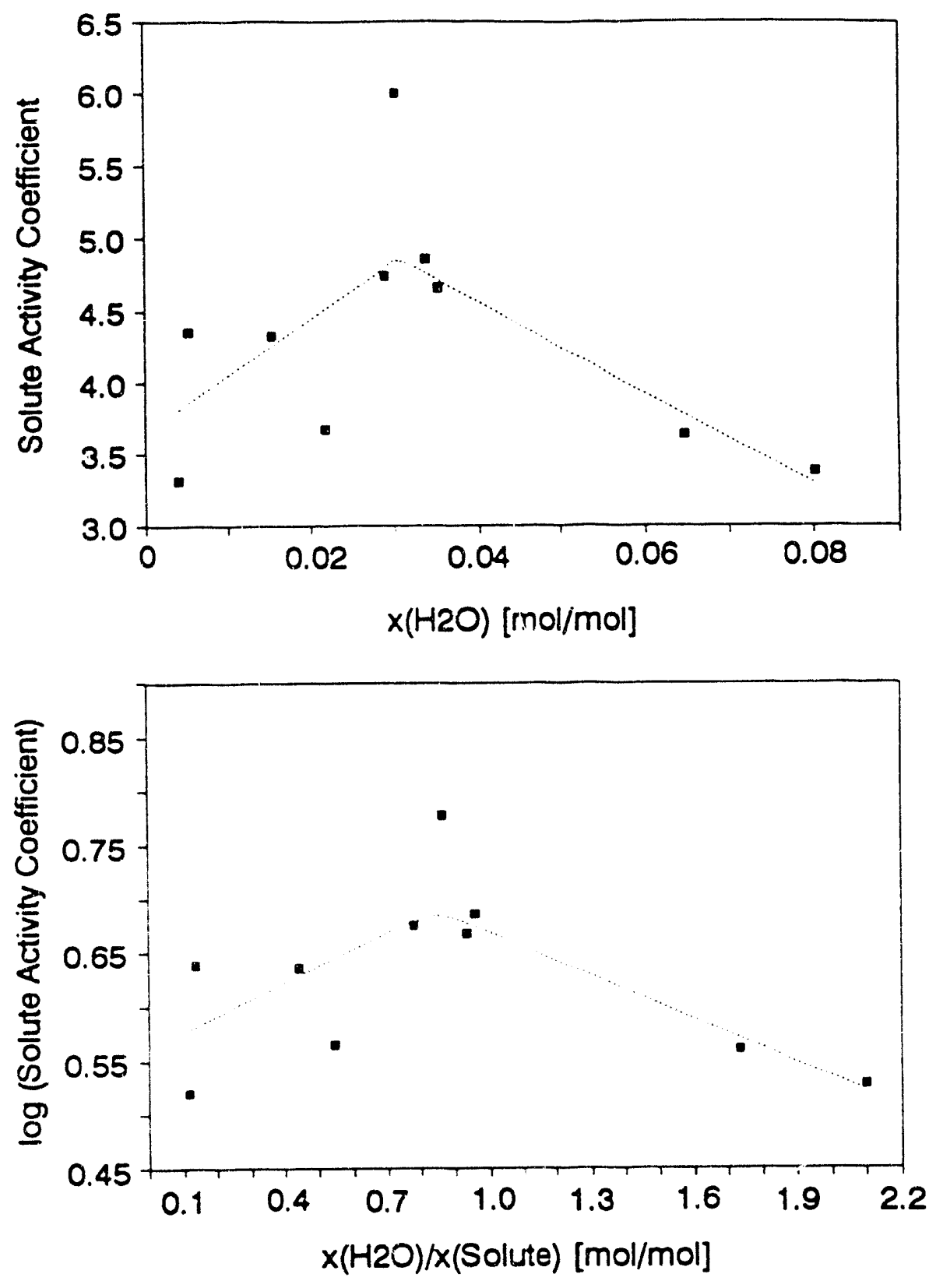

Figure 3.7 Vapor-Liquid Equilibrium at $25 \mathrm{C}$ for a $0.04 \mathrm{Mole}$ Ratio of 2,3-Butanediol in Methylcyclohexanone, with Varying Amounts of Added Water.

(a) Liquid Activity Coefficient of 2,3-Butanediol as a Function of Organic Phase Water Concentration.

(b) Log Activity Coefficient of 2,3-Butanediol as a Function of Water to Diol Mole Ratio. 


\subsection{Solid-Liquid Equilibrium}

The solubilities of solid Lewis acid solutes were measured as solid-liquid equilibria, and the techniques are described in the experimental section. The solid-liquid equilibrium data are reported in Appendix D. The solubility ratio, which is defined as the ratio of the solubility of the solute in a water-saturated (hydrated) solvent to that in a low water content solvent, was reported for each solute and solvent system. The magnitude of the solubility ratio provides information on the effectiveness of water-enhanced solvation.

\subsubsection{Gallic Acid and Citric Acid}

Gallic acid (3,4,5-trihydroxybenzoic acid) was analyzed for water-enhanced solubility by measurements of solid-liquid equilibriurn, and the results are reported in Table 3.3. The solubility of gallic acid increased as the organic phase water concentration increased. The solubility of the acid in water-saturated methylcyclohexanone was somewhat greater than in cyclohexanone, and the effect of water was greater in methylcyclohexanone. In addition, there vas less water in the water-saturated methylcyclohexanone solution.

Water-enhanced solvation was examined for citric acid (2-hydroxy-1,2,3propanetricarboxylic acid) in butyl acetate and methylcyclohexanone (Table 3.3). The solubility of the tricarboxylic acid was enhanced greatly by water in both organic solvents. The solubility of citric acid in butyl acetate at $25^{\circ} \mathrm{C}$ increased by a factor of 9.7 from 0.009 to $0.087 \mathrm{~mol} / \mathrm{L}$. Less than $0.1 \%(\mathrm{~g} / \mathrm{g})$ or $0.5 \%(\mathrm{~mol} / \mathrm{mol})$ water was present in the dry solvent solution, and the saturated solution contained $1.3 \%(\mathrm{~g} / \mathrm{g})$ or $8.0 \%(\mathrm{~mol} / \mathrm{mol})$ water.

In the water-saturated cases, solid gallic acid and citric acid form hydrates. The effect of the solid hydrates on the solubility of the acids has not been determined but it would probably be minimal. 
Table 3.3 Solubilities of Citric Acid and Gallic Acid in Wet and Dry Solvents at $25^{\circ} \mathrm{C}$

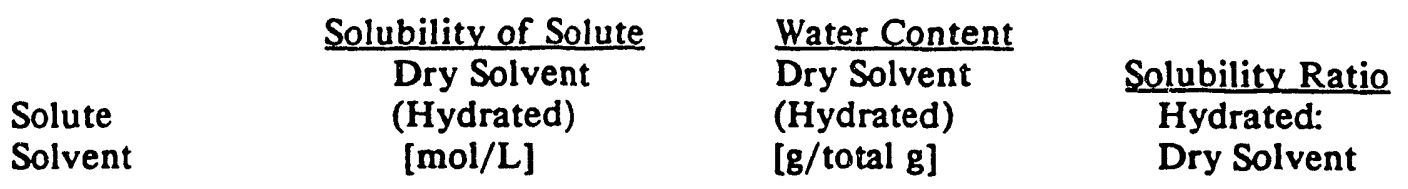

\begin{tabular}{||c|c|c|c|}
\hline Gallic Acid & $\begin{array}{c}0.69 \\
(0.75)\end{array}$ & $\begin{array}{c}0.01 \\
(0.13)\end{array}$ & 1.09 \\
\hline Cyclohexanone & $\begin{array}{c}0.52 \\
(0.83)\end{array}$ & $\begin{array}{c}0.006 \\
(0.079)\end{array}$ & 1.59 \\
\hline Gallic Acid & $\begin{array}{c}0.0090 \\
(0.087)\end{array}$ & $\begin{array}{c}0.001 \\
(0.013)\end{array}$ & 9.67 \\
\hline Citric Acid & $\begin{array}{c}0.25 \\
(1.70)\end{array}$ & $\begin{array}{c}0.002 \\
(0.11)\end{array}$ & 6.89 \\
\hline Butyl Acetate & Citric Acid & Methylcyclohexanone &
\end{tabular}

The concentration of citric acid in butyl acetate was measured by HPLC. The solubility of the acid in methylcyclohexanone was measured by back titration, and the results are reported in Figure 3.8. The solubility of citric acid increased monotonically with the addition of water. For $11 \%(\mathrm{~g} / \mathrm{g})$ water concentration, the molarity of the acid was 1.7 moles of acid per liter of solution, 6.9 times higher than at low water content. In this case, the water concentration in the organic phase did not reach the saturation point.

Water very significantly af fects the solubility of citric acid in the two solvents studied. However, it should be recognized that the solubility of the acid in otherwise pure water is substantially higher than that in butyl acetate or in methylcyclohexanone. At $20^{\circ} \mathrm{C}$, the solubility of citric acid in water is $59.2 \%(\mathrm{~g} / \mathrm{g})^{8}$ or $4.0(\mathrm{~mol} / \mathrm{L})$. Therefore equilibrium distribution ratios for extraction of citric acid from water into these solvents would not be favorable. 


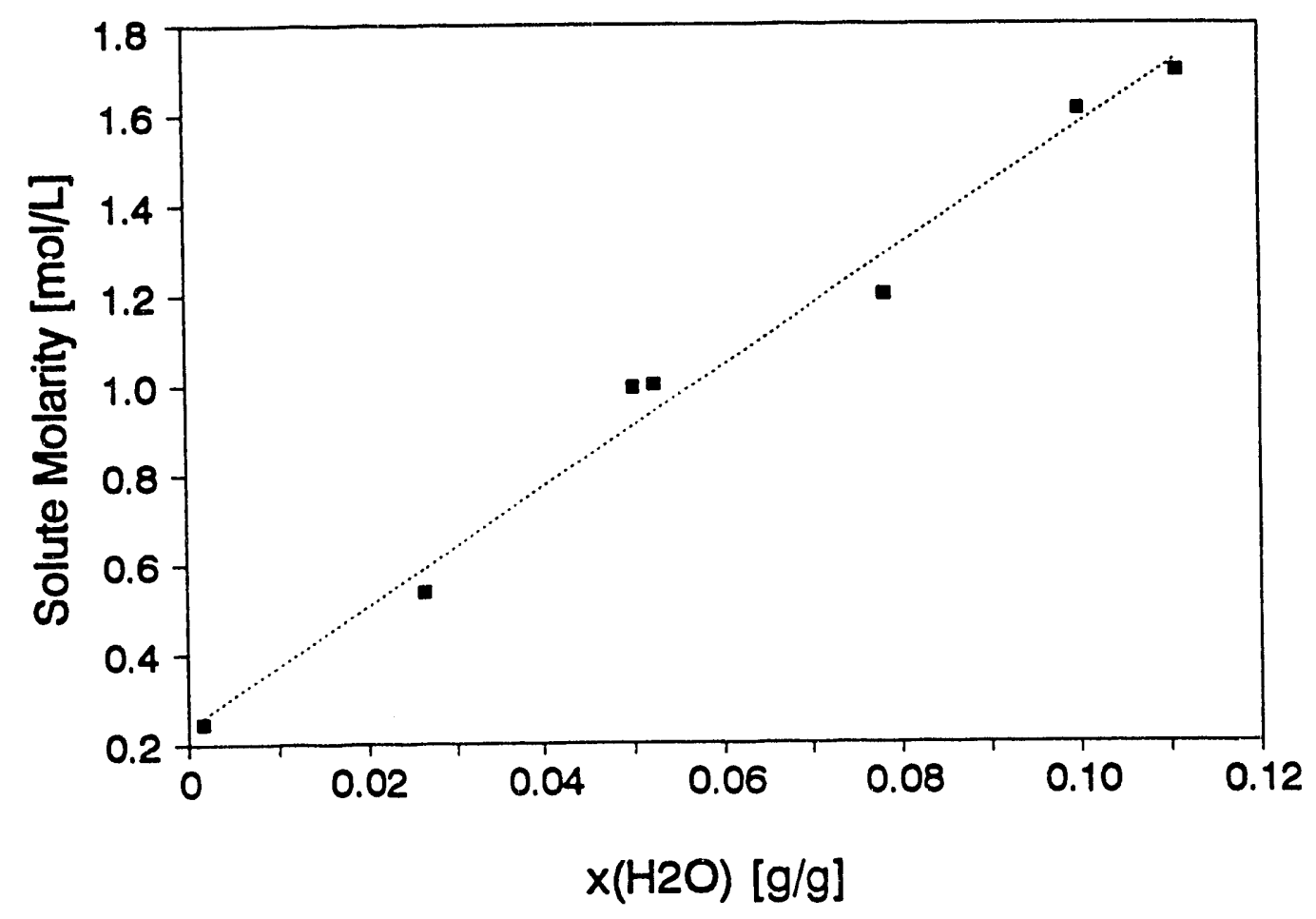

Figure 3.8 Solid-Liquid Equilibrium at $25 \mathrm{C}$ for Citric Acid in Methylcyclohexanone, With Varying Amounts of Added Water. 


\subsubsection{Phenol and Phenol Derivatives}

The solubilities of phenol derivatives were determined by measurements of solidliquid equilibrium, and the results are reported in Table 3.4. For all phenol solutions except 2-naphthol in cyclohexanone, the solubility ratio of the solute between the hydrated solvent and low water content solvent was less than one. There was no increase in solubility of the solute due to the presence of water; unlike the results for other systems examined. The solubilities of phenol and xylenols in anhydrous methylisobutylketone (MIBK) were between 50 and $80 \%(\mathrm{~mol} / \mathrm{mol})$. Because the initial phenol and xylenol concentrations were so large, the effect of water would be expected to be limited.

Table 3.4 Solubilities of Phenols in Wet and Dry Solvents at $25^{\circ} \mathrm{C}$

$$
\begin{aligned}
& \text { Solubility of Solute Water Concentration } \\
& \text { Dry Solvent Dry Solvent } \\
& \text { Solute (Hydrated) (Hydrated) }
\end{aligned}
$$

\begin{tabular}{|c|c|c|c|}
\hline $\begin{array}{l}\text { 2,3-Dimethylphenol } \\
\text { Methylisobutylketone }\end{array}$ & $\begin{array}{c}0.54 \\
(0.48)\end{array}$ & $\begin{array}{c}0.02 \\
(0.20)\end{array}$ & 0.88 \\
\hline $\begin{array}{l}\text { 2,5-Dimethylphenol } \\
\text { Methylisobutylketone }\end{array}$ & $\begin{array}{c}0.51 \\
(0.47) \\
\end{array}$ & $\begin{array}{c}0.06 \\
(0.20) \\
\end{array}$ & 0.91 \\
\hline $\begin{array}{l}\text { 2,6-Dimethylphenol } \\
\text { Methylisobutylketone }\end{array}$ & $\begin{array}{c}0.72 \\
(0.65) \\
\end{array}$ & $\begin{array}{c}0.01 \\
(0.15) \\
\end{array}$ & 0.91 \\
\hline $\begin{array}{c}\text { Phenol } \\
\text { Methylisobutylketone }\end{array}$ & $\begin{array}{c}0.82 \\
(0.42) \\
\end{array}$ & $\begin{array}{c}0.04 \\
(0.44) \\
\end{array}$ & 0.51 \\
\hline $\begin{array}{l}\text { 2-Naphthol } \\
\text { Cyclohexanone }\end{array}$ & $\begin{array}{c}0.24 \\
(0.29) \\
\end{array}$ & $\begin{array}{c}0.01 \\
(0.20)\end{array}$ & 1.20 \\
\hline $\begin{array}{l}\text { 2-Naphthol } \\
\text { Methylisobutylketone }\end{array}$ & $\begin{array}{r}0.19 \\
(0.16) \\
\end{array}$ & $\begin{array}{c}0.01 \\
(0.17) \\
\end{array}$ & 0.88 \\
\hline $\begin{array}{l}\text { 2-Naphthol } \\
\text { Butyl Acetate }\end{array}$ & $\begin{array}{c}0.28 \\
(0.20)\end{array}$ & $\begin{array}{c}0.01 \\
(0.18)\end{array}$ & 0.72 \\
\hline
\end{tabular}$$
\text { Solvent [mol/total } \mathrm{mol}] \quad[\mathrm{mol} / \text { total } \mathrm{mol}]
$$ 
The liquid organic phase for phenol in MIBK was not at the water-saturation point in the measurement at highest water content. Once water exceed its saturation limit in the organic mixture, a one-phase emulsion formed. By adding additional phenol into the flask, the emulsion slowly disappeared and the solution separated into two phases, solid phenol and organic liquid. Because of the emulsion, the solution was not analyzed at the water saturation point.

In addition to the solid-liquid equilibrium measurements, phenol in methylcyclohexanone was investigated by vapor-headspace analysis. The activity of phenol was extremely low in methylcyclohexanone, which made it difficult to detect in the vapor phase. A minimum concentration of $34 \%(\mathrm{~mol} / \mathrm{mol})$ of phenol in the anhydrous solvent was necessary to get a reproducible peak in the vapor phase. Because such high phenol concentrations were required, the effect of water would be expected to be limited and therefore the vapor-headspace analysis of phenol was discontinued.

Due to the high solubility of phenol and its derivatives in ketones and esters, the effect of water on the solubility is small. Water would be more likely to have a substantial effect on solvation in cases when the solute concentration is low in anhydrous organic solvents. Screening experiments were done with other phenol derivatives to determine the solubilities in dry solvents. Hydroquinone (1,4-benzenediol) and phloroglucinol $(1,3,5-$ benzenetriol) were examined because they have high melting points, which correlate to stable solid phases and lower solubilities.

Preliminary results from the hydroquinone screening experiment showed that its solubilities in cyclohexanone, methylcyclohexanone, methylisobutylketone, and butyl acetate at room temperature were greater than $10 \%(\mathrm{~mol} / \mathrm{mol})$. Similarly, the solubility of phloroglucinol was found to be at least $20 \%(\mathrm{~mol} / \mathrm{mol})$ in both cyclohexanone and methylcyclohexanone. Solid-liquid equilibrium of the phenol derivatives in the anhydrous solvents was not reached because this was only a preliminary test to see if the solubilities 
would be low enough so that water might be expected to have more of an effect. It was concluded that these solubilities were still undesirably high. 


\section{Chapter 4. Summary and Conclusions}

\subsection{Vapor-Liquid Equilibrium}

Vapor-liquid equilibrium studies showed that the activity coefficients of monocarboxylic acids, ethanol and glycols in ketone and acetate solvents decrease with increasing organic phase water concentration. The magnitude of water-enhanced solvation was determined by calculating the slope of the $\log \gamma_{\mathrm{B}}$ versus water-to-solute mole ratio curve. The relative changes in the activity coefficients were greater for monocarboxylic acids than for glycols and ethanol.

The activity coefficient of propionic acid in cyclohexanone showed the largest decrease, $\Delta\left(\log \gamma_{\mathrm{s}}\right) / \Delta\left(\mathrm{x}_{\mathrm{w}} / \mathrm{x}_{\mathrm{s}}\right)=-0.25$. In methylcyclohexanone, the water-enhancement effect of propionic acid was $\Delta\left(\log \gamma_{8}\right) / \Delta\left(x_{w} / x_{8}\right)=-0.19$. A possible explanation for the large decrease in the activity coefficients of monocarboxylic acids is the formation of a ternary complex or solvate with the ketone as the hydrogen acceptor, water as both a donor and acceptor, and acid as a hydrogen donor. The activity-coefficient data suggest that a stoichiometric relationship may exist between the water and acid. As the co-dissolved water reached a 2:1 wateracid mole ratio, the activity coefficient of propionic acid leveled off or decreased much less.

The water-enhancement effects for ethanol, 1,2-propylene glycol, and 2,3-butylene glycol in cyclic ketones were smaller than those for the monocarboxylic acids. In addition, the activity coefficients of the alcohol and glycols did not level off as the water-to-solute mole ratio became high.

The degree of water enhancement for monocarboyxlic acids, ethanol and glycols appears to be marginal at best for use as the basis for a separation process. 


\subsection{Solid-Liquid Equilibrium}

The solubilities of citric acid in butyl acetate and methylcyclohexanone were greatly enhanced by the addition of co-dissolved water. The equilibrium concentration of citric acid was increased by a factor of 9.7 over that in low-water content butyl acetate. The addition of $11 \%(\mathrm{~g} / \mathrm{g})$ co-dissolved water increased the solubility of citric acid to a value 6.9 times greater than in the low-water content methylcyclohexanone. The effect of water on the solubility of citric acid in the two solvents was large; however, the solubility of the acid in otherwise pure water is substantially higher. Therefore the equilibrium distributions for extraction of citric acid from water into these organic solvents are not likely to be favorable.

For phenol and phenol derivatives, the effect of water-enhanced solvation is small, if it occurs at all. The solubility ratios of the solutes between the water-saturated solvent and low-water content solvent were less than one except for 2-naphthol in cyclohexanone. The effect of water on the solvation of phenol and xylenols was limited because the initial concentration of the solutes in the dry organic solvents were very large. Water would be more likely to have a substantial effect on solvation in cases were the solute concentration is low in anhydrous organic solvents. 


\section{References}

1. Dechow, F.J., Separation and Purification Techniques in Biotechnology, Noyes Publication, Park Ridge, NJ, 1989

2. Daugulis, A.J., Axford, D.B., McLellan, P.J., The Canadian Journal of Chemical Engineering, 1991, 69, 488-497.

3. Starr, J.N., King, C.J., Industrial \& Engineering Chemistry Research, 1992, 31(11), 2572-2579.

4. Van Brunt, V., King, C.J., unpublished manuscript.

5. Grayson, M., Eckroth, D., Kirk-Othmer.Concise Encyclopedia of Chemical Technology, 3rd ed., 1984, John Wiley \& Sons, NY.

6. Shreve, R.N., Brink Jr., J.A., Chemical Process Industries, 4th ed., 1977, McGrawHill, NY.

7. Busche, R.M., Applied Biochemistry and Biotechnology, 1991, 28/29, 605-621.

8. Windholz, M., Budavari, S., Blumetti, R.F., Otterbein, E.S., The Merck Index, 10th ed., 1983, Merck \& Co., Inc., Rahway, NJ.

9. Chemical Marketing Reporter, April 6, 1992.

10. Tyree, R.W., Clausen E.D., Gaddy, J.L., Journal of Chemical Technology and Biotechnology, 1991, 50, 157-166.

11. Chemical Marketing Reporter, August 12, 1991.

12. Chemical Marketing Reporter, March 25, 1991.

13. Campbell, I., Biomass, Catalysts and Liquid Fuels, 1983, Technomic Publishing Co, Inc., PA.

14. Chemical Marketing Reporter, January 4, 1993.

15. Cocks, F.T., Aguilar, J., Lin, E.C.C., Journal of Bacteriology, 1974, 118, 83-88.

16. Cameron, D.C., Cooney, C.L., Bio/Technology, 1986, 4, 651-654.

17. Nelson, D.A., Molton, R.M., Russell, J.A., Hallen, R.T., Industrial \& Engineering Chemistry, Product Research and Development, 1984, 23, 471-475.

18. Chemical Marketing Reporter, August 6, 1990.

19. Bart, H.J., Marr, R., Bauer, U., Berichte der Bunsen-Gesellschaft fur Physikalische Chemie, 1989, 93, 984-988.

20. Bañiel, A.M., Blumberg, R., Hajdu, K., U.S. Patent 4,257,234. June 23, 1981. 
21. Baniel, A.M., U.S. Patent 4,334,095. June 8, 1982.

22. Kieckbusch, T.G., and King, C.J., Journal of Chromatographic Science, 1979, 17, 273.

23. Stull, D.R., Industrial and Engineering Chemistry, 1947, 39(4), 517.

24. Gmehling, J. Onken U., Arlt, W., Vapor-Liquid Equilibrium Data Collection, DeChema Chemistry Data Series, 1979, 1(3\&4).

25. Prausnitz, J.M., Tsonopoulos, C., The Chemical Engineering Journal, 1970, 1, 273.

26. Sebastiani, E., Lacquaniti, L., Chemical Engineering Science, 1967, 22, 1155-1162.

27. CRC Handbook of Chemistry and Physics, CRC Press, Inc., 64th Edition, Boca Raton, Florida, 1983.

28. Prausnitz, J.M., Lichtenthaler, R.N., Gomez de Azevedo, E., Molecular Thermodynamics of Fluid-Phase Equilibria, 2nd ed., Prentice-Hall, Inc., Englewood Cliffs, NJ, 1986.

29. Christian, S.D., Affsprung, H.E., Ling, C., Journal of Chemical Society, 1965, 2378. 
Appendix A High Pressure Liquid Chromatography as a Scanning Technique

High Pressure Liquid Chromatography (HPLC) was investigated as a method for screening organic solutions for water-enhanced solvation. The objective of this scanning method was to relate the shift in retention time of the solute to an increase or decrease in its activity coefficient in the liquid mobile phase.

For each solute-solvent solution analyzed for water-enhancement, the results from an anhydrous system were compared to those for a hydrated one. In both cases, a UV variable wavelength detector and a non-interactive stationary phase column were used. The HPLC column was packed with alkyl-bonded silica with either eight or eighteen carbon lengths. The alkyl groups provide a non-polar environment and therefore samples are separated on the basis of their interactions with the polar mobile phase.

The injection sample contained the solute dissolved in the mobile phase, which was composed of the solvent of interest. Depending on the experiment, the mobile phase was either the anhydrous or hydrated solvent. The solute retention time was measured for both conditions, anhydrous and hydrated mobile phases. From these data, the size of the waterenhanced solvation effect can in principle be determined.

\section{A.1 Experimental}

A Perkin Elmer LC 75 spectrophotometric detector was set at a fixed wavelength of $250 \mathrm{~nm}$ and was used to measure the retention time of the solute. Three different types of Waters columns were used as non-interactive stationary phases. One of the columns tested was a Nova-Pak $C_{8} 3.9 \mathrm{~mm}$ by $150 \mathrm{~mm}$ stainless steel column, and other two were $8 \mathrm{~mm}$ by $100 \mathrm{~mm}$ cartridges containing $C_{18}$ Resolve ${ }^{\mathrm{T}}$ Radial-Pak and $C_{18}$ Nova-Pak, respectively, and were used in a radial compression module. The mobile phase was either the anhydrous or 
ydrated form of the solvent of interest. A constant mobile phase flow rate was delivered by a Perkin Elmer Series 10 pump, and the data were collected with a Waters 746 data module.

\section{A.2 Results}

A $0.4 \%(\mathrm{~g} / \mathrm{g})$ solution of adipic acid in butyl acetate was analyzed using a UV detector. In both the anhydrous and hydrated experiments, the retention time of adipic acid was measured in the void volume of the column. The solute was not retained sufficiently by the column, and therefore there was no difference in retention time for the anhydrous and hydrated solvents. The hydrogen bonding between the solute and solvent is strong and hence the solute prefers to stay with the mobile phase.

In reverse-phase HPLC, the interactions between the solute and the mobile phase are of greater importance than with the non-interactive stationary phase. The selectivity and retention in reverse-phase HPLC can be controlled by changing the polarity of the mobile phase. However, for this specific application the polarity of the mobile phase is fixed. In addition, the types of columns that can be used for this scanning method are also limited. The column must be non-interactive because the primary goal is to measure the difference in the solute retention due to the interactions with the solvent rather than chemical interactions with column functional groups.

Other possible HPLC columns considered were silica based columns without the alkyl functional groups and polymer columns. Both types of columns would not be appropriate for this study. Silica would interact with the solutes of interest and also bonds very strongly with water. After a few trial runs with a hydrated solvent the column would not be functional. Polymer columns would not be appropriate due to swelling with organic solvents.

The experimental design parameters for HPLC water-scanning method restrict the use of those methods that are commonly used to retain a solute. The essential characteristics of 
both the mobile phase and stationary phase are fixed, and preclude the amount of delay of the solute peak that would be necessary for this study. Due to the constraints of the experiment, HPLC was abandoned as a screening method. 
Table B.1 Materials

Chemical

Absolute Ethanol

Acetic Acid, Glacial

Acetonitrile, HPLC grade

Butyl acetate, HPLC grade

\& 3-Butylene glycol, DL \& meso isomers

Citric Acid

Citric Acid hydrate, AR grade

Cyclohexanone, Assay

2,3 Dimethylphenol

2,5 Dimethylphenol

2,6 Dimethylphenol

Karl Fischer Methanol Free Solvent

Kanl Fischer T-2 titrant

Methanol, HPLC grade

Methylcyclohexanone

$68 \%$ - 3-methylcyclohexanone

$31.4 \%$ - 4-methylcyclohexanone

4--Methyl-2-pentanone, HPLC grade

Naphthalene

Phenol, AR grade

Phloroglucinol dihydrate
Manufacturer

Purity

Quantum Chemical

Fisher

200 proof

$99.7 \%$

Burdick \& Jackson

Aldrich

$99.9 \%$

Sigma

Aldrich

$99.5 \%$

Mallinckrodt

Fluka

$>99.5 \%$

Aldrich

$97 \%$

Janssen Chimica

$99+\%$

Aldrich

$99 \%$

GFS Chemicals

GFS Chemicals

Burdick \& Jackson

Fluka

$99.4 \%$

Aldrich

$99.7 \%$
Eastman

Mallinckrodt

Aldrich 
Chemical

Manufacturer

Purity

Pic A reagent

Waters Associates

1,2 Propanediol

Aldrich

$99 \%$

Propionic Acid

Aldrich

$99+\%$ 
Appendix C GC and HPLC Callbration Curves

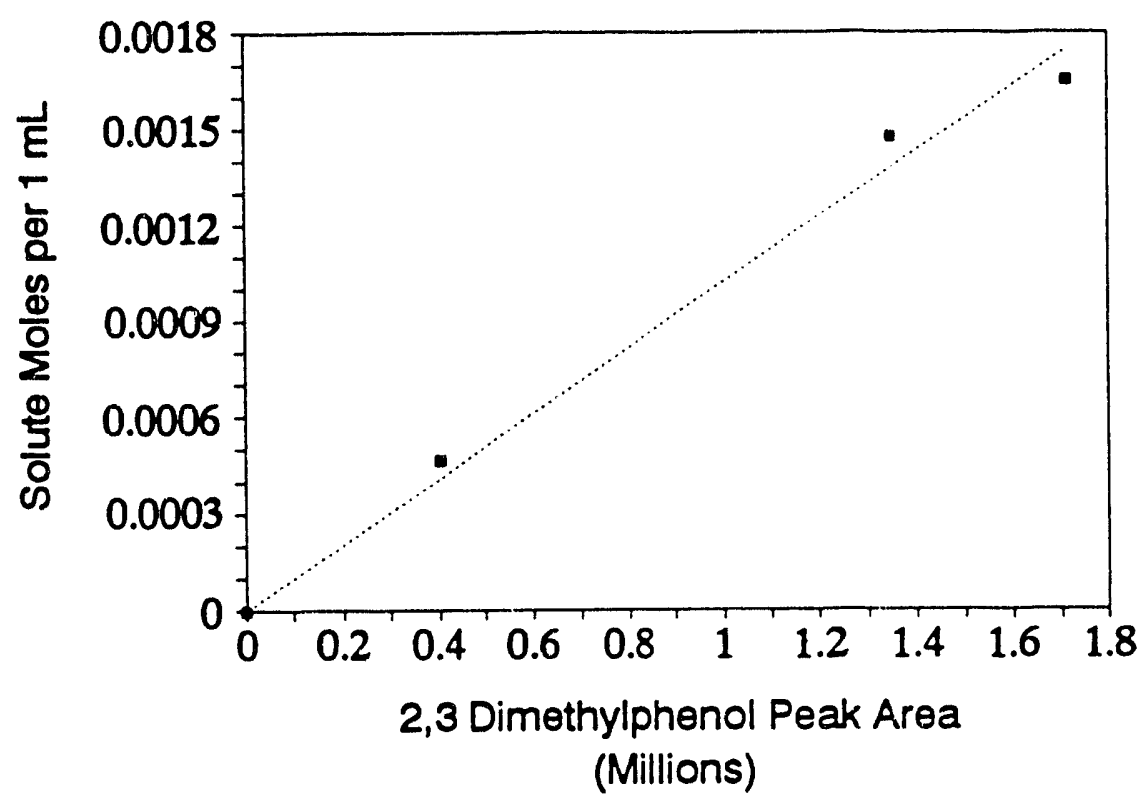

Figure C.1 Gas Chromatograph Liquid Calibration of 2,3-Dimethylphenol in Methylisobutylketone

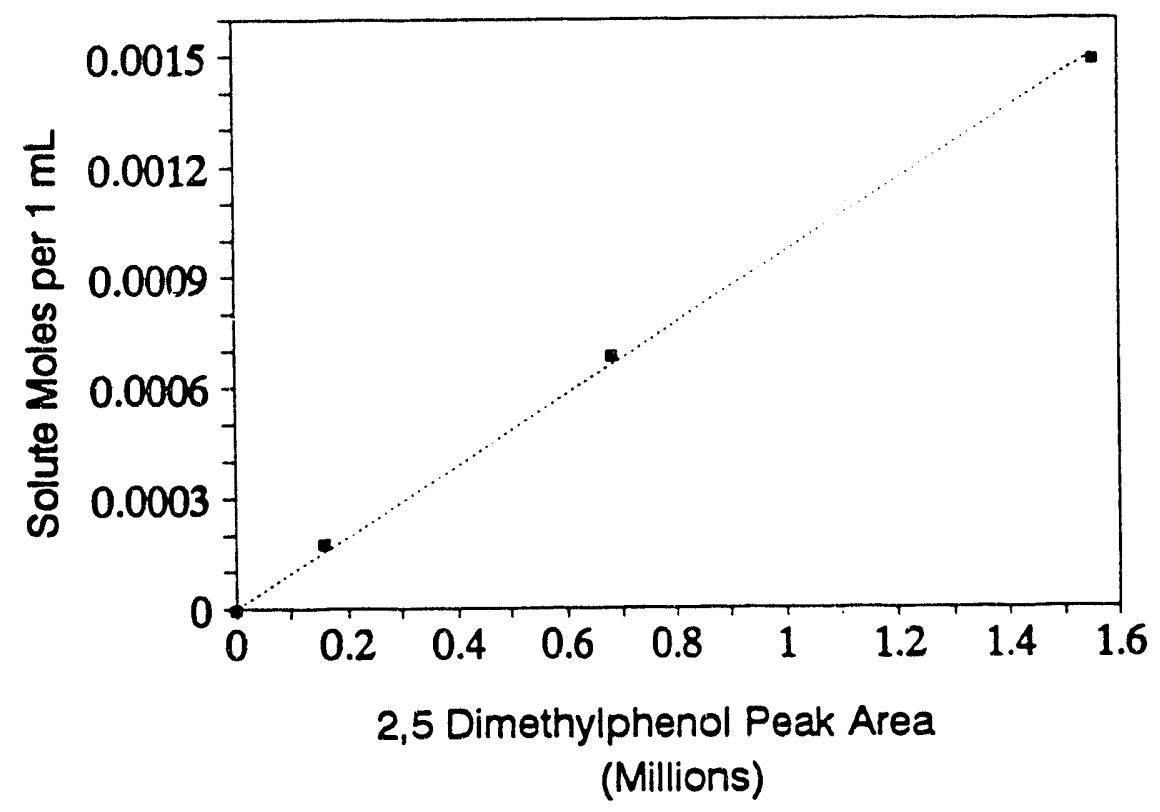

Figure C.2 Gas Chromatograph Liquid Calibration of 2,5-Dimethyipinenoi in Niethyilisoburyiketoñê 


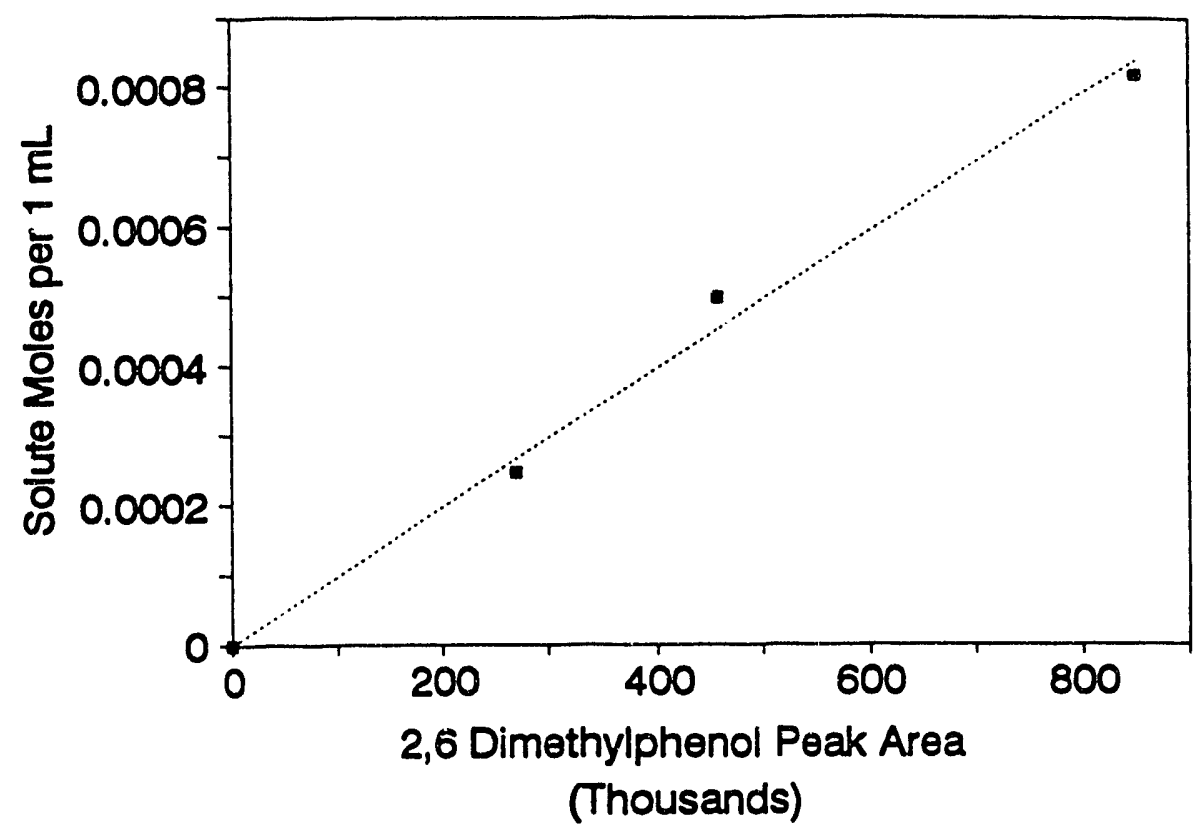

Figure C.3 Gas Chromatograph Liquid Calibration of 2,6-Dimethylphenol in Methylisobutylketone

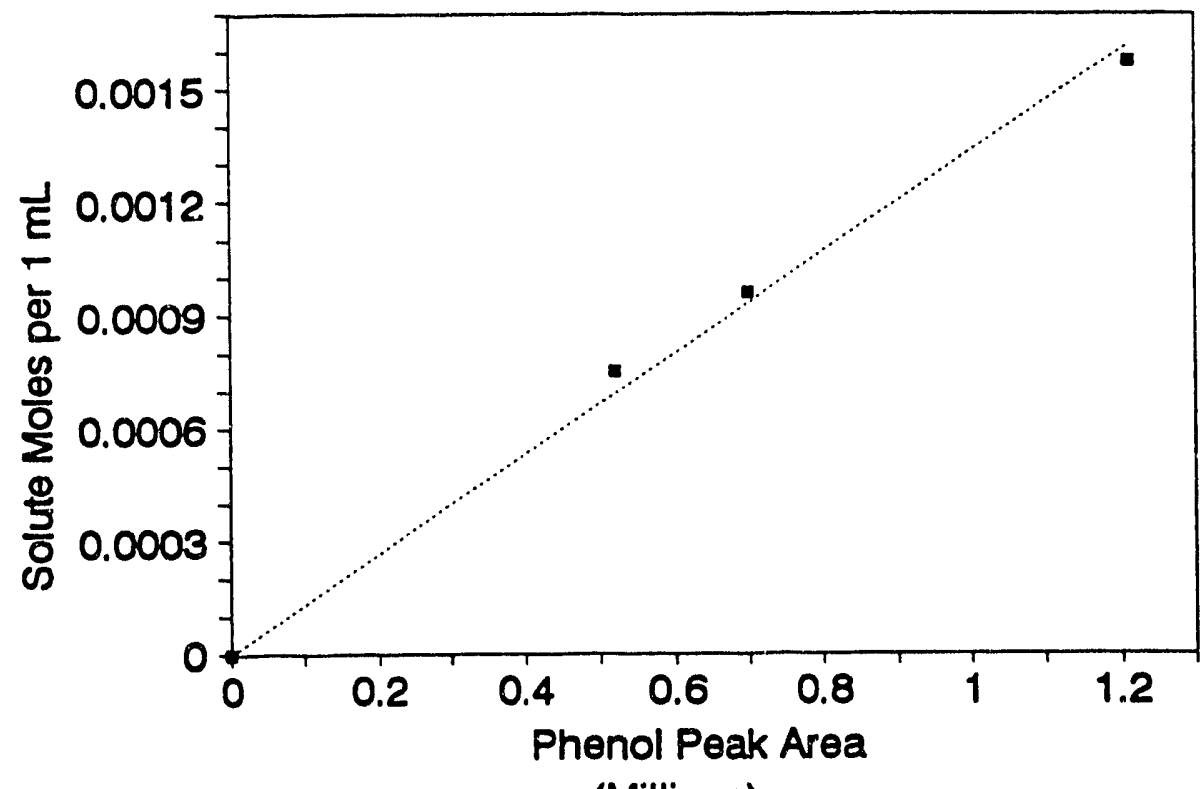

(Millions)

Figure C.4 Gas Chromatograph Liquid Calibration of Phenol in Methylisobutylketone 


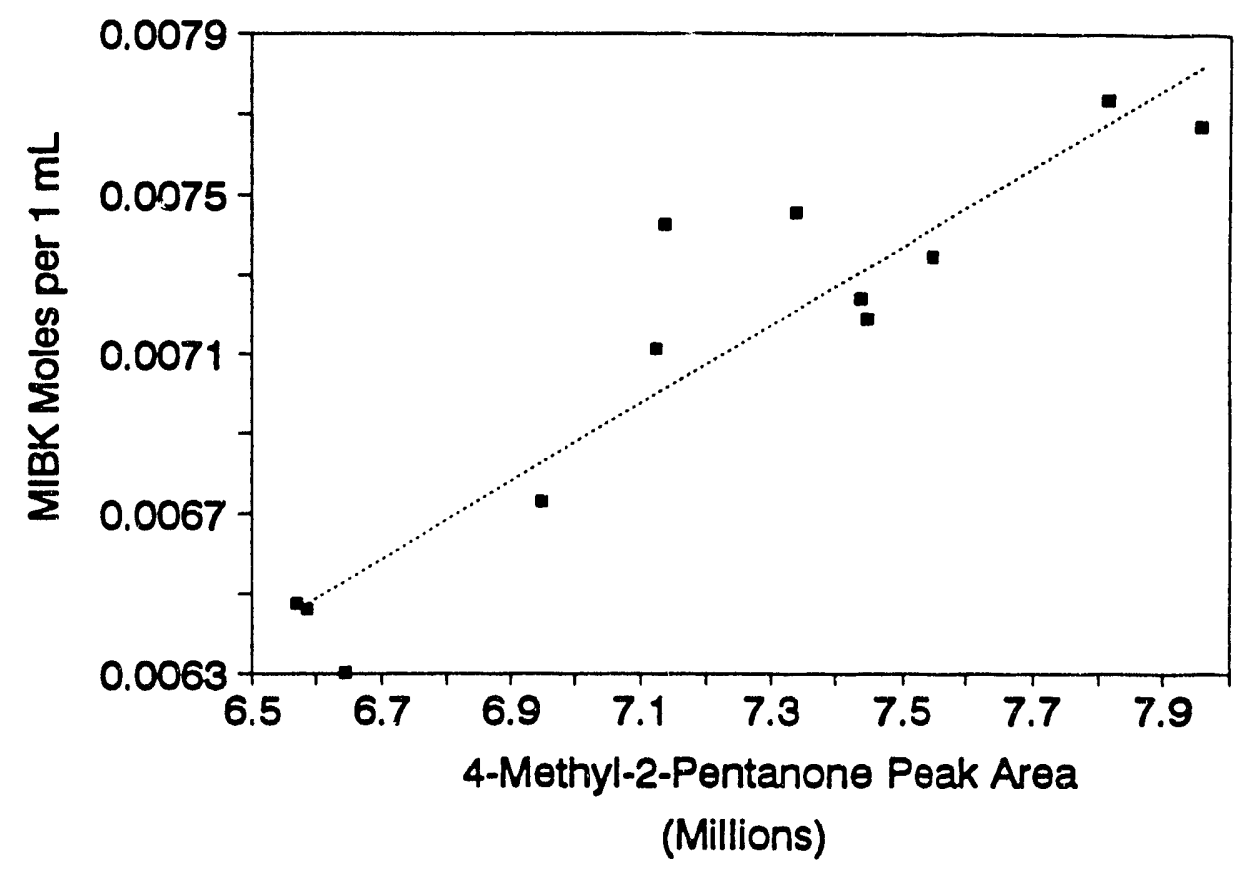

Figure C.5 Gas Chromatograph Liquid Calibration of 4-Methyl-2-Pentanone 

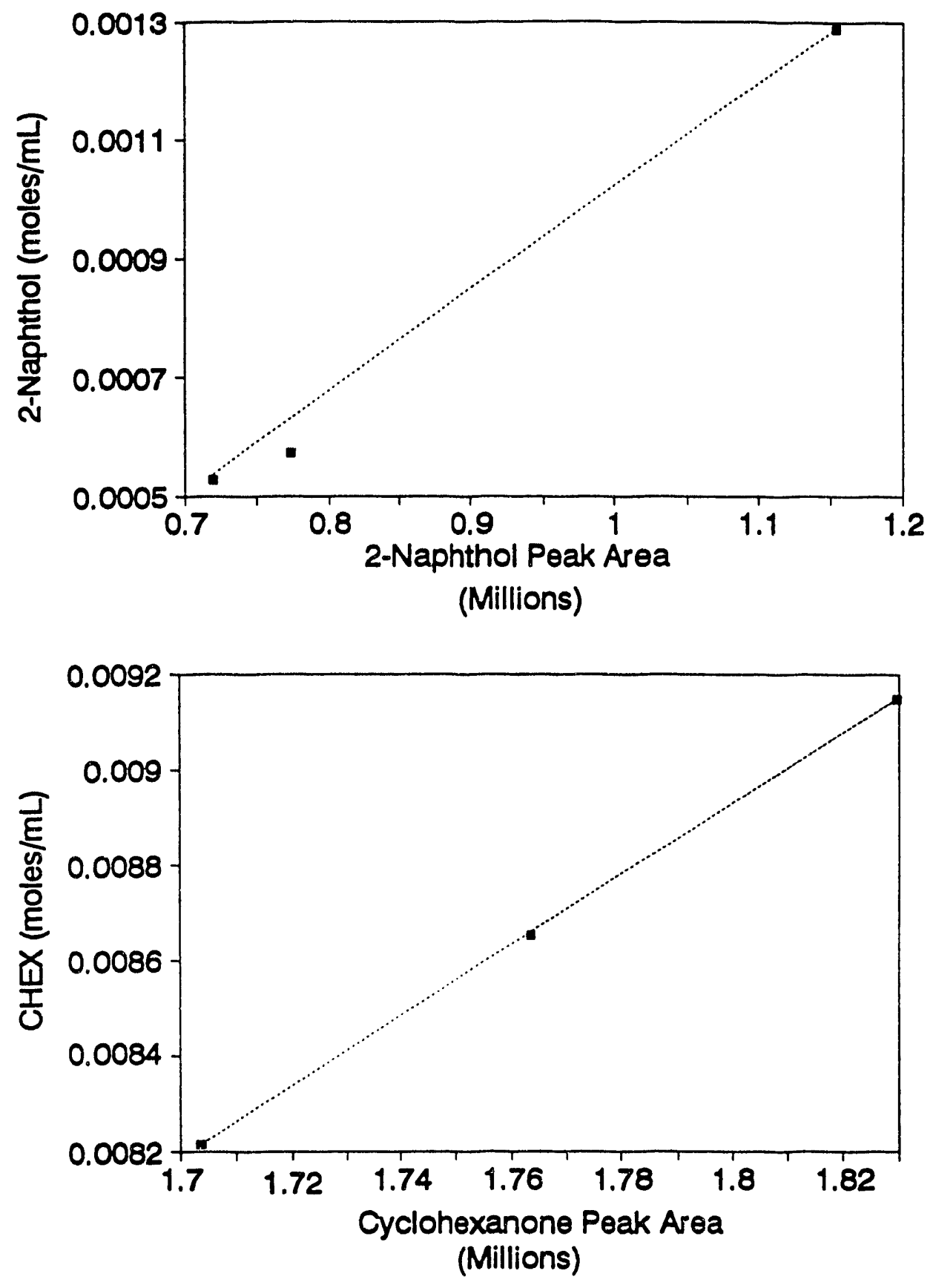

Figure C.6 HPLC Calibration of 2-Naphthol in Cyclohexanone

Resolve C18 Column, Rl detector 30:70 Acetonitrile:Water with $1 \%$ Acetic Acid and 0.03M Pic A reagent 

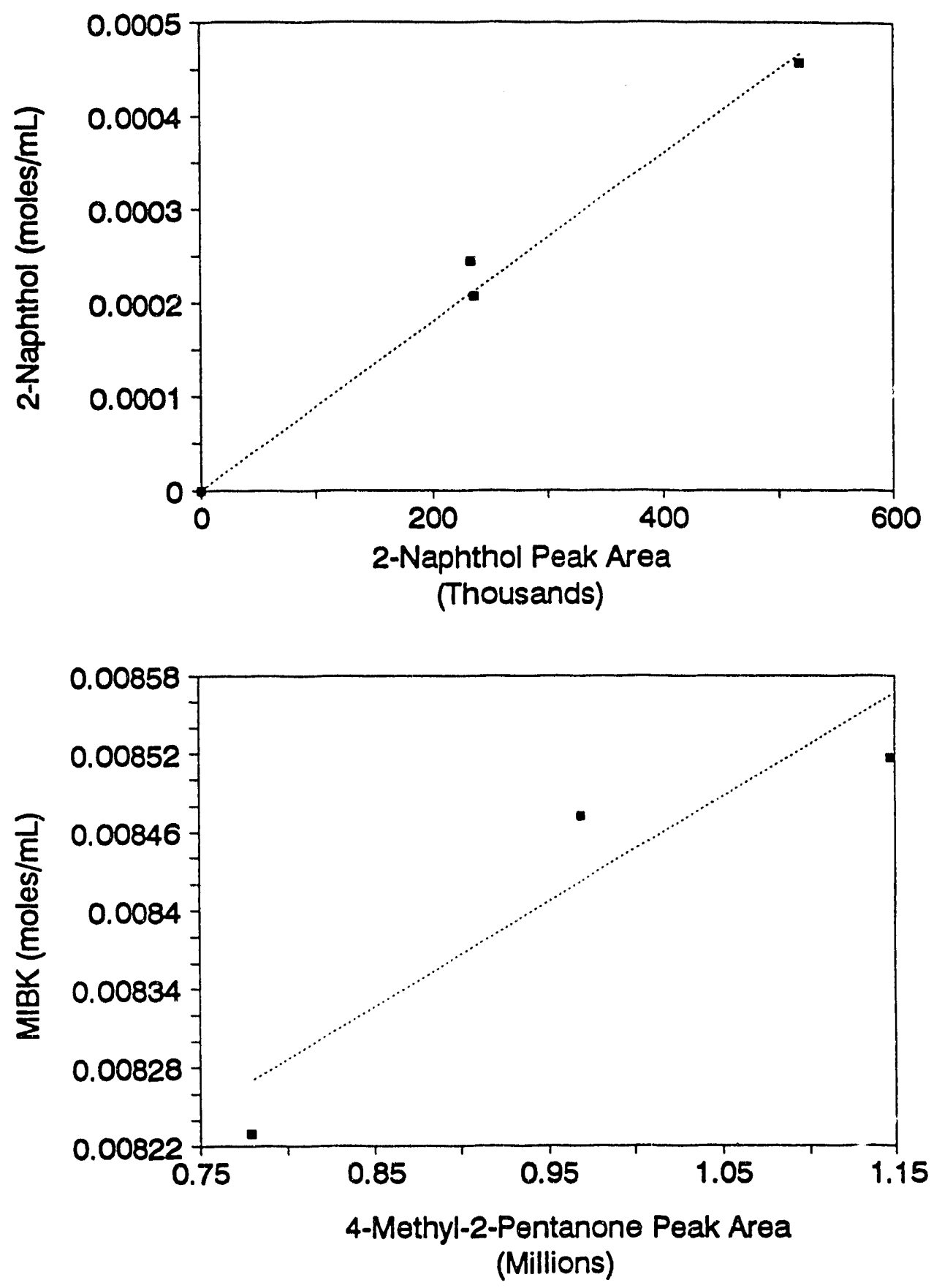

Figure C.7 HPLC Calibration of 2-Naphthol in MIBK

Resolve C18 Column, RI detector 30:70 Acetonitrile:Water with $1 \%$ Acetic Acid and 0.05M Pic A reagent 

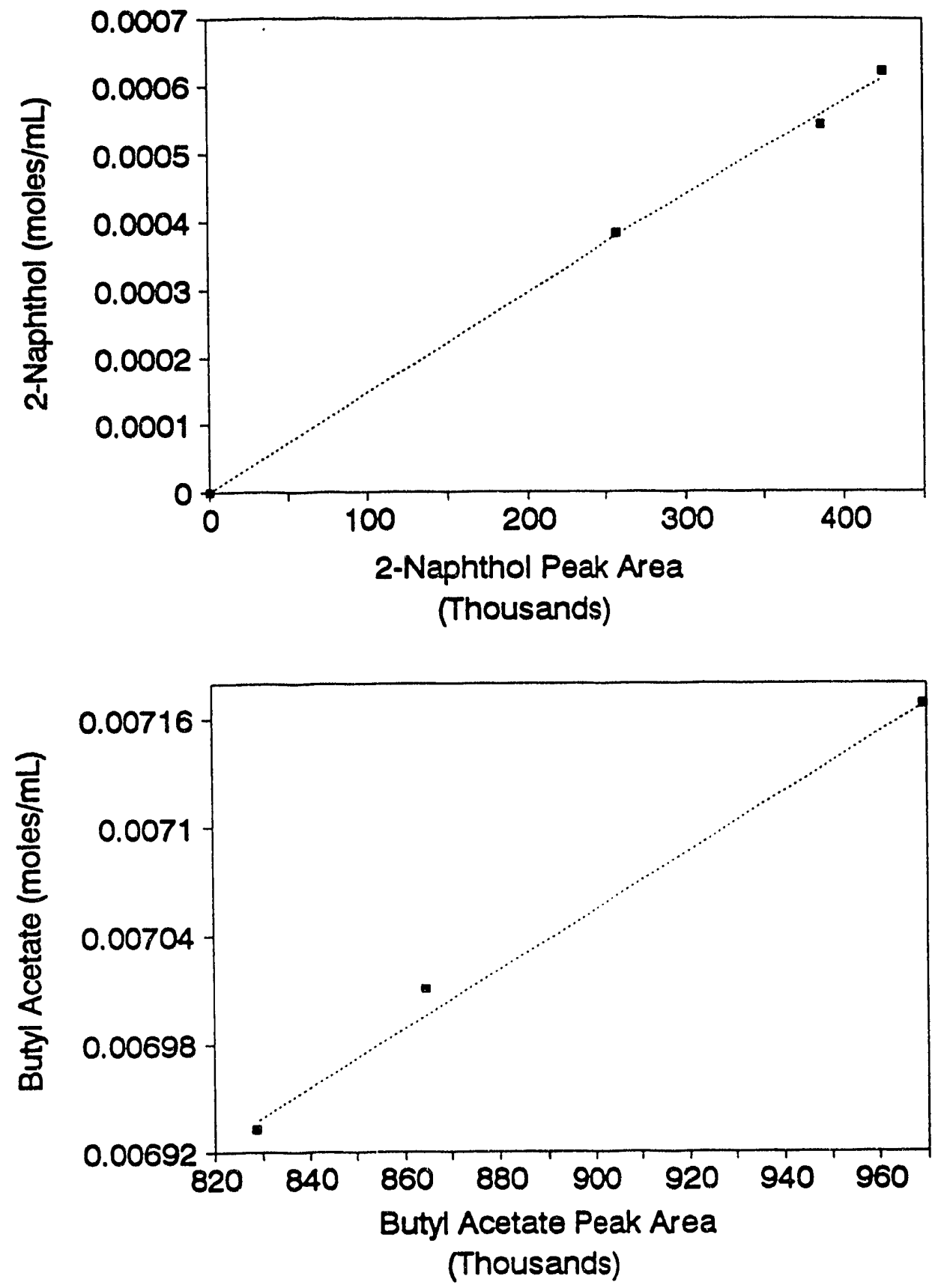

Figure C.8 HPLC Calibration of 2-Naphthol in Butyl Acetate

Resolve C18 Column, RI detector

1:1 Acetonitrile:Water with

$1 \%$ Acetic Acid and 0.05M Pic A reagent 


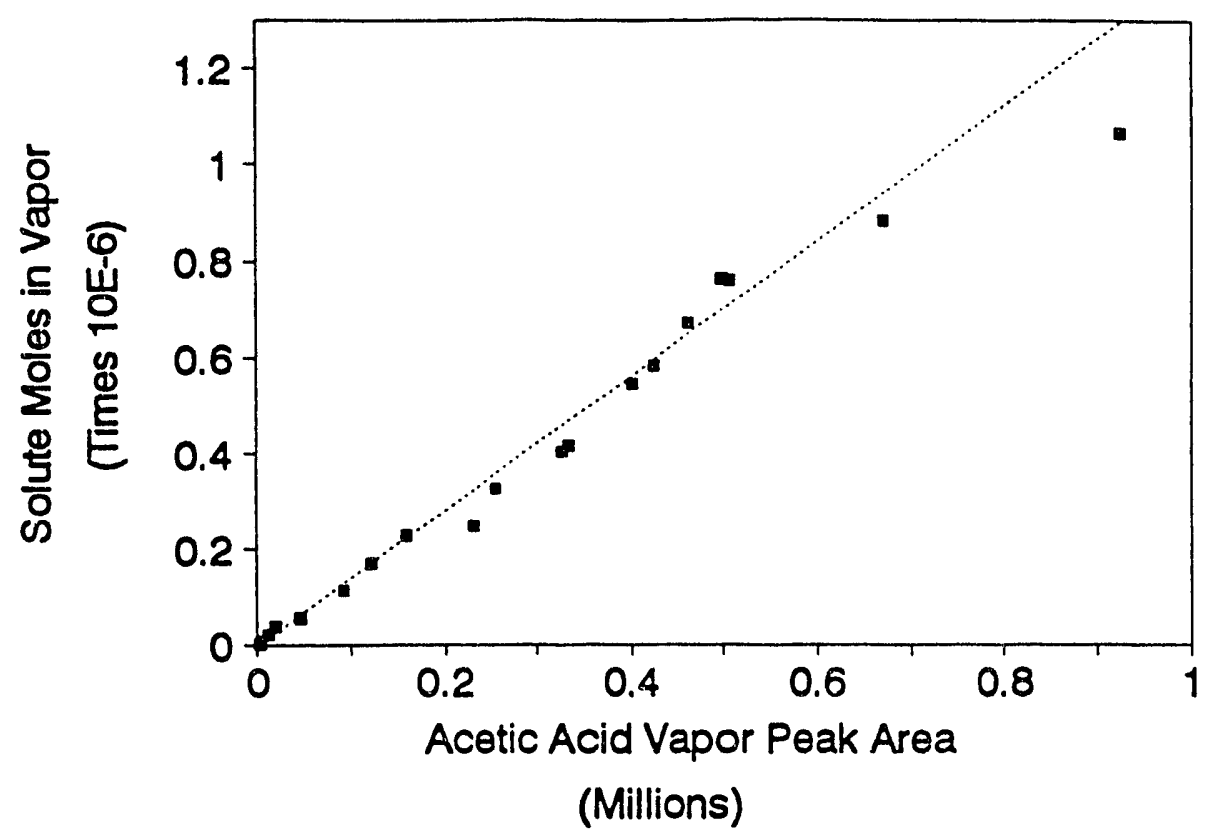

Figure C.9 Gas Chromatograph Vapor Calibration of Acetic Acid

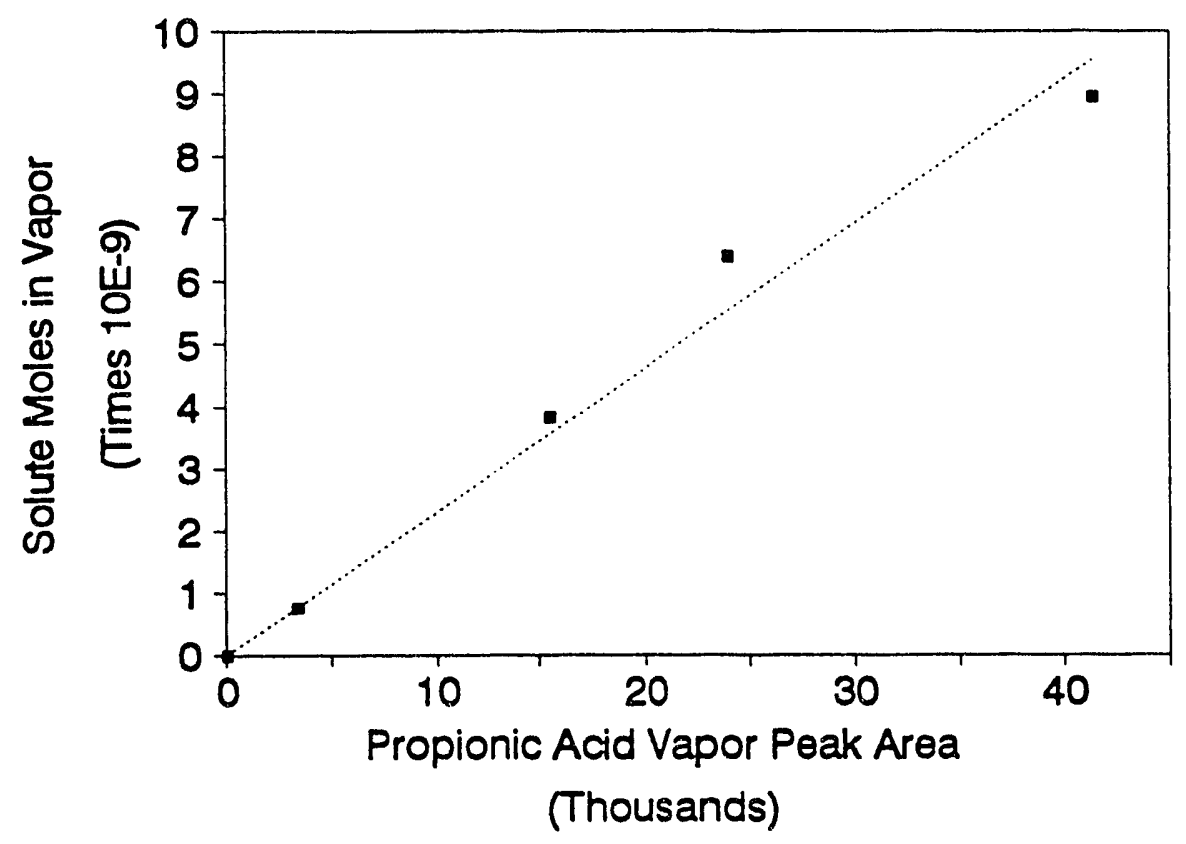

Figure C.10 Gas Chromatograph Vapor Calibration of Propionic Acid 


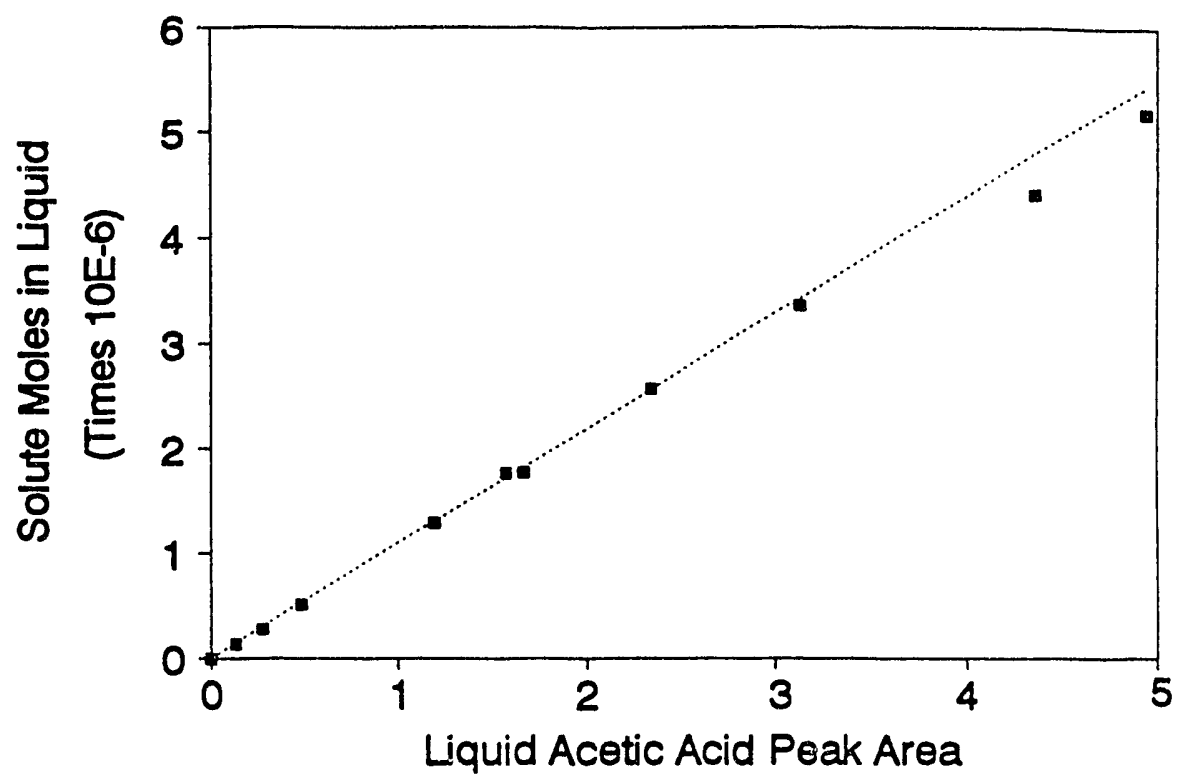

(Millions)

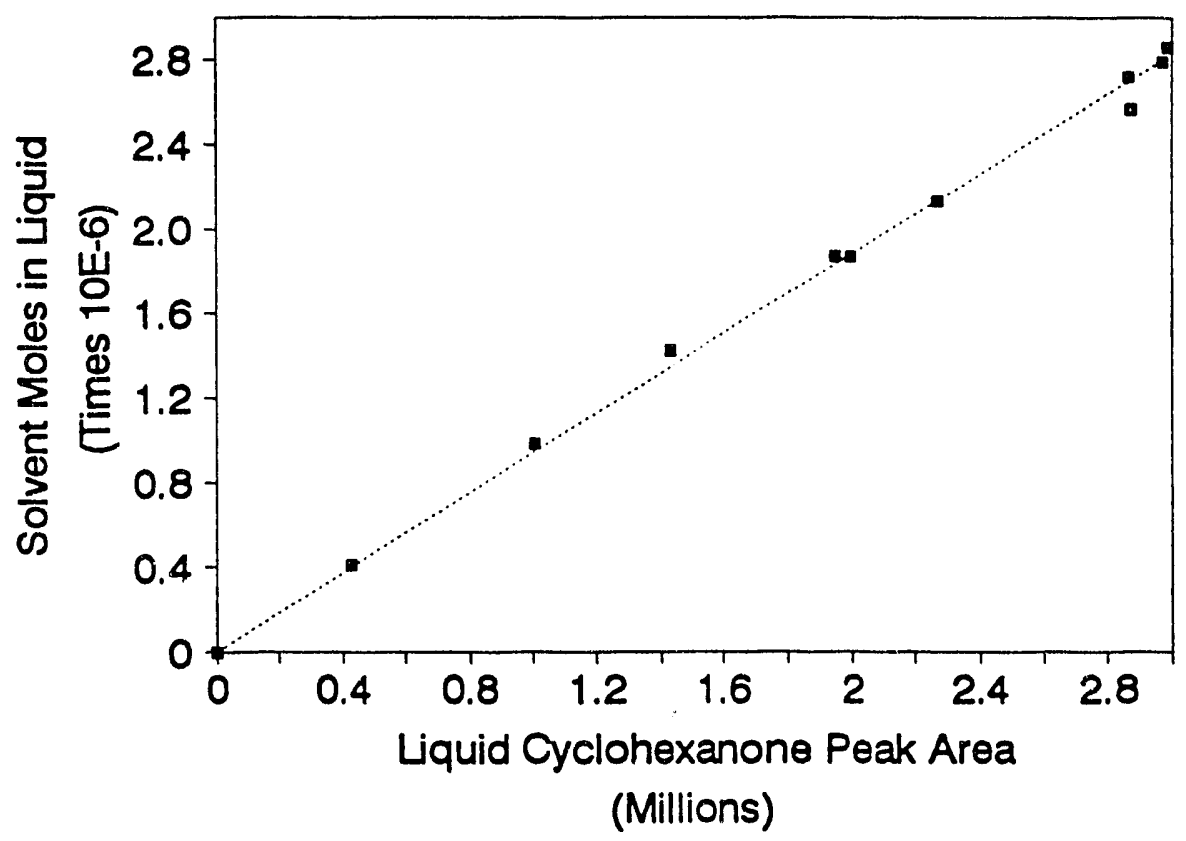

Figure C.11 Acetic Acid in Cyclohexanone Liquid GC Calibration 

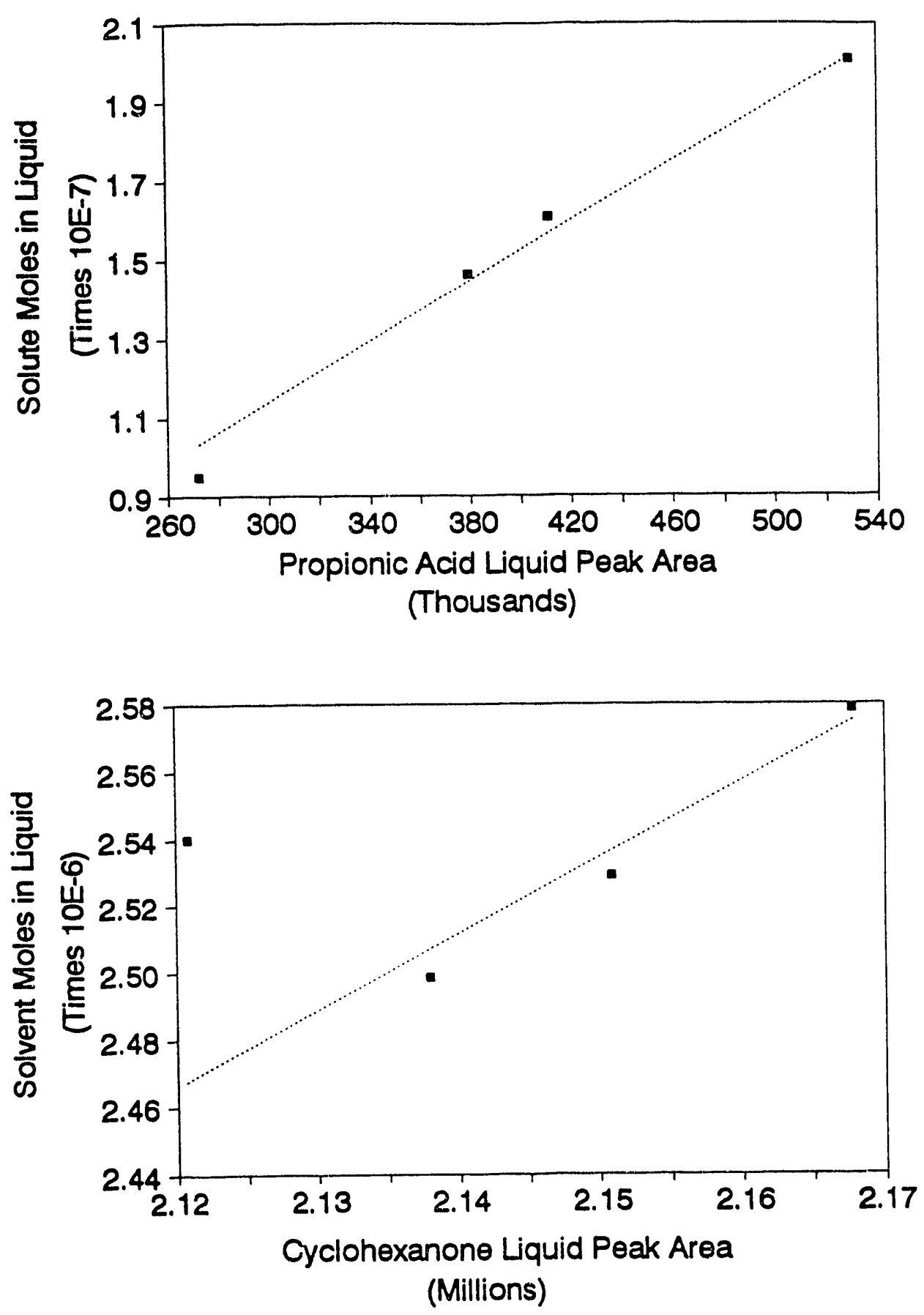

Figure C.12 Propionic Acid in Cyclohexanone Liquid GC Calibration 


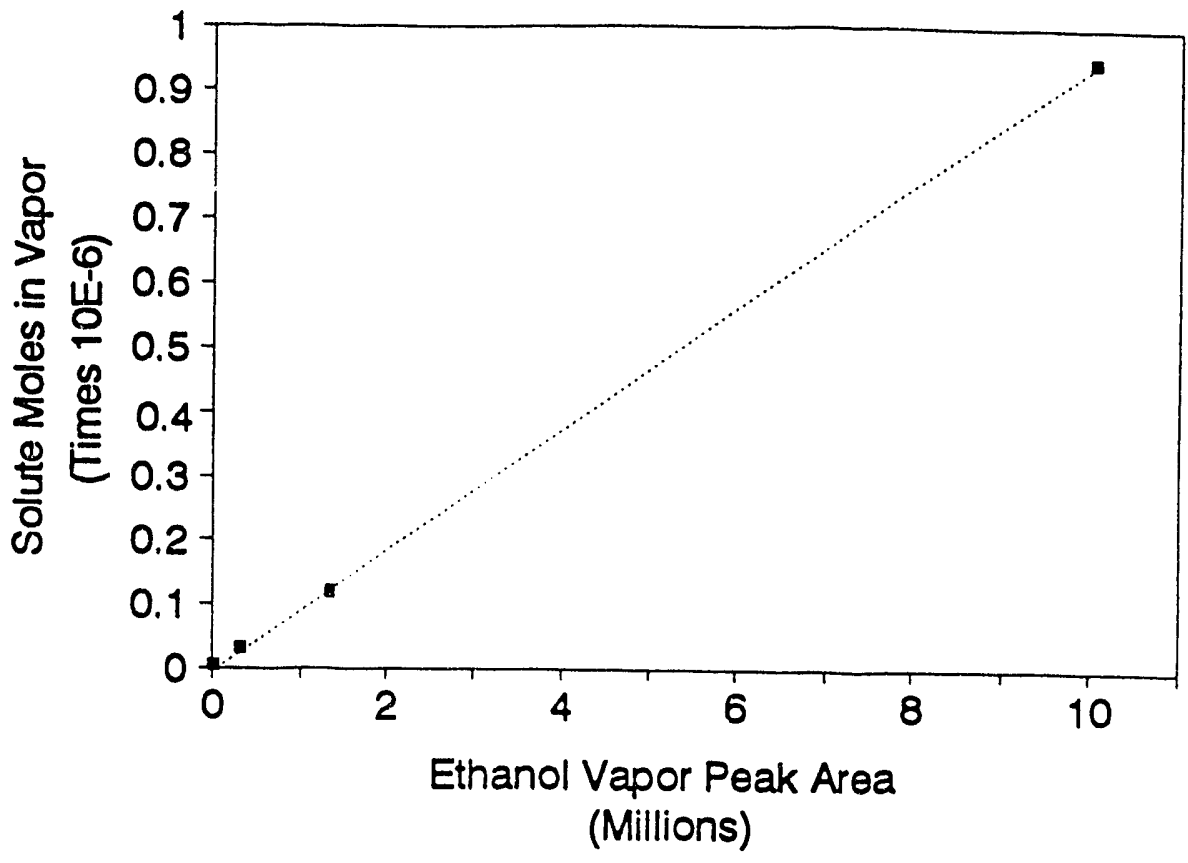

Figure C.13 Gas Chromatograph Vapor Calibration of Ethanol

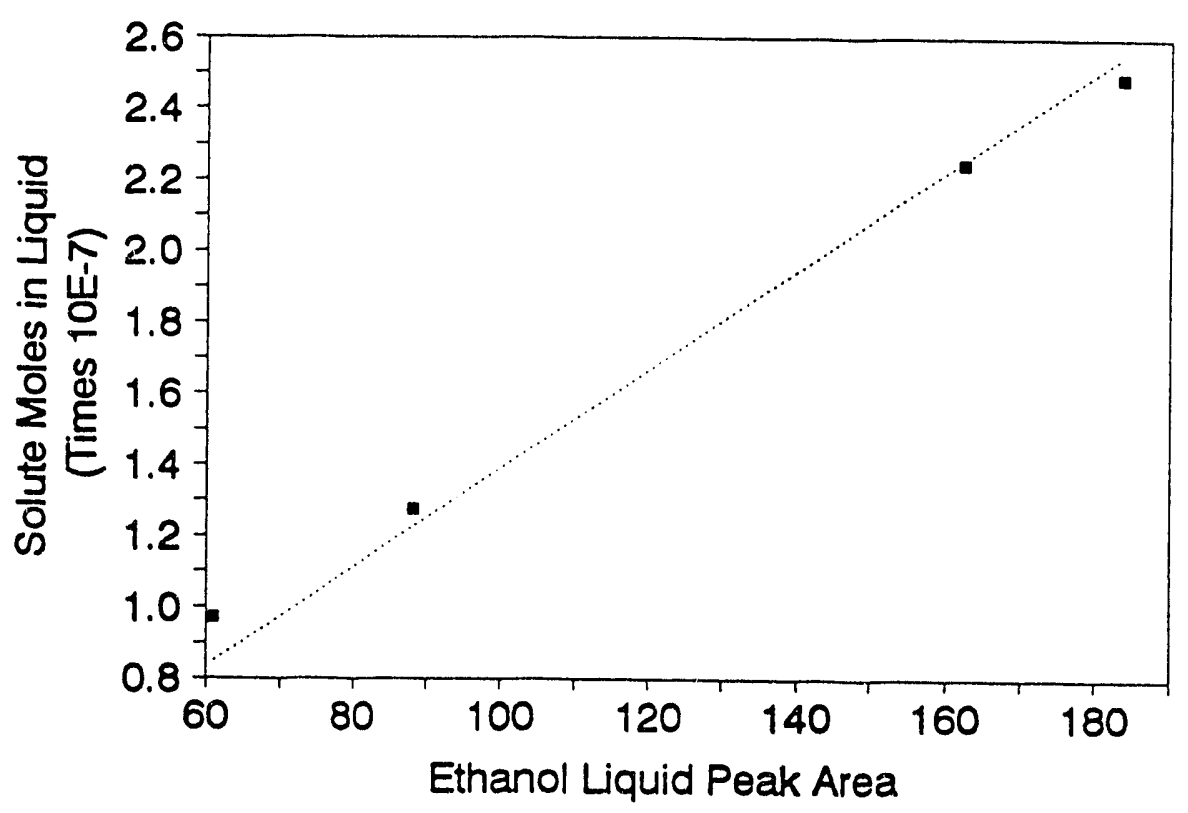

(Thousands)

Figure C.14 Gas Chromatograph Liquid Calibration of Ethanol 


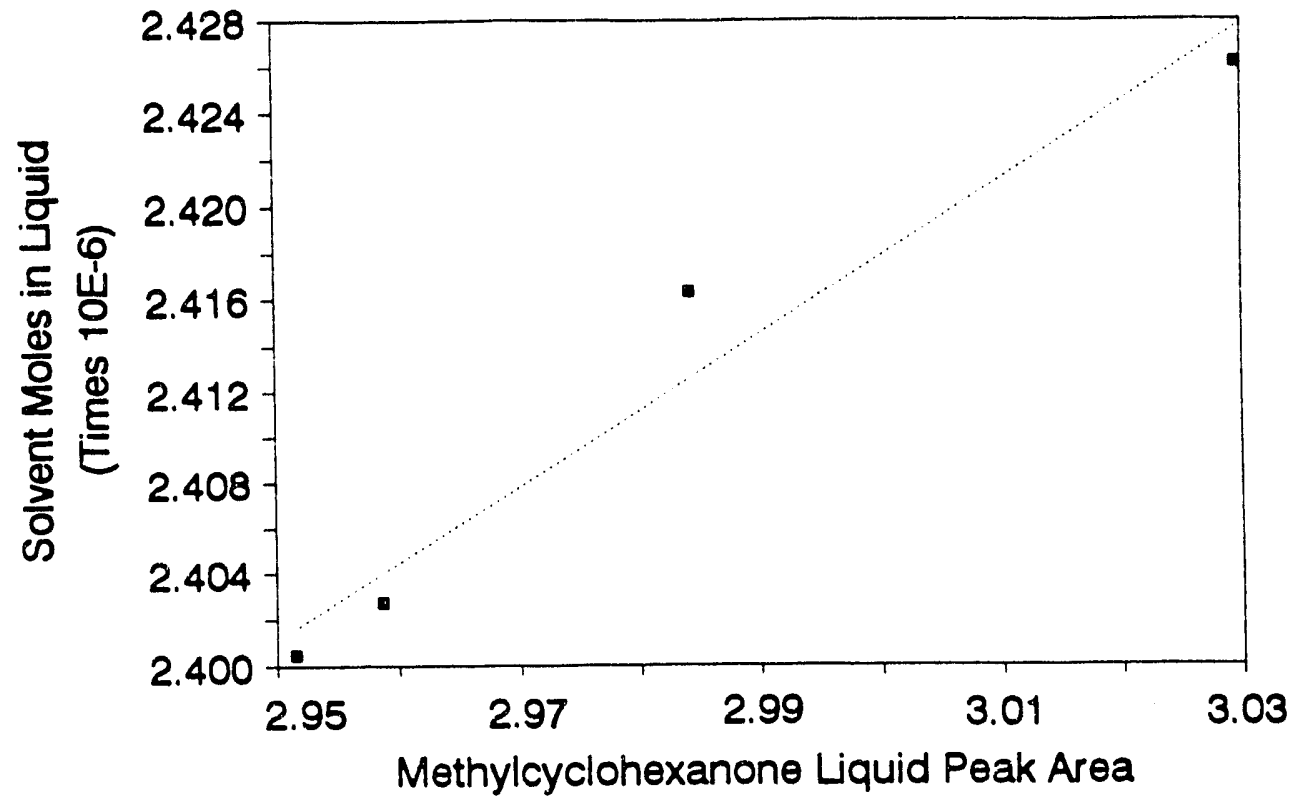

(Millions)

Figure C.15 Ethanol in Methylcyclohexnaone Liquid GC Calibration

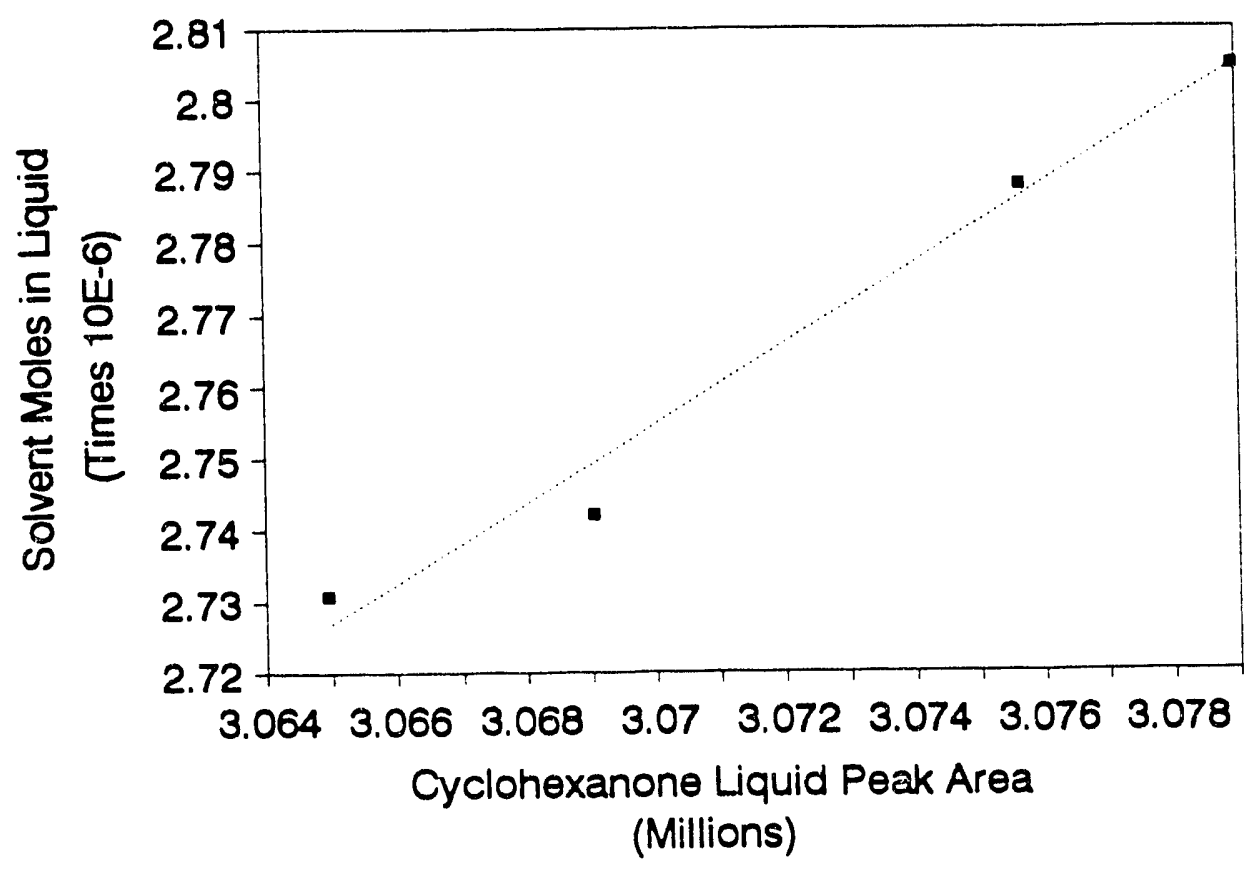

Figure C.16 Ethanol in Cyclohexanone Liquid GC Calibration 


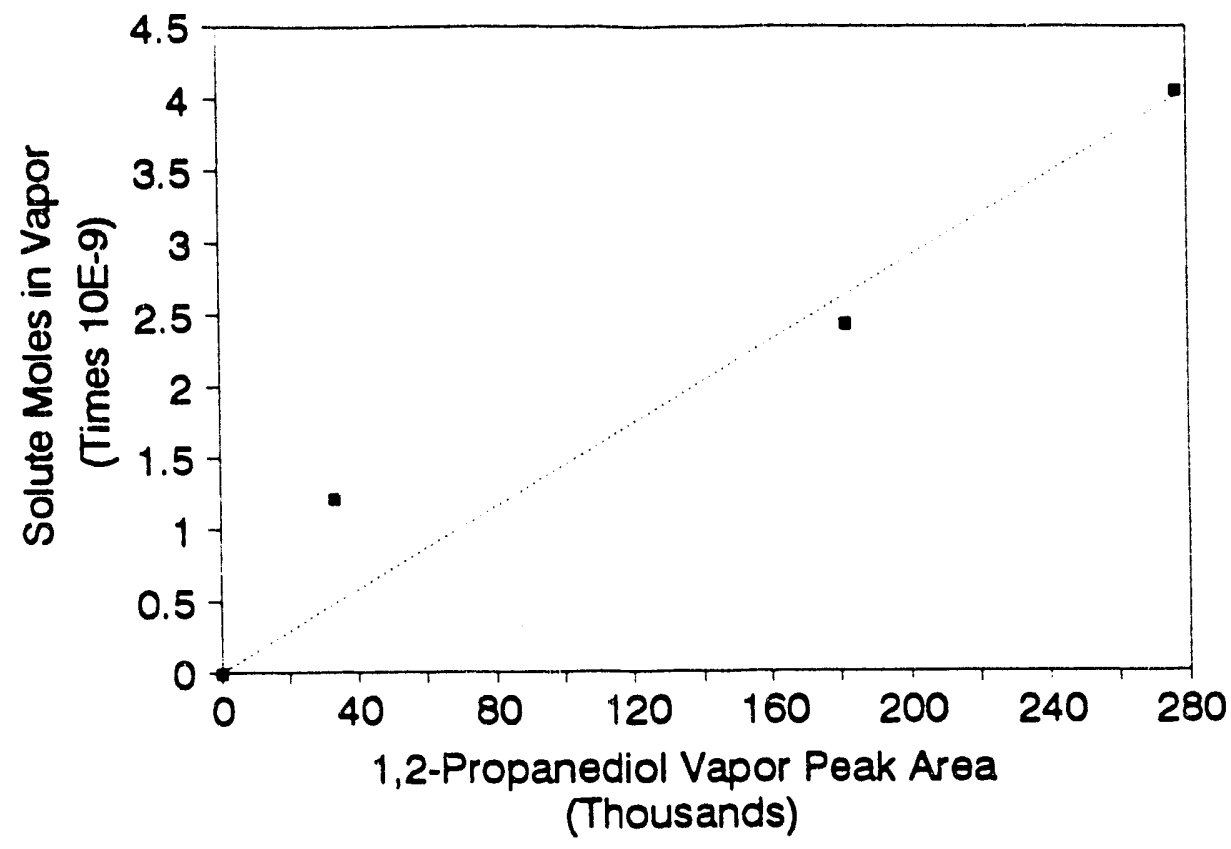

Figure C.17 Gas Chromatograph Vapor Calibration of 1,2-Propanediol

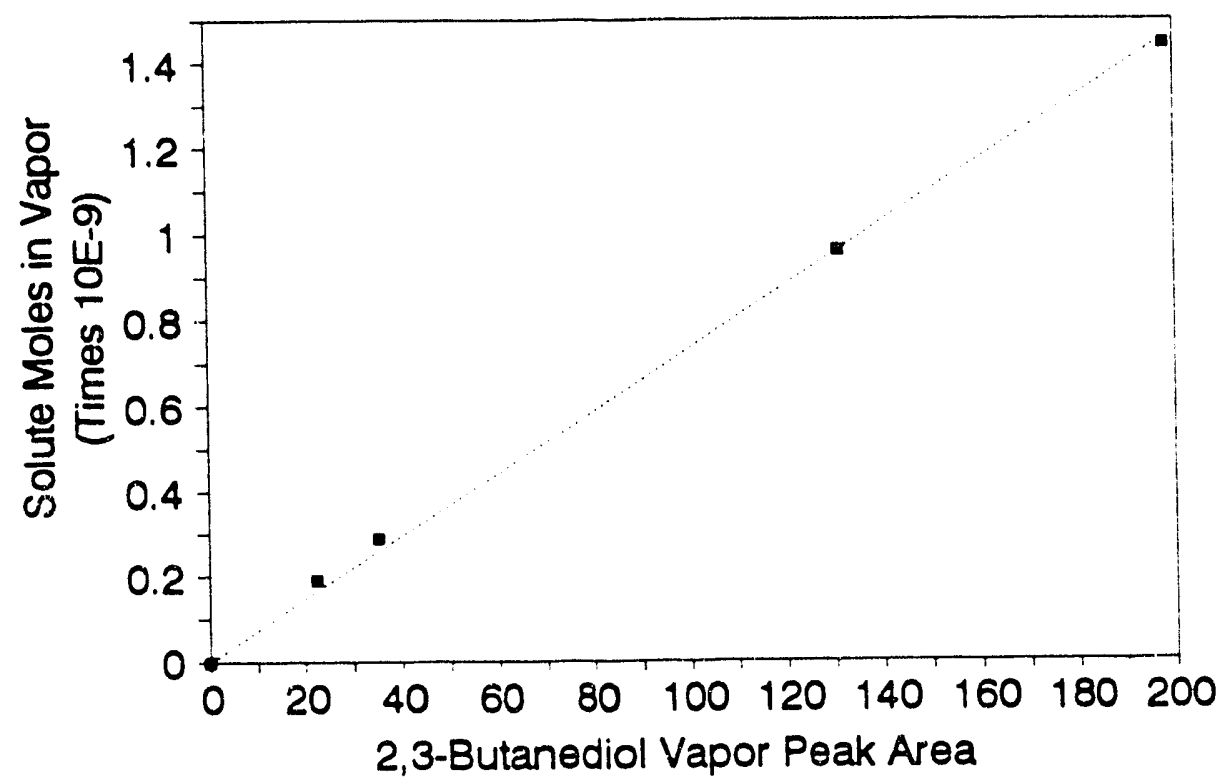

(Thousands)

Figure C.18 Gas Chromatograph Vapor Calibration of 2,3-Butanediol 

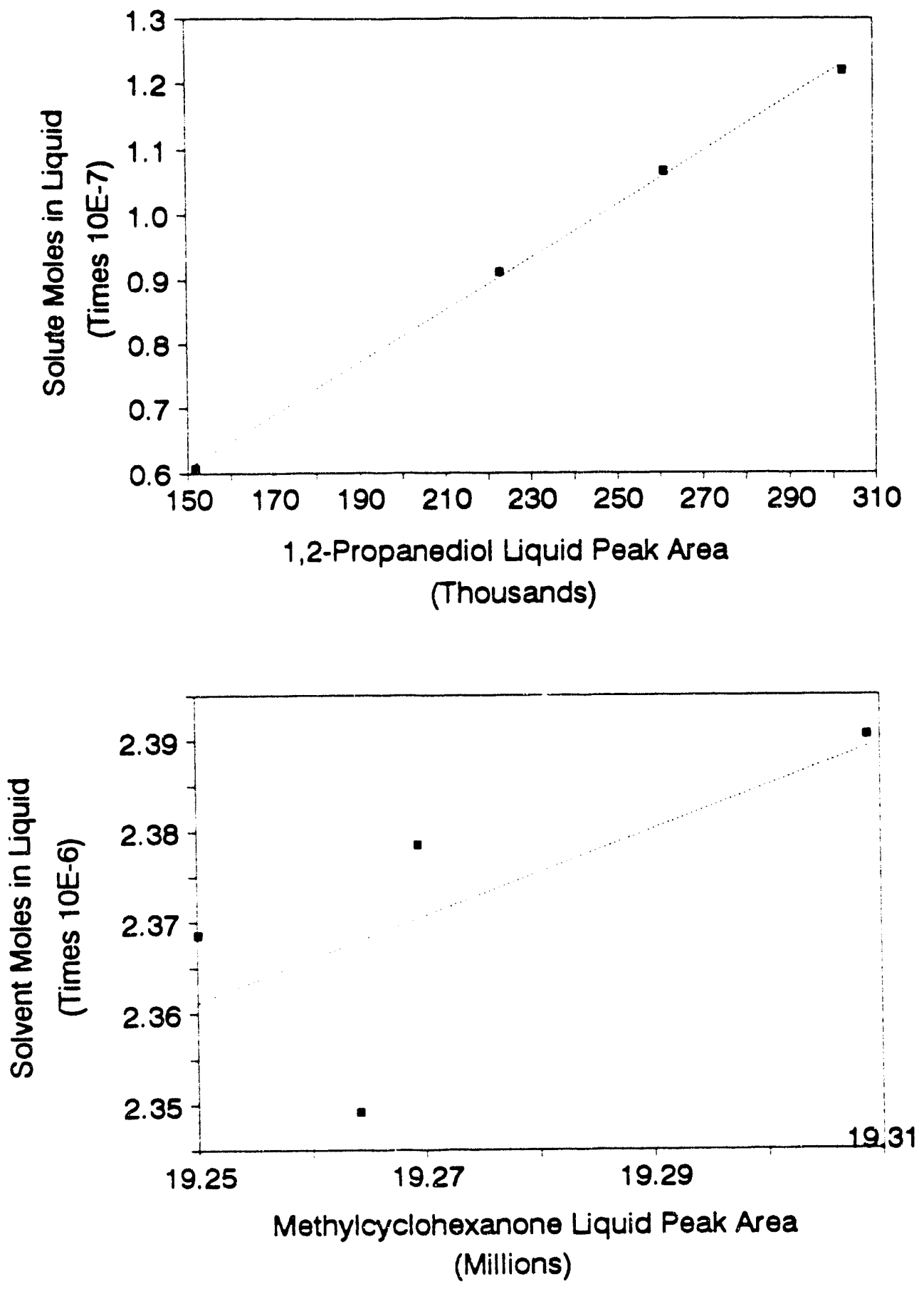

Figure C.19 1,2-Propanediol in Methycyclohexanone Lquid GC Calibration 

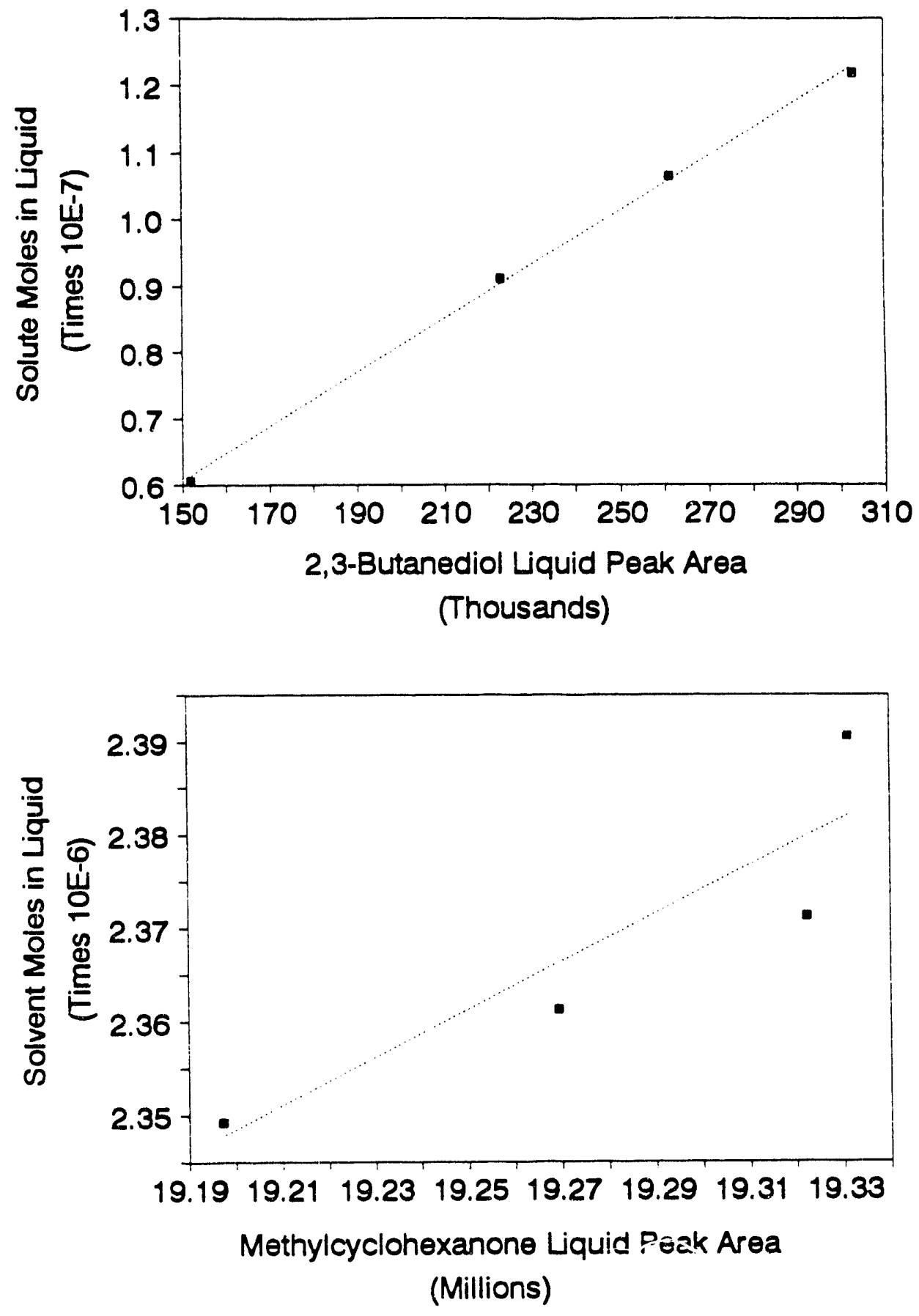

Figure C.20 2,3-Butanediol in Methycyclohexanone Lquid GC Calibration 


\section{Appendix D Experimental Data}

\section{D.1 Solid-Liquid Equilibrium Data}

The data collected from solid-liquid equilibrium experiments are reported in Tables D.1 through D.3. The abbreviations used in Tables D.1 through D.3 are listed below.

\begin{tabular}{|c|c|}
\hline $\mathrm{W}_{\mathrm{i}}$ & $=$ Mass of component $i$ in solution $(g)$ \\
\hline Peak $_{i}$ & $=$ HPLC peak area of component $i$ \\
\hline Vapor $_{i}$ & $=$ GC peak area of component $i$ in vapor phase \\
\hline Liquid $_{\mathrm{i}}$ & $=\mathrm{GC}$ peak area of component $\mathrm{i}$ in liquid phase \\
\hline$\rho$ & $=$ Density of organic phase $(\mathrm{g} / \mathrm{mL})$ \\
\hline $\mathrm{X}_{\text {watter }}$ & $=\mathrm{Karl}$ Fischer water analysis $(\mathrm{g} / \mathrm{g})$ \\
\hline $\mathbf{x}_{\mathbf{i}}$ & $=$ Mole fraction of component $\mathrm{i}(\mathrm{mole} / \mathrm{mole})$ \\
\hline $\mathrm{C}_{\mathbf{i}}$ & $=$ Concentration of component $\mathrm{i}($ mole $/ \mathrm{L})$ \\
\hline $\mathrm{Vol}_{\mathrm{v}}$ & $=$ Volume of vapor sample size $(\mu \mathrm{L})$ \\
\hline Vol $_{L}$ & $=$ Volume of liquid sample size $(\mu \mathrm{L})$ \\
\hline$\gamma_{\mathrm{i}}$ & $=$ Liquid activity coefficient of component $\mathrm{i}$ \\
\hline
\end{tabular}


Table D.1 Solid-Liquid Equilibrium Data at $25^{\circ} \mathrm{C}$. Thermal Conductivity Detector : Gas Chromatograph

Carrier Gas : Helium at $30 \mathrm{~mL} / \mathrm{min}$

Column : Porapak PS at $220^{\circ} \mathrm{C}$

Injection Temperature : $240^{\circ} \mathrm{C}$
Detector Temperature : $240^{\circ} \mathrm{C}$

Filament Temperature : $300^{\circ} \mathrm{C}$

2,3-Dimethylphenol (1) in 4-Methyl-2-Pentanone (2) and Water (3)

\begin{tabular}{llllrlll}
$\mathrm{W}_{1}$ & $\mathrm{~W}_{2}$ & $\mathrm{X}_{\text {water }}$ & $\rho$ & Peak $_{1}$ & Peak $_{2}$ & $\mathrm{x}_{1}$ & $\mathrm{X}_{\text {water }}$ \\
\hline 0.30 & 3.99 & 0.004 & 0.81 & 403803 & 7340367 & 0.06 & 0.02 \\
1.10 & 3.90 & 0.004 & 0.83 & 1349975 & 6570600 & 0.18 & 0.02 \\
1.27 & 4.02 & 0.004 & 0.84 & 1711200 & 6645000 & 0.20 & 0.02 \\
-- & --- & 0.004 & 0.80 & 4554400 & 3796168 & 0.54 & 0.02 \\
--- & --- & 0.044 & 0.84 & 4891000 & 3486869 & 0.48 & 0.20
\end{tabular}

2,5-Dimethylphenol (1) in 4-Methyl-2-Pentanone (2) and Water (3)

\begin{tabular}{llllrlll}
$\mathrm{W}_{1}$ & $\mathrm{~W}_{2}$ & $\mathrm{X}_{\text {water }}$ & $\rho$ & Peak $_{1}$ & Peak $_{2}$ & $\mathrm{x}_{1}$ & $\mathrm{x}_{\text {water }}$ \\
\hline 0.11 & 3.56 & 0.004 & 0.80 & 159955 & 7814000 & 0.02 & 0.02 \\
0.46 & 4.14 & 0.004 & 0.81 & 682540 & 7438950 & 0.08 & 0.02 \\
1.11 & 3.94 & 0.004 & 0.83 & 1553450 & 6585250 & 0.18 & 0.02 \\
-- & --- & 0.011 & 0.81 & 4321350 & 3580186 & 0.51 & 0.06 \\
-- & --- & 0.043 & 0.84 & 4928950 & 3529862 & 0.47 & 0.20
\end{tabular}

2,6-Dimethylphenol (1) in 4-Methyl-2-Pentanone (2) and Water (3)

\begin{tabular}{llllrlll}
$W_{1}$ & $W_{2}$ & $\mathrm{X}_{\text {water }}$ & $\rho$ & Peak $_{1}$ & Peak $_{2}$ & $\mathrm{X}_{1}$ & $\mathrm{X}_{\text {water }}$ \\
\hline 0.16 & 3.84 & 0.004 & 0.80 & 268580 & 7955950 & 0.03 & 0.02 \\
0.32 & 3.68 & 0.004 & 0.81 & 456640 & 7137850 & 0.06 & 0.02 \\
0.55 & 4.03 & 0.004 & 0.82 & 847690 & 7124750 & 0.10 & 0.02 \\
$\cdots-$ & --- & 0.003 & 0.80 & 6740150 & 2513214 & 0.72 & 0.01 \\
-- & --- & 0.035 & 0.83 & 3875250 & 2030514 & 0.65 & 0.15
\end{tabular}

Phenol (1) in 4-Methyl-2-Pentanone (2) and Water (3)

\begin{tabular}{ccccrccc}
$\mathrm{W}_{1}$ & $\mathrm{~W}_{2}$ & $\mathrm{X}_{\text {water }}$ & $\rho$ & Peak $_{1}$ & Peak & $\mathrm{x}_{1}$ & $\mathrm{X}_{\text {water }}$ \\
\hline 0.38 & 3.84 & 0.004 & 0.81 & 520410 & 7548100 & 0.09 & 0.02 \\
0.50 & 4.05 & 0.004 & 0.81 & 698965 & 7548100 & 0.12 & 0.02 \\
0.87 & 3.96 & 0.004 & 0.83 & 1211050 & 6947600 & 0.19 & 0.02 \\
$\cdots-$ & --- & 0.011 & 0.81 & 7539733 & 1712608 & 0.82 & 0.04 \\
--- & --- & 0.212 & 0.89 & 7438100 & 3251897 & 0.42 & 0.44
\end{tabular}


Table D.2 Solid-Liquid Equilibrium Data at $25^{\circ} \mathrm{C}$

Refractive Index Detector : High Pressure Liquid Chromatograph

Resolve $C_{18} 8 \mathrm{~mm}^{*} 100 \mathrm{~mm}$ Cartridge in a Radial Compression Module

\section{2-Naphthol (1) in Cyclohexanone (2) and Water (3)}

Mobile Phase : $0.05 \mathrm{M}$ Low UV Pic A Reagent in $1: 1$ Acetonitrile : $1 \%(\mathrm{~g} / \mathrm{g})$ Acetic Acid.

Flow Rate : $1 \mathrm{~mL} / \mathrm{min}$

Back Pressure : 600 psi

\begin{tabular}{cccccccc}
$W_{1}$ & $W_{2}$ & $\mathbf{X}_{\text {water }}$ & $\rho$ & Peak $_{1}$ & Peak $_{2}$ & $\mathbf{X}_{1}$ & X $_{\text {water }}$ \\
\hline 1.31 & 15.07 & 0.061 & 0.95 & 71825 & 1763542 & 0.04 & 0.26 \\
0.45 & 4.72 & 0.002 & 0.95 & 77252 & 1829704 & 0.06 & 0.01 \\
1.12 & 4.68 & 0.002 & 0.96 & 115385 & 1703489 & 0.13 & 0.01 \\
--- & --- & 0.002 & 0.97 & 272671 & 2315824 & 0.24 & 0.01 \\
--- & --- & 0.049 & 0.98 & 255095 & 1489394 & 0.29 & 0.20
\end{tabular}

2-Naphthol (1) in 4-Methyl-2-Pentanone (2) and Water (3)

Mobile Phase : 0.03M Low UV Pic A Reagent in 30:70 Acetonitrile : 1\% (g/g) Acetic Acid. Flow Rate : $1.7 \mathrm{~mL} / \mathrm{min}$ Back Pressure : 1200 psi

\begin{tabular}{llllrlll}
$\mathrm{W}_{1}$ & $\mathrm{~W}_{2}$ & $\mathrm{X}_{\text {water }}$ & $\rho$ & Peak $_{1}$ & Peak & $\mathrm{x}_{1}$ & $\mathrm{X}_{\text {water }}$ \\
\hline 0.78 & 22.16 & 0.061 & 0.95 & 71825 & 1763542 & 0.04 & 0.26 \\
0.92 & 22.08 & 0.002 & 0.95 & 77252 & 1829704 & 0.06 & 0.01 \\
3.51 & 43.92 & 0.002 & 0.96 & 115385 & 1703489 & 0.13 & 0.01 \\
--- & --- & 0.001 & 0.90 & 227494 & 1146934 & 0.19 & 0.01 \\
--- & --- & 0.040 & 0.94 & 240890 & 969654 & 0.16 & 0.17
\end{tabular}

\section{2-Naphthol (1) in Butyl Acetate (2) and Water (3)}

Mobile Phase : $0.03 \mathrm{M}$ Low UV Pic A Reagent in 30:70 Acetonitrile : $1 \%(\mathrm{~g} / \mathrm{g})$ Acetic Acid. Flow Rate : $1.7 \mathrm{~mL} / \mathrm{min}$ Back Pressure : 1200 psi

\begin{tabular}{llllrlll}
$\mathrm{W}_{1}$ & $\mathrm{~W}_{2}$ & $\mathrm{X}_{\text {water }}$ & $\rho$ & Peak $_{1}$ & Peak $_{2}$ & $\mathrm{x}_{1}$ & $\mathrm{X}_{\text {water }}$ \\
\hline 1.46 & 22.03 & 0.001 & 0.89 & 25765 & 969232 & 0.05 & 0.01 \\
2.11 & 21.82 & 0.001 & 0.89 & 38571 & 864390 & 0.07 & 0.01 \\
2.44 & 21.94 & 0.001 & 0.90 & 42519 & 828521 & 0.08 & 0.01 \\
-- & --- & 0.001 & 0.92 & 195417 & 863935 & 0.28 & 0.01 \\
--- & --- & 0.035 & 0.94 & 149019 & 548007 & 0.20 & 0.18
\end{tabular}


Citric Acid (1) in Butyl Acetate (2) and Water (3)

Mobile Phase : 65:35 Methanol : Water

Flow Rate : $1.5 \mathrm{~mL} / \mathrm{min}$

Back Pressure : 500 psi

\begin{tabular}{lccccccc}
$\mathrm{W}_{1}$ & $\mathrm{~W}_{2}$ & $\mathrm{X}_{\text {water }}$ & $\rho$ & Peak $_{1}$ & Peak & $\mathrm{x}_{1}$ & $\mathrm{X}_{\text {water }}$ \\
\hline 0.009 & 8.76 & 0.001 & 0.87 & 25005 & 4529552 & 0.0006 & 0.0006 \\
0.015 & 8.76 & 0.002 & 0.87 & 40736 & 4422578 & 0.0010 & 0.0007 \\
0.020 & 8.77 & 0.003 & 0.87 & 55478 & 4246051 & 0.0014 & 0.0008 \\
-- & --- & 0.001 & 0.87 & 49198 & 4259892 & 0.0012 & 0.0047 \\
-- & --- & 0.013 & 0.88 & 459472 & 4189083 & 0.0107 & 0.0789
\end{tabular}

Table D.3 Solid-Liquid Equilibrium Data at $25^{\circ} \mathrm{C}$ Back Titration with Phenolphthalein Indicator

Citric Acid (1) in Methylcyclohexanone (2) and Water (3)

\begin{tabular}{cc}
$\mathrm{X}_{\text {water }}$ & $\mathrm{C}_{1}$ \\
\hline 0.002 & 0.25 \\
0.026 & 0.54 \\
0.050 & 1.00 \\
0.053 & 1.00 \\
0.078 & 1.20 \\
0.100 & 1.61 \\
0.111 & 1.70
\end{tabular}

Gallic Acid (1) in Cyclohexanone (2) and Water (3)

\begin{tabular}{lll} 
& $\mathrm{X}_{\text {water }}$ & $\mathrm{C}_{1}$ \\
\cline { 2 - 3 } Dry Solvent & 0.0087 & 0.69 \\
Hydrated Solvent & 0.133 & 0.75
\end{tabular}

Gallic Acid (1) in Methylcyclohexanone (2) and Water (3)

\begin{tabular}{lll} 
& $\mathrm{X}_{\text {water }}$ & $\mathrm{C}_{1}$ \\
\cline { 2 - 3 } Dry Solvent & 0.0058 & 0.52 \\
Hydrated Solvent & 0.080 & 0.83
\end{tabular}




\section{D.2 Vapor-Liquid Equilibrium Data}

The data from vapor-liquid equilibrium experiments are reported in Tables D.4 through D.8. The abbreviations used in Tables D.4 through D.8 are listed on the first page of Appendix D.

Table D.4 Acetic Acid Vapor-Liquid Equilibrium Data at $25^{\circ} \mathrm{C}$ Flame Ionization Detector : Gas Chromatograph

Column : $45.7 \mathrm{~cm}$ in length, Porapak PS Carrier Gas : Helium at 20 psig

Detector Temperature : $210^{\circ} \mathrm{C}$ Injector Temperature : $210^{\circ} \mathrm{C}$

Acetic Acid Pure Component (1), Vapor Phase Calibration Range : $10^{*-12} \mathrm{Amps} / \mathrm{mV}$

\begin{tabular}{lrrrrr} 
T [K] & Vol $_{\mathrm{v}}$ & $\mathrm{P}_{\text {tot }}$ & Vapor $_{1}$ & $\mathrm{n}_{1}$ & $\mathrm{y}_{1}$ \\
\hline 293 & 4.0 & 758.7 & 3032 & $4.6^{*} 10^{-9}$ & 0.028 \\
293 & 8.0 & 758.7 & 4424 & $9.2^{*} 10^{-9}$ & 0.028 \\
293 & 20.0 & 764.8 & 12119 & $2.3^{*} 10^{-8}$ & 0.028 \\
293 & 35.0 & 764.8 & 19617 & $4.1^{*} 10^{-8}$ & 0.028 \\
293 & 50.0 & 758.7 & 45673 & $5.8^{*} 10^{-8}$ & 0.028 \\
293 & 100.0 & 758.7 & 92276 & $1.2^{*} 10^{-7}$ & 0.028 \\
293 & 150.0 & 758.7 & 122337 & $1.7^{*} 10^{-7}$ & 0.028 \\
293 & 200.0 & 758.7 & 160153 & $2.3^{*} 10^{-7}$ & 0.028 \\
287 & 300.0 & 762.6 & 230939 & $2.5^{*} 10^{-7}$ & 0.020 \\
292 & 300.0 & 761.7 & 255173 & $3.3^{*} 10^{-7}$ & 0.026 \\
296 & 300.0 & 761.6 & 328260 & $4.0^{*} 10^{-7}$ & 0.033 \\
287 & 500.0 & 762.6 & 334822 & $4.2^{*} 10^{-7}$ & 0.020 \\
292 & 500.0 & 761.7 & 400719 & $5.5^{*} 10^{-7}$ & 0.026 \\
287 & 700.0 & 762.6 & 425678 & $5.8^{*} 10^{-7}$ & 0.020 \\
296 & 500.0 & 761.6 & 463378 & $6.7^{*} 10^{-7}$ & 0.033 \\
292 & 700.0 & 761.7 & 499004 & $7.7^{*} 10^{-7}$ & 0.026 \\
298 & 500.0 & 760.3 & 506602 & $7.6^{*} 10^{-7}$ & 0.037 \\
301 & 500.0 & 760.3 & 671065 & $8.9^{*} 10^{-7}$ & 0.044 \\
305 & 500.0 & 760.3 & 923738 & $1.1^{*} 10^{-6}$ & 0.053
\end{tabular}


Acetic Acid (1) and Cyclohexanone (2), Liquid Phase Calibration Range : $10^{*-10} \mathrm{Amps} / \mathrm{mV}$

\begin{tabular}{lccr}
$\mathbf{x}_{1}$ & Vol $_{L}$ & Liquid $_{1}$ & \multicolumn{1}{c}{ Liquid $_{2}$} \\
& & & \multicolumn{1}{c}{$\div 5)$} \\
\hline 0.05 & 0.30 & 138365 & 2968889 \\
0.10 & 0.30 & 281046 & 2863577 \\
0.17 & 0.30 & 486330 & 2871296 \\
0.38 & 0.30 & 1197085 & 2269429 \\
0.49 & 0.30 & 1579753 & 1947546 \\
0.49 & 0.30 & 1670655 & 1994589 \\
0.64 & 0.30 & 2343146 & 1432982 \\
0.77 & 0.30 & 3128487 & 1006572 \\
0.91 & 0.30 & 4370018 & 429322 \\
1.00 & 0.30 & 4944028 & 0
\end{tabular}

Acetic Acid (1) and Cyclohexanone (2), with Additional Water (3)

Range for Vapor: $10^{*-12} \mathrm{Amps} / \mathrm{mV}$

Room Pressure : $760.3 \mathrm{~mm} \mathrm{Hg}$

Vapor Volume : $0.5 \mathrm{~mL}$
Range for Liquid: $10^{*-10} \mathrm{Amps} / \mathrm{mV}$

Room Temperature : $25.5^{\circ} \mathrm{C}$

Liquid Volume : $0.3 \mu \mathrm{L}$

\begin{tabular}{llllllll}
$\mathrm{x}_{1} / \mathrm{x}_{2}$ & $\begin{array}{c}\text { Vapor }_{1} \\
(\div 100)\end{array}$ & $\begin{array}{c}\text { Vapor }_{2} \\
(\div 500)\end{array}$ & Liquid $_{1}$ & $\begin{array}{c}\text { Liquid }_{2} \\
(\div 5)\end{array}$ & $\rho$ & $\mathrm{X}_{\text {water }}$ & $\gamma_{1}$ \\
\hline 0.02 & 483 & 102584 & 53291 & 3039063 & 0.94 & 0.003 & 0.44 \\
0.02 & 456 & 105415 & 53595 & 3039063 & 0.93 & 0.008 & 0.43 \\
0.02 & 424 & 98056 & 51540 & 3012346 & 0.94 & 0.013 & 0.41 \\
0.02 & 418 & 99138 & 54589 & 2950151 & 0.94 & 0.017 & 0.39 \\
0.02 & 385 & 91803 & 55680 & 2843075 & 0.94 & 0.023 & 0.36
\end{tabular}

Acetic Acid (1) and Cyclohexanone (2), with Additional Water (3)

Range for Vapor: $10^{*-12} \mathrm{Amps} / \mathrm{mV}$

Room Pressure : $760.3 \mathrm{~mm} \mathrm{Hg}$

Vapor Volume : $0.5 \mathrm{~mL}$

\begin{tabular}{lccccccc}
$\mathrm{x}_{1} / \mathrm{x}_{2}$ & $\begin{array}{c}\text { Vapor }_{1} \\
(\div 100)\end{array}$ & $\begin{array}{c}\text { Vapor }_{2} \\
(\div 500)\end{array}$ & Liquid $_{1}$ & $\begin{array}{c}\text { Liquid }_{2} \\
(\div 5)\end{array}$ & $\rho$ & $\mathrm{X}_{\text {water }}$ & $\gamma_{1}$ \\
\hline 0.04 & 1836 & 104686 & 104275 & 2977375 & 0.94 & 0.003 & 0.73 \\
0.04 & 1385 & 103325 & 105675 & 3016382 & 0.94 & 0.008 & 0.59 \\
0.04 & 796 & 104096 & 104445 & 3003427 & 0.94 & 0.013 & 0.37 \\
0.04 & 559 & 107061 & 101718 & 2722222 & 0.94 & 0.018 & 0.26 \\
0.04 & 596 & 92298 & 105547 & 3085037 & 0.94 & 0.025 & 0.31
\end{tabular}

Range for Liquid: $10^{*-10} \mathrm{Amps} / \mathrm{mV}$ Room Temperature : $25.5^{\circ} \mathrm{C}$

Liquid Volume : $0.3 \mu \mathrm{L}$ 
Table D.5 Propionic Acid Vapor-Liquid Equilibrium Data at $25^{\circ} \mathrm{C}$ Flame Ionization Detector : Gas Chromatograph

Column : $45.7 \mathrm{~cm}$ in length, Porapak PS Carrier Gas : Helium at 20 psig
Detector Temperature : $210^{\circ} \mathrm{C}$ Injector Temperature : $210^{\circ} \mathrm{C}$

Propionic Acid Pure Component (1), Vapor Phase Calibration Range : $10^{*-12} \mathrm{Amps} / \mathrm{mV}$

$\begin{array}{llllll}T[K] & \text { Vol }_{\mathrm{v}} & \mathrm{P}_{\text {tot }} & \text { Vapor }_{1} & \mathrm{n}_{1} & \mathrm{y}_{1}\end{array}$ $(\div 2)$

\begin{tabular}{rrrrll}
\hline 291.5 & 3.0 & 758.8 & 3394 & $7.7^{*} 10^{-10}$ & 0.0061 \\
291.5 & 15.0 & 758.8 & 15518 & $3.8^{*} 10^{-9}$ & 0.0061 \\
291.5 & 25.0 & 758.8 & 23950 & $6.4^{*} 10^{-9}$ & 0.0061 \\
291.5 & 35.0 & 758.8 & 41372 & $8.9^{*} 10^{-9}$ & 0.0061
\end{tabular}

Propionic Acid (1) and Methylcyclohexanone (2), Liquid Phase Calibration Range : $10^{*-10} \mathrm{Amps} / \mathrm{mV}$

$\begin{array}{cccc}\mathrm{x}_{1} & \text { Vol }_{\mathrm{L}} & \underset{(\div 2)}{\text { Liquid }_{1}} & \underset{(\div 6)}{\text { Liquid }_{2}}\end{array}$

\begin{tabular}{llll}
\hline 0.031 & 0.30 & 27277 & 1601515 \\
0.057 & 0.30 & 44689 & 1573332 \\
0.072 & 0.30 & 63713 & 1570204 \\
0.097 & 0.30 & 79454 & 1537607
\end{tabular}

Propionic Acid (1) and Cyclohexanone (2), Liquid Phase Calibration Range : $10^{*-10} \mathrm{Amps} / \mathrm{mV}$

\begin{tabular}{llll}
$\mathrm{x}_{1}$ & Vol $_{\mathrm{L}}$ & $\begin{array}{c}\text { Liquid }_{1} \\
(\div 2)\end{array}$ & $\begin{array}{l}\text { Liquid }_{2} \\
(\div 5)\end{array}$ \\
\hline 0.034 & 0.30 & 271878 & 2167818 \\
0.052 & 0.30 & 379120 & 2120872 \\
0.057 & 0.30 & 411442 & 2150930 \\
0.072 & 0.30 & 529453 & 2138002
\end{tabular}


Propionic Acid (1) and Methylcyclohexanone (2), with Additional Water (3)

Range for Vapor: $10^{*-12} \mathrm{Amnc} / \mathrm{mV}$

Room Pressure : $761.8 \mathrm{~mm} \mathrm{Hg}$

Vapor Volume : $0.5 \mathrm{~mL}$
Range for Liquid: $10^{*-10} \mathrm{Amps} / \mathrm{mV}$

Room Temperature : $25.2^{\circ} \mathrm{C}$

Liquid Volume : $0.3 \mu \mathrm{L}$

\begin{tabular}{lccccccc}
$\mathrm{x}_{1} / \mathrm{x}_{2}$ & $\begin{array}{c}\text { Vapor } \\
(\div 2)\end{array}$ & $\begin{array}{c}\text { Vapor }_{2} \\
(\div 6)\end{array}$ & $\begin{array}{c}\text { Liquid }_{1} \\
(\div 2)\end{array}$ & $\begin{array}{c}\text { Liquid }_{2} \\
(\div 6)\end{array}$ & $\rho$ & $\mathrm{X}_{\text {water }}$ & $\gamma_{1}$ \\
\hline 0.05 & 302533 & 3585364 & 23066 & 1274592 & 0.90 & 0.001 & 1.03 \\
0.05 & 251221 & 3211086 & 26957 & 1252766 & 0.90 & 0.005 & 0.74 \\
0.05 & 153241 & 3362541 & 40866 & 1419279 & 0.92 & 0.016 & 0.40 \\
0.05 & 163206 & 3324037 & 37983 & 1376137 & 0.92 & 0.021 & 0.44 \\
0.05 & 159694 & 3273150 & 37996 & 1357549 & 0.92 & 0.023 & 0.45 \\
0.05 & 150041 & 3283495 & 38891 & 1438798 & 0.92 & 0.024 & 0.44 \\
0.05 & 141202 & 2949846 & 36014 & 1361123 & 0.92 & 0.026 & 0.43
\end{tabular}

Propionic Acid (1) and Cyclohexanone (2), with Additional Water (3)

Range for Vapor: $10^{*-12} \mathrm{Amps} / \mathrm{mV}$ Room Pressure : $756.2 \mathrm{~mm} \mathrm{Hg}$

Vapor Volume : $0.5 \mathrm{~mL}$
Range for Liquid: $10^{*-10} \mathrm{Amps} / \mathrm{mV}$ Room Temperature : $22.2^{\circ} \mathrm{C}$ Liquid Volume : $0.3 \mu \mathrm{L}$

\begin{tabular}{lccccccc}
$\mathbf{x}_{1} / \mathbf{x}_{2}$ & $\begin{array}{c}\text { Vapor }_{1} \\
(\div 2)\end{array}$ & $\begin{array}{c}\text { Vapor }_{2} \\
(\div 5)\end{array}$ & $\begin{array}{c}\text { Liquid }_{1} \\
(\div 2)\end{array}$ & $\begin{array}{c}\text { Liquid }_{2} \\
(\div 5)\end{array}$ & $\rho$ & $\mathbf{X}_{\text {water }}$ & $\gamma_{1}$ \\
\hline 0.06 & 11023 & 5677885 & 433533 & 2182174 & 0.94 & 0.001 & 1.17 \\
0.06 & 8728 & 5756941 & 394037 & 2179595 & 0.94 & 0.003 & 1.07 \\
0.06 & 5932 & 5567153 & 433174 & 2187399 & 0.94 & 0.007 & 0.70 \\
0.06 & 5404 & 5273426 & 459762 & 2202389 & 0.94 & 0.010 & 0.65 \\
0.06 & 4176 & 5413679 & 408385 & 2190951 & 0.94 & 0.014 & 0.58
\end{tabular}


Table D.6 Ethanol Vapor-Liquid Equilibrium Data at $25^{\circ} \mathrm{C}$ Flame Ionization Detector: Gas Chromatograph

Column : $45.7 \mathrm{~cm}$ in length, Porapak PS

Detector Temperature : $210^{\circ} \mathrm{C}$

Carrier Gas: Helium at 20 psig

Injector Temperature : $210^{\circ} \mathrm{C}$

Ethanol Pure Component (1), Vapor Phase Calibration

Range : $10^{*-11} \mathrm{Amps} / \mathrm{mV}$

$\begin{array}{llllll}\mathrm{T}[\mathrm{K}] & \mathrm{Vol}_{\mathrm{v}} & \mathrm{P}_{\text {tot }} & \text { Vapor }_{1} & \mathrm{n}_{1} & \mathrm{y}_{1}\end{array}$

$(\div 20)$

\begin{tabular}{lrrcrc}
\hline 291.7 & 3.0 & 758.7 & 8979 & $6.4^{*} 10^{-9}$ & 0.051 \\
291.7 & 15.0 & 758.7 & 309060 & $3.2^{*} 10^{-8}$ & 0.051 \\
291.7 & 20.0 & 758.7 & 430501 & $4.3^{*} 10^{-8}$ & 0.051 \\
298.8 & 30.0 & 760.9 & 1003583 & $9.5^{*} 10^{-7}$ & 0.077
\end{tabular}

Ethanol (1) and Cyclohexanone (2), Liquid Phase Calibration

Range : $10^{*-10} \mathrm{Amps} / \mathrm{mV}$

\begin{tabular}{lccc}
$\mathrm{x}_{1}$ & Vol $_{\mathrm{L}}$ & $\begin{array}{c}\text { Liquid }_{1} \\
(\div 2)\end{array}$ & $\begin{array}{c}\text { Liquid }_{2} \\
(\div 5)\end{array}$ \\
\hline 0.032 & 0.30 & 60985 & 3078963 \\
0.044 & 0.30 & 88240 & 3075651 \\
0.077 & 0.30 & 162513 & 3069054 \\
0.084 & 0.30 & 183644 & 3064954
\end{tabular}

Ethanol (1) and Methylcyclohexanone (2), Liquid Phase Calibration Range : $10^{*-10} \mathrm{Amps} / \mathrm{mV}$

\begin{tabular}{lccc}
$\mathrm{x}_{1}$ & Vol $_{\mathrm{L}}$ & $\begin{array}{c}\text { Liquid }_{1} \\
(\div 2)\end{array}$ & $\begin{array}{c}\text { Liquid }_{2} \\
(\div 6)\end{array}$ \\
\hline 0.0094 & 0.30 & 12895 & 3029626 \\
0.021 & 0.30 & 27515 & 2984407 \\
0.034 & 0.30 & 43503 & 2958667 \\
0.039 & 0.30 & 51921 & 2951591
\end{tabular}


Ethanol (1) and Cyclohexanone (2), with Additional Water (3)

Range for Vapor: $10^{*-11} \mathrm{Amps} / \mathrm{mV}$

Room Pressure : $761.9 \mathrm{~mm} \mathrm{Hg}$

Vapor Volume : $0.3 \mathrm{~mL}$

Range for Liquid: $10^{*-10} \mathrm{Amps} / \mathrm{mV}$

Room Temperature : $25.0^{\circ} \mathrm{C}$

Liquid Volume : $0.3 \mu \mathrm{L}$

\begin{tabular}{lccccccc}
$\mathrm{x}_{1} / \mathrm{x}_{2}$ & $\begin{array}{c}\text { Vapor }_{1} \\
(\div 2)\end{array}$ & $\begin{array}{c}\text { Vapor }_{2} \\
(\div 5)\end{array}$ & $\begin{array}{c}\text { Liquid }_{1} \\
(\div 2)\end{array}$ & $\begin{array}{c}\text { Liquid }_{2} \\
(\div 5)\end{array}$ & $\rho$ & $\mathrm{X}_{\text {water }}$ & $\gamma_{1}$ \\
\hline 0.05 & 1299582 & 595167 & 127484 & 3211906 & 0.92 & 0.0007 & 2.84 \\
0.05 & 1179950 & 572671 & 125311 & 3131879 & 0.92 & 0.0053 & 2.36 \\
0.05 & 1042040 & 612466 & 125722 & 3158778 & 0.92 & 0.012 & 2.23 \\
0.05 & 954939 & 542772 & 126740 & 3188187 & 0.92 & 0.015 & 2.15 \\
0.05 & 974768 & 556639 & 122487 & 3070238 & 0.92 & 0.020 & 1.86
\end{tabular}

Ethanol (1) and Cyclohexanone (2), with Additional Water (3)

Range for Vapor: $10^{*-11} \mathrm{Amps} / \mathrm{mV}$ Range for Liquid: $10^{*-10} \mathrm{Amps} / \mathrm{mV}$ Room Pressure : $760.9 \mathrm{~mm} \mathrm{Hg}$

Vapor Volume : $0.3 \mathrm{~mL}$

Room Temperature : $25.0^{\circ} \mathrm{C}$

Liquid Volume : $0.3 \mu \mathrm{L}$

\begin{tabular}{llllllll}
$\mathrm{x}_{1} / \mathrm{x}_{2}$ & $\begin{array}{c}\text { Vapor }_{1} \\
(\div 2)\end{array}$ & $\begin{array}{c}\text { Vapor }_{2} \\
(\div 5)\end{array}$ & $\begin{array}{c}\text { Liquid }_{1} \\
(\div 2)\end{array}$ & $\begin{array}{c}\text { Liquid }_{2} \\
(\div 5)\end{array}$ & $\rho$ & $\mathrm{X}_{\text {wat }^{\prime} \mathrm{r}}$ & $\gamma_{1}$ \\
\hline 0.02 & 653422 & 717253 & 35290 & 3079000 & 0.93 & 0.0023 & 4.25 \\
0.02 & 631014 & 675440 & 33254 & 2946623 & 0.93 & 0.006 & 3.12 \\
0.02 & 559230 & 661640 & 34539 & 3041308 & 0.93 & 0.011 & 3.40 \\
0.02 & 519996 & 634431 & 34664 & 3006208 & 0.93 & 0.015 & 3.00 \\
0.02 & 498926 & 676648 & 35054 & 2988528 & 0.93 & 0.021 & 2.84
\end{tabular}

Ethanol (1) and Methylcyclohexanone (2), with Additional Water (3)

Range for Vapor: $10^{*-11} \mathrm{Amps} / \mathrm{mV}$ Range for Liquid: $10^{*-10} \mathrm{Amps} / \mathrm{mV}$ Room Pressure : $762 \mathrm{~mm} \mathrm{Hg}$

Vapor Volume : $0.3 \mathrm{~mL}$

Room Temperature : $25.4^{\circ} \mathrm{C}$

Liquid Volume : $0.3 \mu \mathrm{L}$

\begin{tabular}{llllllll}
$\mathrm{x}_{1} / \mathrm{x}_{2}$ & $\begin{array}{c}\text { Vapor }_{1} \\
(\div 2)\end{array}$ & $\begin{array}{c}\text { Vapor }_{2} \\
(\div 6)\end{array}$ & $\begin{array}{c}\text { Liquid }_{1} \\
(\div 2)\end{array}$ & $\begin{array}{c}\text { Liquid }_{2} \\
(\div 6)\end{array}$ & $\rho$ & $\mathrm{X}_{\text {water }}$ & $\gamma_{1}$ \\
\hline 0.02 & 490724 & 426218 & 24253 & 2822653 & 0.91 & 0.0007 & 2.69 \\
0.02 & 471111 & 542376 & 23727 & 2802066 & 0.91 & 0.0039 & 2.63 \\
0.02 & 449851 & 444624 & 23864 & 2818424 & 0.92 & 0.0065 & 2.41 \\
0.02 & 377224 & 437260 & 24300 & 2810235 & 0.92 & 0.014 & 2.07 \\
0.02 & 340550 & 434725 & 24441 & 2799781 & 0.92 & 0.022 & 1.95
\end{tabular}


Table D.7 1,2-Propylene Glycol Vapor-Liquid Equilibrium Data at $25^{\circ} \mathrm{C}$ Flame Ionization Detector: Gas Chromatograph

Column : $45.7 \mathrm{~cm}$ in length, Porapak PS Carrier Gas : Helium at 20 psig
Detector Temperature : $210^{\circ} \mathrm{C}$ In jector Temperature : $210^{\circ} \mathrm{C}$

1,2-Propylene Glycol Pure Component (1), Vapor Phase Calibration Range : $10^{*-12} \mathrm{Amps} / \mathrm{mV}$

\begin{tabular}{lllrll}
$\mathrm{T}[\mathrm{K}]$ & $\mathrm{Vol}_{\mathrm{v}}$ & $\mathrm{P}_{\text {tot }}$ & Vapor $_{1}$ & $\mathrm{n}_{1}$ & $\mathrm{y}_{1}$ \\
\hline 292.2 & 150.0 & 762.3 & 33471 & $1.22^{*} 10^{-9}$ & $1.94^{*} 10^{-4}$ \\
292.2 & 300.0 & 762.3 & 182070 & $2.44^{*} 10^{-8}$ & $1.94^{*} 10^{-4}$ \\
292.2 & 500.0 & 762.3 & 277161 & $3.80^{*} 10^{-8}$ & $1.94^{*} 10^{-4}$
\end{tabular}

1,2-Propylene Glycol (1) and Methylcyclohexanone (2), Liquid Phase Calibration Range : $10^{*-10} \mathrm{Amps} / \mathrm{mV}$

\begin{tabular}{llll}
$\mathbf{x}_{1}$ & Vol $_{L}$ & Liquid $_{1}$ & Liquid $_{2}$ \\
\hline 0.025 & 0.30 & 151938 & 19264207 \\
0.037 & 0.30 & 223063 & 19250124 \\
0.043 & 0.30 & 261424 & 19269446 \\
0.049 & 0.30 & 302973 & 19308945
\end{tabular}

1,2-Propylene Glycol (1) and Methylcyclohexanone (2), with Additional Water (3) Range for Vapor: $10^{*-12} \mathrm{Amps} / \mathrm{mV}$ Range for Liquid: $10^{*-10} \mathrm{Amps} / \mathrm{mV}$

Room Pressure : $761.2 \mathrm{~mm} \mathrm{Hg}$

Vapor Volume : $0.4 \mathrm{~mL}$

Room Temperature : $25.2^{\circ} \mathrm{C}$

Liquid Volume : $0.3 \mu \mathrm{L}$

\begin{tabular}{lcccccc}
$\mathrm{x}_{1} / \mathrm{x}_{2}$ & Vapor $_{1}$ & Liquid $_{1}$ & Liquid $_{2}$ & $\rho$ & $\mathrm{X}_{\text {water }}$ & $\gamma_{1}$ \\
\hline 0.04 & 45289 & 73.028 & 8730261 & 0.91 & 0.0006 & 6.66 \\
0.04 & 46400 & 74928 & 8894418 & 0.91 & 0.0028 & 6.47 \\
0.04 & 42436 & 79271 & 9166644 & 0.91 & 0.065 & 6.14 \\
0.04 & 35870 & 78255 & 9206223 & 0.91 & 0.081 & 5.64 \\
0.04 & 21666 & 81220 & 9428558 & 0.91 & 0.012 & 4.97 \\
0.04 & 18328 & 76999 & 9124402 & 0.91 & 0.013 & 4.99 \\
0.04 & 9284 & 81005 & 9292052 & 0.91 & 0.018 & 4.34 \\
0.04 & 8229 & 85527 & 9704260 & 0.91 & 0.025 & 4.22 \\
0.04 & 7074 & 88012 & 9841397 & 0.91 & 0.030 & 4.15
\end{tabular}


Table D.8 2,3-Butylene Glycol Vapor-Liquid Equilibrium Data at $25^{\circ} \mathrm{C}$ Flame Ionization Detector: Gas Chromatograph

Column : $45.7 \mathrm{~cm}$ in length, Porapak PS Carrier Gas : Helium at 20 psig
Detector Temperature : $210^{\circ} \mathrm{C}$ Injector Temperature : $210^{\circ} \mathrm{C}$

2,3-Butylene Glycol Pure Component (1), Vapor Phase Calibration

Range : $10^{*-12} \mathrm{Amps} / \mathrm{mV}$

\begin{tabular}{lccccc} 
T [K] & Vol $_{\mathrm{v}}$ & $\mathrm{P}_{\text {tot }}$ & Vapor $_{1}$ & $\mathrm{n}_{1}$ & $\mathrm{y}_{1}$ \\
\hline 293.1 & 20.0 & 758.0 & 22305 & $1.93^{*} 10^{-10}$ & $2.32^{*} 10^{-4}$ \\
293.1 & 30.0 & 758.0 & 35197 & $2.89^{*} 10^{-10}$ & $2.32^{*} 10^{-4}$ \\
293.1 & 100.0 & 758.0 & 130798 & $9.63^{*} 10^{-10}$ & $2.32^{*} 10^{-4}$ \\
293.1 & 150.0 & 758.0 & 198113 & $1.44^{*} 10^{-9}$ & $2.32^{*} 10^{-4}$
\end{tabular}

2,3-Butylene Glycol (1) and Methylcyclohexanone (2), Liquid Phase Calibration Range : $10^{*-10} \mathrm{Amps} / \mathrm{mV}$

\begin{tabular}{lccc}
$\mathbf{x}_{1}$ & Vol $_{\mathrm{L}}$ & Liquid $_{1}$ & Liquid $_{2}$ \\
\hline 0.025 & 0.30 & 151938 & 19264207 \\
0.037 & 0.30 & 223063 & 19250124 \\
0.043 & 0.30 & 261424 & 19269446 \\
0.049 & 0.30 & 302973 & 19308945
\end{tabular}

2,3-Butylene Glycol (1) and Methylcyclohexanone (2), with Additional Water (3)

Range for Vapor: $10^{*-12} \mathrm{Amps} / \mathrm{mV} \quad$ Range for Liquid: $10^{*-10} \mathrm{Amps} / \mathrm{mV}$

Room Pressure : $757.7 \mathrm{~mm} \mathrm{Hg} \quad$ Room Temperature : $25.5^{\circ} \mathrm{C}$

Vapor Volume : $0.5 \mathrm{~mL} \quad$ Liquid Volume : $0.3 \mu \mathrm{L}$

\begin{tabular}{lllllll}
$\mathrm{x}_{1} / \mathrm{x}_{2}$ & Vapor $_{1}$ & Liquid $_{1}$ & Liquid $_{2}$ & $\rho$ & $\mathrm{X}_{\text {water }}$ & $\gamma_{1}$ \\
\hline 0.04 & 115055 & 244553 & 18397443 & 0.91 & 0.0008 & 3.32 \\
0.04 & 160210 & 241162 & 19058774 & 0.91 & 0.0009 & 4.36 \\
0.04 & 144558 & 238255 & 18647929 & 0.91 & 0.0028 & 4.33 \\
0.04 & 133355 & 238255 & 19418728 & 0.91 & 0.0035 & 3.68 \\
0.04 & 160409 & 239151 & 18939017 & 0.91 & 0.0052 & 4.74 \\
0.04 & 161189 & 241294 & 18738599 & 0.91 & 0.0056 & 6.00 \\
0.04 & 173748 & 249606 & 18642437 & 0.91 & 0.0064 & 4.86 \\
0.04 & 178469 & 253346 & 18950602 & 0.91 & 0.0063 & 4.66 \\
0.04 & 137947 & 256667 & 18989187 & 0.91 & 0.012 & 3.64 \\
0.04 & 131037 & 267469 & 18989214 & 0.91 & 0.015 & 3.38
\end{tabular}




\section{Appendix E Nomenclature}

\begin{tabular}{|c|c|}
\hline $\mathbf{n}_{\mathbf{i}}$ & Number of moles of component i (mole) \\
\hline $\mathbf{P}_{\mathbf{i}}$ & Vapor pressure of component i (mm Hg) \\
\hline$P_{1}$ & Partial pressure of monomer $(\mathrm{mm} \mathrm{Hg})$ \\
\hline $\mathbf{P}_{2}$ & Partial pressure of dimer $(\mathrm{mm} \mathrm{Hg})$ \\
\hline V & Volume $(\mathrm{mL})$ \\
\hline $\mathbf{R}$ & Universal gas constant $\left(\mathrm{mmHg} \mathrm{L} \mathrm{mol}{ }^{-1} \mathrm{~K}^{-1}\right)$ \\
\hline $\mathrm{T}$ & Temperature (K) \\
\hline K & Dimerization constant \\
\hline$y_{i}$ & Vapor mole fraction of component $\mathrm{i}(\mathrm{mol} / \mathrm{mol})$ \\
\hline$\mu_{\mathrm{i}}$ & Chemical potential of component $\mathrm{i}$ \\
\hline$f_{\mathrm{i}}$ & Fugacity of component $i$ \\
\hline $\mathbf{x}_{\mathbf{i}}$ & Liquid mol: fraction of component $\mathrm{i}(\mathrm{mol} / \mathrm{mol})$ \\
\hline$\gamma_{\mathrm{i}}$ & Liquid activity coefficient of component $i$ \\
\hline$\Phi_{\mathrm{i}}$ & Fugacity coefficient of component $i$ \\
\hline E & Enhancement factor, $\Delta\left(\log \gamma_{\text {solute }}\right) / \Delta\left(x_{w} / x_{\text {solute }}\right)$ \\
\hline $\mathrm{w}_{\mathrm{i}}$ & Mass of component $\mathrm{i}$ in solution $(\mathrm{g})$ \\
\hline Peak $_{i}$ & HPLC peak area of component $i$ \\
\hline Vapor $_{i}$ & GC peak area of cornponent $i$ in vapor phase \\
\hline Liquid $_{\mathrm{i}}$ & GC peak area of component $i$ in liquid phase \\
\hline$\rho$ & Density of orgaric phase $(\mathrm{g} / \mathrm{mL})$ \\
\hline$Y_{\text {water }}$ & Karl Fischer water analysis $(\mathrm{g} / \mathrm{g})$ \\
\hline$r_{i}$ & Concentration of component $\mathrm{i}(\mathrm{mole} / \mathrm{L})$ \\
\hline $\mathrm{Vol}_{\mathrm{v}}$ & Volume of vapor sample size $(\mu \mathrm{L})$ \\
\hline$V 0 !_{L}$ & Volume of liquid sample size $(\mu \mathrm{L})$ \\
\hline
\end{tabular}



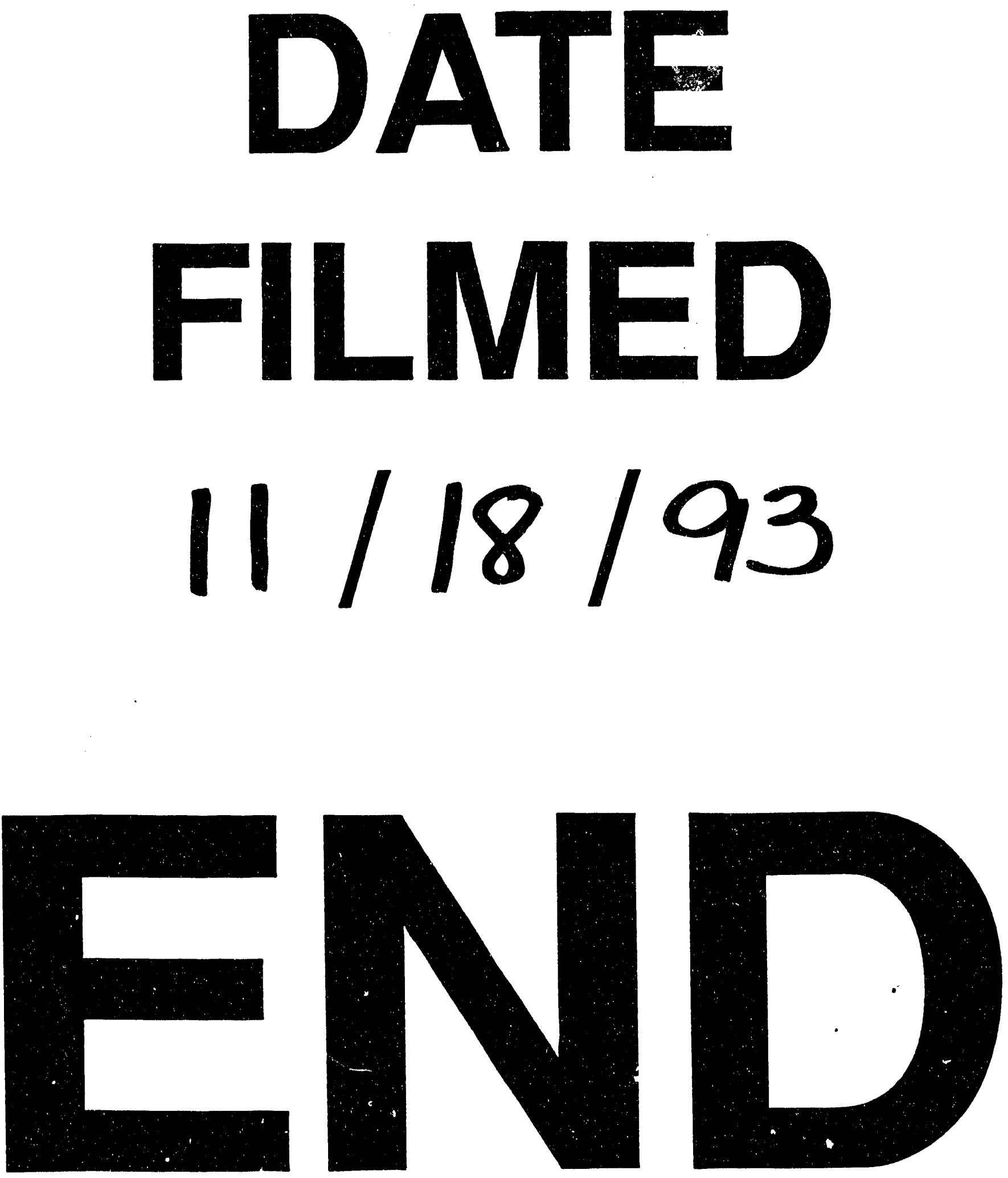
